Technological University Dublin

DÜBLIN

ARROW@TU Dublin

2015-08-01

\title{
15 Years on siRNA Delivery: Beyond the State-of-the-Art on Inorganic Nanoparticles for RNAi Therapeutics
}

Joao Conde

Universidad de Zaragoza, Spain

Furong Tian

Technological University Dublin, furong.tian@tudublin.ie

Alfredo Ambrosone

Istituto di Cibernetica "E. Caianiello", Consiglio Nazionale delle Ricerche, Via Campi Flegrei, Pozzuoli, Italy

See next page for additional authors

Follow this and additional works at: https://arrow.tudublin.ie/schfsehart

Part of the Nanomedicine Commons

\section{Recommended Citation}

Nano Today Volume 10, Issue 4, August 2015, Pages 421-450

This Article is brought to you for free and open access

by the School of Food Science and Environmental

Health at ARROW@TU Dublin. It has been accepted

for inclusion in Articles by an authorized administrator

of ARROW@TU Dublin. For more information, please

contact arrow.admin@tudublin.ie,

aisling.coyne@tudublin.ie,

gerard.connolly@tudublin.ie.

Funder: FP7

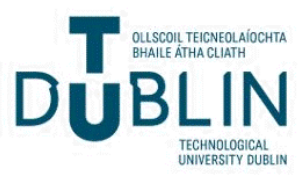




\section{Authors}

Joao Conde, Furong Tian, Alfredo Ambrosone, Yulán Hernandez, Mark McCully, Catherine C. .Berry, Pedro Baptista, Claudia Tortiglione, and Jesus M. de la Fuented 


\title{
15 years on siRNA delivery: beyond the State-of-the-Art on inorganic nanoparticles for RNAi therapeutics
}

João Conde ${ }^{1,2, *}$, Alfredo Ambrosone ${ }^{3}$, Yulán Hernandez ${ }^{4}$, Furong Tian ${ }^{5}$, Mark McCully ${ }^{6}$, Catherine C. Berry ${ }^{6}$, Pedro V. Baptista ${ }^{7}$, Claudia Tortiglione ${ }^{3}$, Jesus M. de la Fuente ${ }^{4,8,9}$

${ }^{1}$ Massachusetts Institute of Technology, Institute for Medical Engineering and Science, Harvard-MIT Division for Health Sciences and Technology, Cambridge, Massachusetts, USA.

${ }^{2}$ School of Engineering and Materials Science, Queen Mary University of London, London, United Kingdom.

${ }^{3}$ Istituto di Cibernetica "E. Caianiello", Consiglio Nazionale delle Ricerche, Via Campi Flegrei, Pozzuoli, Italy.

${ }^{4}$ Instituto de Nanociencia de Aragon, University of Zaragoza, C/Mariano Esquillor s/n, Zaragoza, Spain.

${ }^{5}$ Focas Research Institute, Dublin Institute of Technology, Camden Row, Dublin, Ireland.

${ }^{6}$ Centre for Cell Engineering, University of Glasgow, Joseph Black Building, University Place, Glasgow, United Kingdom.

${ }^{7}$ UCIBIO, Departamento de Ciências da Vida, Faculdade de Ciências e Tecnologia, Universidade Nova de Lisboa, Campus de Caparica, Portugal.

${ }^{8}$ Instituto de Ciencia de Materiales de Aragón-CSIC/Universidad de Zaragoza, Zaragoza, Spain.

${ }^{9}$ Department of Instrument Science and Engineering, School of Electronic Information and Electrical Engineering, Research Institute of Translation Medicine, Shanghai Jiao Tong University, Shanghai, People's Republic of China.

* Corresponding author, João Conde, Massachusetts Institute of Technology, Harvard-MIT Division for Health Sciences and Technology, jdconde@mit.edu

Keywords: RNAi therapy; siRNA delivery; inorganic nanoparticles; targeting; nanotoxicity; nanomedicine.

\begin{abstract}
RNAi has always captivated scientists due to its tremendous power to modulate the phenotype of living organisms. This natural and powerful biological mechanism can now be harnessed to downregulate specific gene expression in diseased cells; opening up endless opportunities. Since most of the conventional siRNA delivery methods are limited by a narrow therapeutic index and significant side and off-target effects, we are now in the dawn of a new age in gene therapy driven by nanotechnology vehicles for RNAi therapeutics. Here, we outlook the "do's and dont's" of the
\end{abstract}


inorganic RNAi nanomaterials developed in the last 15 years and the different strategies employed are

\section{Introduction}

During the last 15 years we assisted to a fast and significant revolution in the RNA world. One of the most astonishing milestones was the discovery of RNA interference (RNAi), a regulatory mechanism of gene expression widely diffused in eukaryotes, including fungi, plants, and animals. Overall, based on noncoding double-stranded RNA (dsRNA) molecules, RNAi drives homology-dependent degradation of target mRNA leading to specific gene silencing [1]. The discovery of RNAi has expanded our knowledge of gene regulation since Fire, Mello and colleagues demonstrated that long dsRNA mixtures were 10-100 fold more efficient at triggering gene silencing than single strand RNAs in Caenorhabditis elegans. However, the use of RNAi as a potent tool for gene regulation came when Elbashir and co-workers proved that synthetic small interfering RNAs (siRNAs) enabled sequence specific gene knockdown in a mammalian cell line [2]. These observations laid the foundations to employ RNAi as a key tool for gene functional analysis as well as a therapeutic tool

So far, four major types of noncoding RNAs have been identified as RNAi effectors: siRNAs, microRNAs (miRNAs), piwi-interacting RNAs (piRNAs) and long intervening noncoding RNAs (lincRNAs) [3]. While the main goal of piRNA goes from transcriptional gene silencing and genome defence to transgenerational epigenetic mechanisms [4], miRNA and siRNA act more specifically as triggering molecules of gene silencing. Specifically, miRNAs are a large class of endogenous small regulatory molecules, derived from imperfectly paired hairpin RNA structures naturally encoded in the genome [5]. They prevalently act to control translational repression or mRNA degradation. Instead, siRNAs represent a heterogeneous class of noncoding RNAs typically including exogenous synthetic or viral inducers of RNAi (Figure 1). Despite their different biogenesis, miRNA and siRNA once into the cytoplasm share common molecular machineries as Dicer enzymes for precursors excision, and Ago proteins, which vehicle their silencing functions [6,7]. Consequently, the enzymes Dicer and Ago, together with the 21-23 nt duplex-derived RNAs represent the key components of the RNA silencing pathway. 


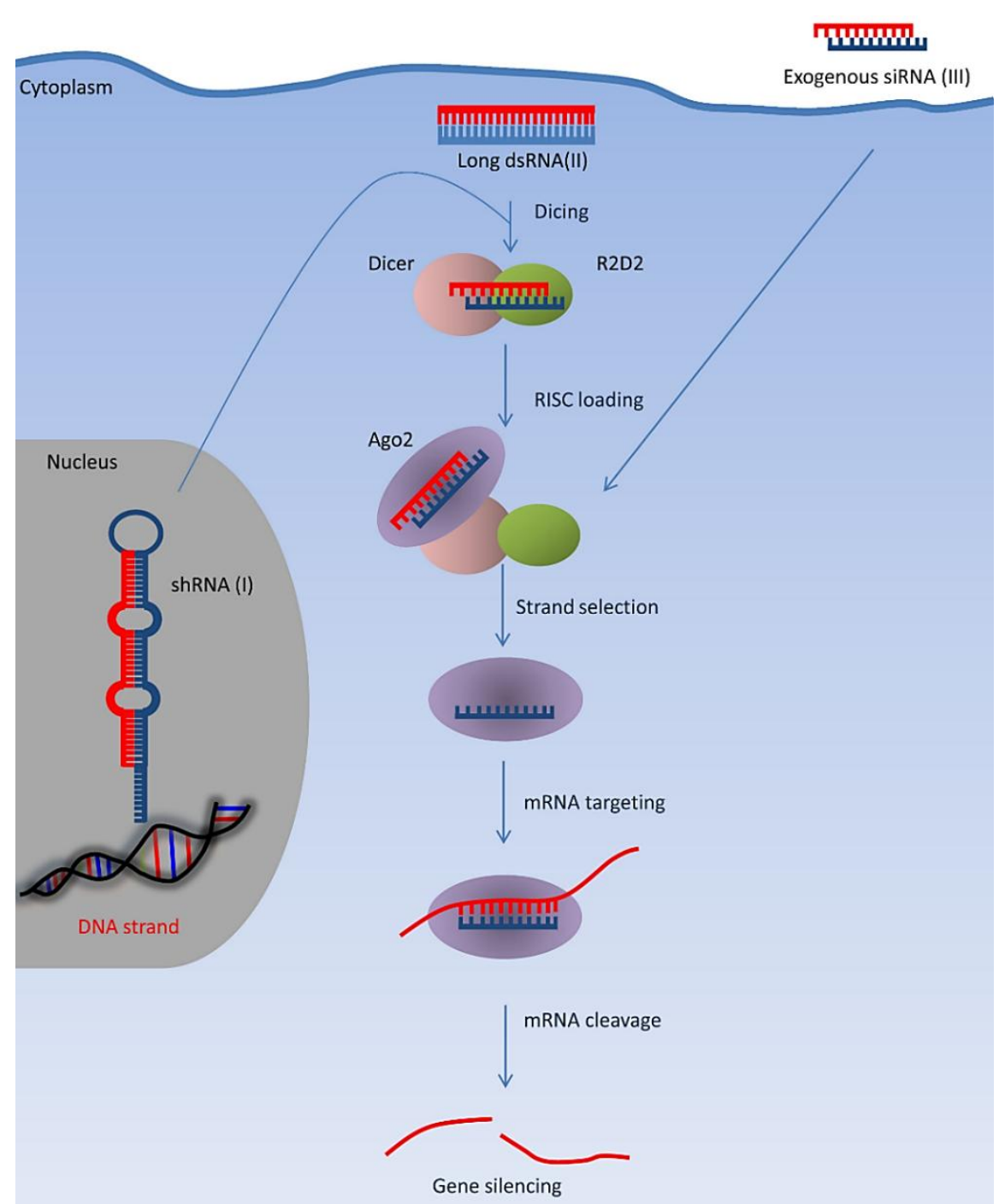

Figure 1. The RNA interference pathway begins with long dsRNA precursors that are processed to siRNA duplexes by the RNase-III-like enzyme Dicer. These short dsRNAs are subsequently unwound and assembled into an effector complex, RNA Induced Silencing Complex (RISC), which can direct RNA cleavage, mediate translational repression or induce chromatin modification. The antisense strand then binds to its complementary/target mRNA. The strand antisense to the targeted mRNA is often referred to as the guide strand, and its base-paired sense strand is known as the passenger strand, which is destroyed upon incorporation of the guide strand into RISC. The catalytic RISC recognizes mRNAs containing perfect or near-perfect complementary sequence to the guide siRNA and cleaves the mRNAs at a site precisely 10 nucleotides from the 5 '-end of the guide strand. Finally, mRNA degradation is achieved by endo- and exonucleases, resulting in knockdown of the expression of the corresponding genes.

For a long time, RNAi has been considered a regulatory mechanisms merely controlling gene expression at the post-transcriptional level. Recent findings have now established that RNAi also plays a central role in transcriptional repression (RNA-induced transcriptional silencing, RITS). Nevertheless, a growing body of evidence supports RNAi regulating transcription through interactions with the transcriptional machinery. In light of this paramount potential, RNAi approaches are tremendously appealing for developing new therapies [8]. In fact, it has been shown that many human developmental and degenerative disorders as well as cancers encompass some form of aberrant gene 
regulation. One of the first clinical approaches aiming to harness the RNAi pathway for gene silencing

employed siRNA by intravenous administration in patients with age-related macular degeneration (AMD) to downregulate the vascular endothelial growth factor transcript [9]. Beside this and other ocular diseases, ongoing clinical trials using RNAi-based strategies hold promise for treating fatal disorders (viral infections, neurodegenerative diseases, inflammatory diseases, cancer) [9,10] or provide alternatives to traditional small molecule therapies [11-13]. However, several hurdles must be overcome before RNAi technology can be translated from an effective research tool into a feasible clinical practice. In this respect, one of the primary obstacles remains the efficient in vivo delivery of these small molecules to the target cell type. Depending on the mode of administration, siRNA must cross many biological barriers before reaching the target cells, facing degradation by nucleases, issues related to their relative instability and half-life, short-lived nature of their transient gene silencing, sequestration by the immune system and elicitation of an immune response [14]. Upon reaching the targeted cells, siRNA molecules cannot readily diffuse across cellular membranes due to their anionic backbone and hydrophilic nature. Thus, delivery vehicles must be used to protect/conceal the siRNA within biological fluids, while facilitating its transfection to the cytoplasm of the target cells. The different strategies developed for efficient siRNA delivery can be grouped in two categories: those involving a chemical modification of the siRNA and those mediating the delivery by exogenous compounds, such as aptamers, liposomes, nanoparticles (NPs), polymers, dendrimers, all requiring a specific chemistry to preserve the biological activity of the siRNA upon conjugation. In fact, the therapeutic efficiency of delivery vehicles and a specific siRNA can be increased by modifications in key characteristics such as charge, size, shape, composition, surface chemistry and targeting motifs. DNA/RNA nanomaterials have also been developed in the last year for miRNA sensing and delivery [15]. Probably those relying on nanoparticles hold the best promise to improving stability, cell penetration, increasing administration dose, while enabling the specificity and/or self-tracking properties (via conjugation to antibodies and/or fluorophores) or other nanoparticle dependent properties (magnetic, electric, optical properties). Among the numerous nanoparticle formulations employed for siRNA delivery, here we will focus on inorganic nanoparticles [16], i.e. nanosized structures made by an inorganic material (e.g. silica, gold, iron oxide, quantum dots, carbon nanotubes, calcium phosphate), coated by polymeric layers and conjugated to siRNA through specific approaches including covalent binding, electrostatic absorption and encapsulation, depending on the material [17-22]. Compared to conventional transfection agents, nanoparticle-conjugated siRNAs have been shown to be less susceptible to degradation by nuclease activity, exhibit greater cellular uptake and higher siRNA effective concentration; which has accelerated siRNA delivery in this direction over the past few years. 
Table 1 depicts examples of nanoparticle formulations successfully employed to induce RNAi in vitro and in some case also in vivo. The material core dictates the strategy of siRNA conjugation, so that the absorption method is generally employed for mesoporous silica NPs (MSNs) and nanostructures made positively charged by chemical engineering, while covalent binding is the preferred approach for NP surfaces coated by reactive groups. The latter ensures more effective delivery of siRNA into the cell cytoplasm, avoiding undesired cargo release in biological fluids external to the target cells and thus decreasing RNAi efficacy. The strong thiol-gold interaction has been used extensively to decorate gold nanoparticles with thiol-derivatized oligonucleotides, while more sophisticated methods (including the siRNA conjugation to polymers coating the NP, i.e. Polyethylene glycol (PEG), Polyethylenimine (PEI)) have been developed more recently. These strategies have been implemented with others to graft other reactive groups onto the NP, allowing for further conjugation with multiple bioactive molecules, such as peptides to enhance cell penetration, fluorophores for imaging, and antibodies for specific cell targeting (see Table 1).

Table 1. Examples of nanoparticle-based siRNA delivery systems.

\begin{tabular}{|c|c|c|c|c|c|}
\hline Nanoparticle type & $\begin{array}{c}\text { Conjugation } \\
\text { type }\end{array}$ & Target gene & Biological system & $\begin{array}{c}\text { Efficiency of silencing/ } \\
\text { detection method }\end{array}$ & Ref \\
\hline \multirow[t]{2}{*}{ Magnetic NP } & Covalent binding & $\begin{array}{l}\text { GFP/RFP/ } \\
\text { survivin }\end{array}$ & $\begin{array}{l}\text { 9LGliosarcoma } \\
\text { cells } \\
\text { mouse }\end{array}$ & $\begin{array}{l}50 \% \text {-fluorescence intensity } \\
>80 \% \text {-qRT-PCR }\end{array}$ & {$[18]$} \\
\hline & $\begin{array}{l}\text { Absorption via } \\
\text { lipids }\end{array}$ & luciferase & HeLa cells & $90 \%$ - enzymatic activity & {$[23]$} \\
\hline $\begin{array}{l}\text { Magnetic } \\
\text { nanobeads }\end{array}$ & $\begin{array}{l}\text { Surface } \\
\text { absorption }\end{array}$ & GFP & HeLa cells & n.d. -fluorescence intensity & {$[22]$} \\
\hline \multirow{6}{*}{ Gold NP } & $\begin{array}{l}\text { Gold-thiol } \\
\text { conjugation }\end{array}$ & luciferase & HeLa cells & $>70 \%$-enzymatic activity & {$[24]$} \\
\hline & $\begin{array}{l}\text { Gold-thiol } \\
\text { conjugation }\end{array}$ & luciferase & HeLa cells & $>90 \%$-enzymatic activity & {$[25]$} \\
\hline & Covalent binding & $\mathrm{c}-\mathrm{Myc}$ & $\begin{array}{l}\text { HeLa cells } \\
\text { Hydra } \\
\text { mouse }\end{array}$ & $\begin{array}{l}80 \% \text {-enzymatic activity } \\
80 \% \text {-qRT-PCR } \\
70 \% \text {-qRT-PCR }\end{array}$ & [26-28] \\
\hline & Ionic interaction & Lamin A/C & HeLa cells & $80 \%$-immunoblot & [29] \\
\hline & $\begin{array}{l}\text { Gold-thiol } \\
\text { conjugation }\end{array}$ & c-Myc & $\begin{array}{l}\text { LA4-cells } \\
\text { mouse }\end{array}$ & $\begin{array}{l}80 \% \text {-qRT-PCR } \\
\text { 80-90\% -bioluminescence } \\
\text { imaging }\end{array}$ & {$[27]$} \\
\hline & $\begin{array}{l}\text { Ciclodextrin/ } \\
\text { adamantin } \\
\text { interaction }\end{array}$ & RRM2 & human & $\begin{array}{l}\text { 30-70\% -qRT-PCR, } \\
\text { immunolocalization }\end{array}$ & {$[30]$} \\
\hline $\begin{array}{l}\text { Mesoporous silica } \\
\text { NP }\end{array}$ & $\begin{array}{l}\text { Pore/surface } \\
\text { adsorption }\end{array}$ & GFP/VEGF & $\begin{array}{l}\text { HeLa cells } \\
\text { MDA-MB-231 } \\
\text { cells } \\
\text { mouse }\end{array}$ & $\begin{array}{l}80 \% \text {-fluorescence intensity } \\
60 \% \text {-RT-PCR } \\
80 \% \text {-fluorescence intensity } \\
\text { RT-PCR }\end{array}$ & {$[31]$} \\
\hline $\begin{array}{l}\text { Mesoporous silica } \\
\text { NP } \\
(+ \text { doxorubicin })\end{array}$ & Adsorption & $\begin{array}{l}\text { Pgp (ABC drug } \\
\text { efflux } \\
\text { transporter) }\end{array}$ & $\begin{array}{l}\text { MCF-7 cells } \\
\text { mouse }\end{array}$ & $\begin{array}{l}\text { 50\% - immunoblot } \\
\text { 10-90\% -tumour weight, } \\
\text { immunoblot, qRT-PCR }\end{array}$ & {$[32]$} \\
\hline $\begin{array}{l}\text { Gold nanorods- } \\
\text { mesoporous silica }\end{array}$ & Covalent binding & GFP & HeLa cells & $60 \%$-fluorescence intensity & {$[33]$} \\
\hline Calcium & Encapsulation & luciferase & H460 cells & $50 \%$ enzymatic activity & {$[20]$} \\
\hline
\end{tabular}




\begin{tabular}{l|l|l|l|l|l}
\hline Phosphate NP & & mouse & $50 \%$ enzymatic activity & \\
\hline Quantum dots & Adsorption & $\begin{array}{l}\text { BACE1 } \\
\text { (b-secretase) }\end{array}$ & SK-N-SH cells & $50 \%$-immunoblot & [34] \\
\hline $\begin{array}{l}\text { Single walled } \\
\text { carbon nanotubes }\end{array}$ & Covalent binding & $\begin{array}{l}\text { (cell surface } \\
\text { co-receptor) } \\
\text { CD4 }\end{array}$ & $\begin{array}{l}\text { T cells } \\
\text { peripheral blood } \\
\text { mononuclear cells }\end{array}$ & $\begin{array}{l}50 \%-90 \% \text { qRT-PCR } \\
60 \% \text { qRT-PCR }\end{array}$ & [17] \\
\hline
\end{tabular}

Despite the enormous efforts to develop NP based siRNA carriers, most of the studies have been performed in cell cultures, using reporter genes such as the green fluorescent protein or luciferase, allowing easy recording of the RNAi efficacy. Less abundant are studies employing pre-clinical animal models (mainly mouse) $[18,28,31]$, or targeting biologically relevant genes, and very rare those reporting on clinical trials using inorganic nanoparticles [30,35]. In fact, there are no active clinical trials reporting the use of inorganic NPs to target any gene using siRNA delivery (see Table 2).

Table 2. Inorganic nanoparticles in clinical trials.

\begin{tabular}{|c|c|c|c|c|c|}
\hline Delivery vehicle & $\begin{array}{c}\text { Target } \\
\text { gene }\end{array}$ & Disease & Phase & Status & ClinicalTrials.gov ID \\
\hline $\begin{array}{l}\text { Gold + Iron } \\
\text { Oxide-Silica }\end{array}$ & NA & $\begin{array}{l}\text { Coronary Artery Disease } \\
\text { Atherosclerosis }\end{array}$ & 1 & Completed & NCT01436123 \\
\hline Gold + silica & NA & $\begin{array}{l}\text { Stable Angina } \\
\text { Heart Failure } \\
\text { Atherosclerosis } \\
\text { Multivessel Coronary Artery Disease }\end{array}$ & $\begin{array}{l}1 \\
2\end{array}$ & Completed & NCT01270139 \\
\hline Gold & NA & Stomach Diseases & 0 & Recruiting & NCT01420588 \\
\hline Silica & NA & $\begin{array}{l}\text { Head and Neck Cancer } \\
\text { Melanoma } \\
\text { Prostate Cancer } \\
\text { Cervical Cancer } \\
\text { Uterine Cancer }\end{array}$ & 0 & Recruiting & NCT02106598 \\
\hline \multirow{12}{*}{$\begin{array}{l}\text { Iron oxide } \\
\text { (magnetic) }\end{array}$} & NA & Head and Neck Cancer & 0 & Recruiting & NCT01895829 \\
\hline & NA & Leukemia & - & Completed & NCT01411904 \\
\hline & NA & Brain Neoplasms & 1 & Completed & NCT00769093 \\
\hline & NA & Multiple Sclerosis & 0 & Recruiting & NCT01973517 \\
\hline & NA & $\begin{array}{l}\text { Papillary Carcinoma of Thyroid } \\
\text { Metastatic to Regional Lymph Node } \\
\text { Metastatic Medullary Thyroid Cancer } \\
\text { Follicular Thyroid Cancer Lymph Node } \\
\text { Metastasis }\end{array}$ & 0 & Recruiting & NCT01927887 \\
\hline & NA & Cancer of Lymph Node & 0 & Recruiting & NCT01815333 \\
\hline & NA & $\begin{array}{l}\text { Myocardial Infarction } \\
\text { Inflammation }\end{array}$ & 2 & Recruiting & NCT01995799 \\
\hline & NA & Pancreatic Cancer & 4 & Recruiting & NCT00920023 \\
\hline & NA & $\begin{array}{l}\text { Bladder Cancer } \\
\text { Genitourinary Cancer } \\
\text { Prostate Cancer }\end{array}$ & - & Completed & NCT00147238 \\
\hline & NA & Myocardial Infarction & - & Completed & NCT01323296 \\
\hline & NA & $\begin{array}{l}\text { Myocardial Infarction } \\
\text { Inflammation }\end{array}$ & - & - & NCT01127113 \\
\hline & NA & Renal Transplant Rejection & - & Recruiting & NCT02006108 \\
\hline
\end{tabular}


NA: not applicable

From all the RNAi-based drugs in clinical trials, approximately 52\% are lipid-based and polymeric NPs (organic NPs), 36\% are naked siRNAs and 12\% are bacteria/viral vectors [14] (see Table 3). Although necessary for a preliminary evaluation of the NP-based siRNA vehicles, in vitro studies do not mirror the complexities of the same cells within a physiological context, such as a whole animal; and many obstacles may arise in vivo, such as administration route, stability in blood, lymphatic systems and extracellular matrix, impacting on the RNAi efficiency. As such, in vivo evaluation of functional NPs using model organisms must be a priority to allow fast, cost and time saving screenings of intermediate and final abducts, before clinical trials are initiated [35].

Table 3. RNAi-based drugs in clinical trials. Adapted from [14].

\begin{tabular}{|c|c|c|c|c|c|}
\hline $\begin{array}{c}\text { Delivery } \\
\text { vehicle }\end{array}$ & Target gene & Disease & Phase & Status & $\begin{array}{c}\text { ClinicalTrials.gov } \\
\text { ID }\end{array}$ \\
\hline \multirow{9}{*}{ lipid-based } & $c-M y c$ & Hepatocellular Carcinoma & $\begin{array}{l}1 \\
2\end{array}$ & Recruiting & NCT02314052 \\
\hline & $c-M y c$ & $\begin{array}{l}\text { Solid Tumours } \\
\text { Multiple Myeloma } \\
\text { Non-Hodgkins Lymphoma }\end{array}$ & 1 & Recruiting & NCT02110563 \\
\hline & HSP47 & $\begin{array}{l}\text { Moderate to Extensive Hepatic } \\
\text { Fibrosis }\end{array}$ & 1 & Recruiting & NCT02227459 \\
\hline & PLK1 & $\begin{array}{l}\text { Colorectal, Pancreas, Gastric, } \\
\text { Breast and Ovarian Cancers With } \\
\text { Hepatic Metastases }\end{array}$ & 1 & Completed & NCT01437007 \\
\hline & EphA2 & Advanced Cancers & 1 & $\begin{array}{l}\text { Not yet } \\
\text { recruiting }\end{array}$ & NCT01591356 \\
\hline & $A p o B$ & Hypercholesterolaemia & 1 & Completed & NCT00927459 \\
\hline & $\begin{array}{l}V P 24, V P 35, \\
\text { Zaire Ebola } \\
\text { L-polymerase }\end{array}$ & Ebola-virus infection & 1 & Recruiting & NCT01518881 \\
\hline & $K S P, V E G F$ & Solid tumours & 1 & Completed & NCT01158079 \\
\hline & $T T R$ & $\begin{array}{l}\text { Transthyretin-mediated } \\
\text { amyloidosis }\end{array}$ & 2 & Recruiting & NCT01617967 \\
\hline \multirow{5}{*}{ naked siRNAs } & $\begin{array}{l}\text { K6a }(\mathrm{N} 171 \mathrm{~K} \\
\text { mutation })\end{array}$ & Pachyonychia congenita & 1 & Completed & NCT00716014 \\
\hline & VEGFRI & $\begin{array}{l}\text { Age-related macular degeneration, } \\
\text { choroidal neovascularization }\end{array}$ & 2 & Completed & NCT00395057 \\
\hline & CASP2 & $\begin{array}{l}\text { Optic atrophy, non-arteritic } \\
\text { anterior ischaemic optic } \\
\text { neuropathy }\end{array}$ & 1 & Completed & NCT01064505 \\
\hline & $P 53$ & Kidney injury, acute renal failure & 1 & Completed & NCT00554359 \\
\hline & RTP801 & $\begin{array}{l}\text { Choroidal neovascularization, } \\
\text { diabetic retinopathy, diabetic } \\
\text { macular edema }\end{array}$ & 2 & Completed & NCT01445899 \\
\hline
\end{tabular}




\begin{tabular}{l|l|l|l|l|l}
\hline & $\begin{array}{l}\text { RSV } \\
\text { nucleocapsid }\end{array}$ & $\begin{array}{l}\text { Respiratory syncytial virus } \\
\text { infections }\end{array}$ & 2 & Completed & NCT00658086 \\
\hline \multirow{2}{*}{$\begin{array}{l}\text { bacteria/viral } \\
\text { vectors }\end{array}$} & $\begin{array}{l}\text { Conserved } \\
\text { regions of HBV }\end{array}$ & HBV (human hepatitis B virus) & 1 & Recruiting & NCT01872065 \\
\cline { 2 - 6 } & CTNN1 & Familial adenomatous polyposis & 1 & Recruiting & - \\
\hline
\end{tabular}

Only the continuous discussions and knowledge's exchange between different disciplines may lay the foundations of an interdisciplinary platform for the smart design, testing and safe assessment of novel nanoconjugates for medical application. With this aim our consortium, in the frame of an European project (European Consortium NANOTRUCK, ERANET - NanoSciera $^{+}$), adopted a hierarchical strategy to test siRNA functionalized gold nanoparticles, using biological systems of increasing complexity, ranging from cells, diblastic animal (the freshwater polyp, Hydra vulgaris) to mouse. By targeting the $c-M y c$ protooncogene, and using both ionic and covalent approaches to conjugate siRNA to gold NP four potentially active siRNA-NP conjugates, from a total of eighteen compounds, were selected via evaluation using cell lines, which were tested in Hydra. In this more complex model two compounds were found to induce $80 \% c-M y c$ silencing; these were subsequently tested in a mouse model, where a single dose showed to be highly efficient in inducing $c$-Myc gene silencing [27,28]. Thus, our strategy not only reduced vertebrate experimentation, but also showed the broad functionality of the novel nanoconjugate across evolutionary distant species, suggesting universal rules underlying RNAi and nanoparticle/cell interaction.

In recent years, inorganic nanoparticles have been gaining momentum as robust and effective nanodelivery alternative to organic NP for the effective delivery of therapeutic siRNA owing to their inherent properties, chemical stability and physical constancy, high purity via reproducible synthetic protocols allowing for adjustable size and morphology control, ease of surface modification for improved siRNA binding and targeted delivery. These inorganic nanoformulations present several advantages for cell targeting and selective delivery of siRNA that are now coming of age and translating to the clinics. This strenuous evolution shall be discussed in the present review. In addition, in this review we examined in detail the synthetic approaches for the effective conjugation of the nanoparticles and the siRNA. We also reviewed the most common approaches to assess gene silencing in vitro and in vivo. Finally we envisioned the upcoming perspectives of nanoparticlemediated gene silencing in nanomedicine. 


\section{Inorganic nanoparticles as SiRNA carriers}

Since the first publication on RNA interference in 1998 [1], several RNAi-based therapeutic approaches have been proposed for promising clinical applications. Although this seems easy, the complexity of siRNA transfection is challenging once these biomolecules are too large and too hydrophilic to cross the cell membrane without the help of a transfection agent. Nanotechnology offers versatile targeted delivery platforms for RNAi therapeutics [36,37]. In the last 15 years the use of inorganic nanoparticles (gold, magnetic, silica and quantum dots) as siRNAs delivery agents has been investigated and extensively described. A milestone timeline of the last 15 years summarizing the greatest events in RNAi discovery and RNAi nanomaterials development is depicted in Figure 2.

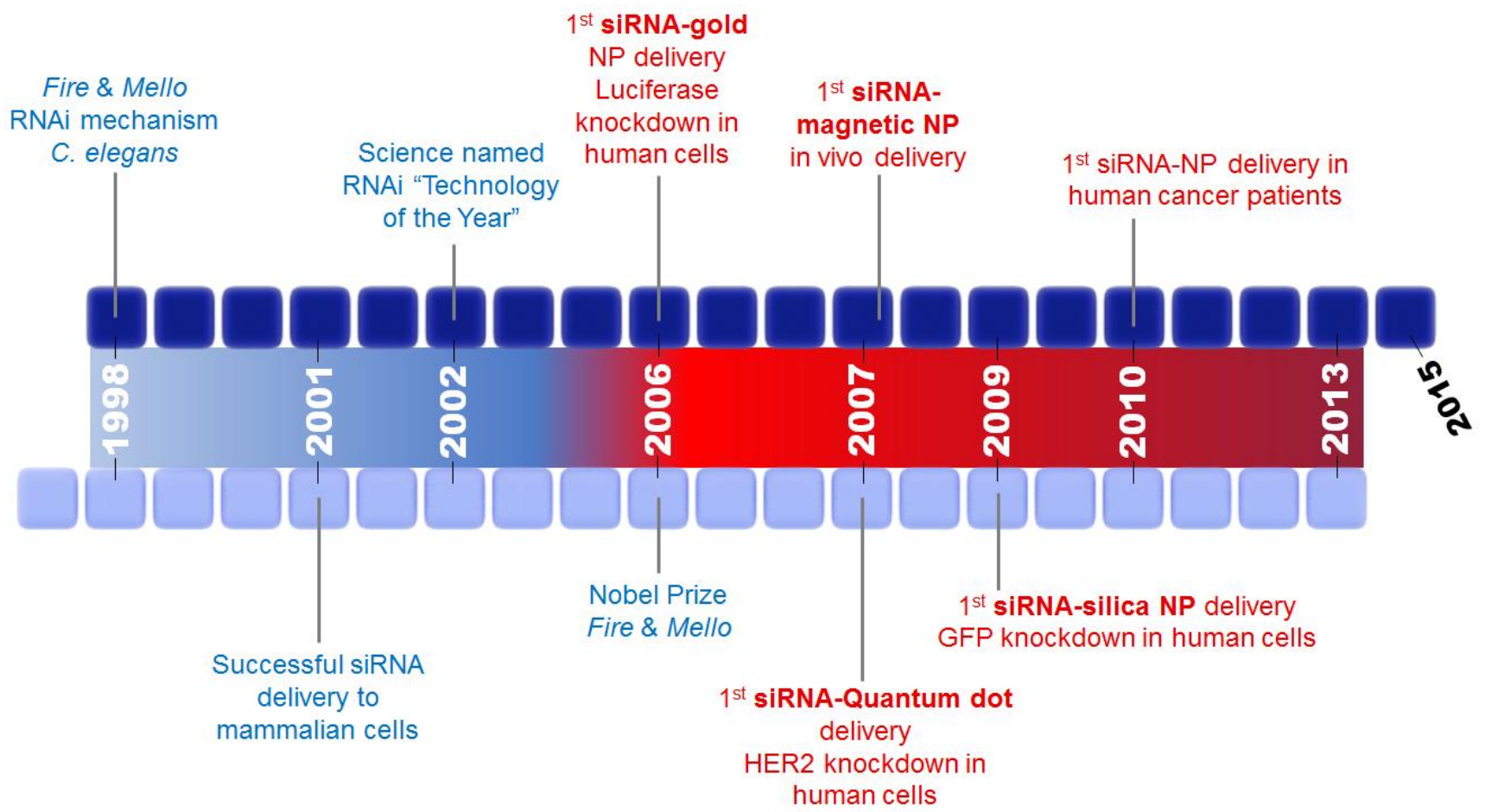

Figure 2. Milestone timeline of the last 15 years summarizing the greatest events in RNAi discovery (in blue) and RNAi inorganic (gold, silica, magnetic and quantum dot) nanoparticles development (in red).

\section{1. siRNA-Gold Nanoparticles}

In 2006, the first application of siRNA-gold nanoparticles (AuNPs) reported the use of $15 \mathrm{~nm}$-AuNPs with thiolated PEG-PAMA and siRNA capable of silencing $65 \%$ of a reporter gene (luciferase) in human hepatocarcinoma cells [38]. Later, Mirkin and co-workers reported polyvalent siRNA-AuNP conjugates could be readily taken up by cells and that the particle bound siRNA could effectively regulate genes in the context of RNA interference [24]. In this system, PEG is significantly smaller than the siRNA in order to fully expose the siRNA on the particle surface presented to the cells. AuNPs modified with the hydrophilic PEG polymer, siRNAs and then coated with poly $(\beta$ - 
aminoester)s have been shown to facilitate high levels of in vitro siRNA delivery and gene silencing in human cell lines [25]. Also, Braun et al. developed a laser-activated Au-nanoshell functionalized with TAT-lipid layer for transfection and selective siRNA delivery [39]. The authors reported that the TAT-lipid coating was able to efficiently mediate the cellular uptake of the nanoformulations and siRNA release occurred as a response to proficient and time dependent near-infrared (NIR) laser pulses.

Recently, Conde et al. developed a theranostic system capable of intersecting all RNA pathways: from gene specific downregulation to silencing the silencers, i.e. siRNA and miRNA pathways. In fact, the only study reported so far concerning the use of AuNPs for the detection in living cells at the same time as oncomiR inhibition occurs was reported by Conde et al. The authors reported the development AuNPs functionalized with a fluorophore labelled hairpin-DNA, i.e. Gold nanobeacons, capable of efficiently silencing single gene expression, exogenous siRNA and endogenous miRNAs while yielding a quantifiable fluorescence signal directly proportional to the level of silencing [40-43] (Figure 3). 
$\mathbf{A}$

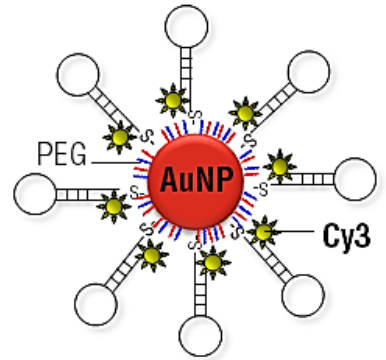

Gold Nanobeacon Antisense to silenc EGFP

ANTISENSE APPROACH
HUMAN CELL

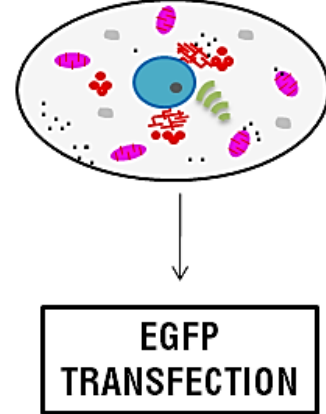

B

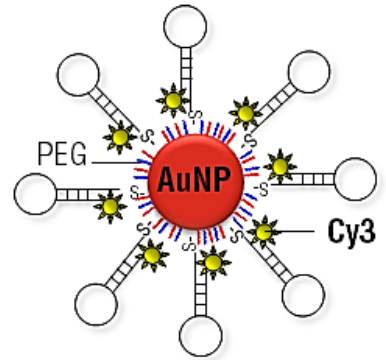

Gold Nanobeacon Anti-siRNA

to block siRNA for EGFP
mRNA
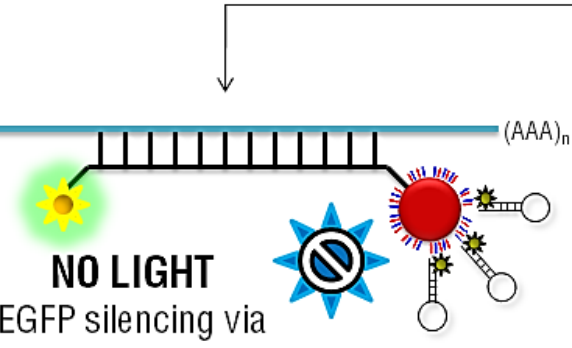

Gold Nanobeacon Antisense

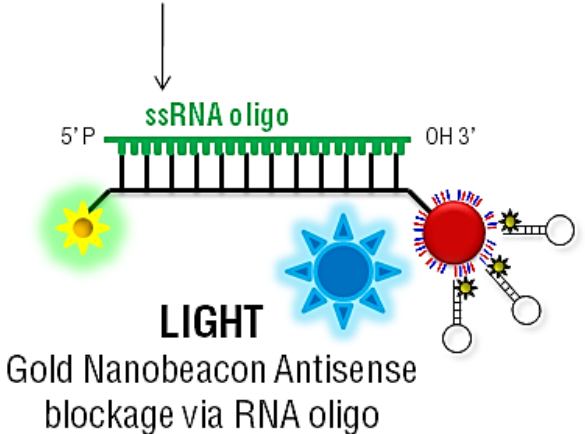

C

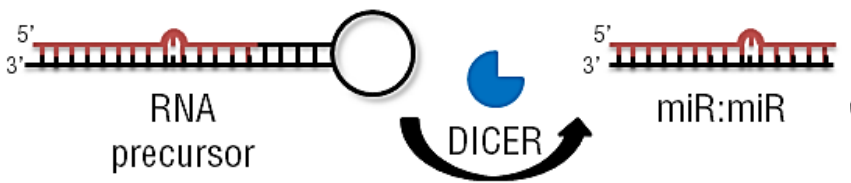

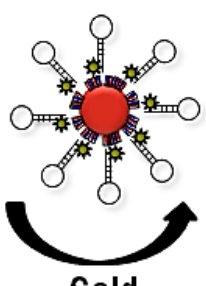

Gold

\section{INTERFERENCE APPROACH}

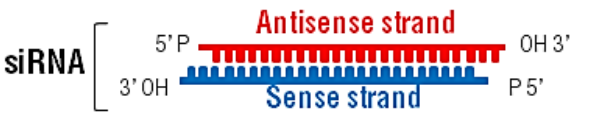

NO LIGHT

EGFP silencing via SiRNA

siRNA blockage via Gold Nanobeacon Anti-siRNA

\section{Nanobeacon} , miR blockage

Anti-miR

Figure 3. "Silencing the Silencers" with Gold Nanobeacons. (A-B) Human cells efficiently transfected with EGFP vector are tested for the blockage/recovery of gene expression mediated by a nanoparticle delivery technology. Gold nanoparticles functionalize with hairpin DNA (Au-nanobeacons) act as both promoters of gene silencing from an antisense (A) and RNA interference (B) approaches and as supporters for the recovery of gene expression. In the antisense approach (A), the EGFP silencing occur via gold nanobeacons-Antisense and the recovery of the EGFP expression by the action of small ssRNA oligos that block gold nanobeaconsAntisense. In the RNA interference pathway (B), siRNAs for the silencing of EGFP expression and a gold nanobeacon Anti-siRNA were used to successfully blocking the antisense strand of siRNA molecules and the repression of gene silencing. (C) Blocking the microRNA pathway via a gold nanobeacon Anti-miRNA complementary to a specific microRNA involved in cancer progression, for example. Reproduced with permission [40]. Copyright 2015, Nature Publishing Group. 
Several other studies using engineered NPs modified with siRNA have demonstrated a cytoplasmic delivery system of siRNA and efficient gene silencing using AuNPs. These include AuNPs functionalized with PEG or PEI polymers, cationic biodegradable polymers poly( $\beta$-aminoester) (PBAEs), cationic lipid bilayer coated AuNPs [29,44-46]. However, almost all nanoconjugates using siRNA have exclusively been tested in cell cultures and targeting only reporter genes (i.e. GFP or luciferase).

As mentioned earlier, we provided evidence of in vitro and in vivo RNAi via the synthesis of a library of multifunctional AuNPs, using a hierarchical approach including three biological systems of increasing complexity: in vitro cultured human cells, in vivo freshwater polyp (Hydra vulgaris), and in vivo mice model $[27,28]$ (Figure 4). We developed effective conjugation strategies to combine, in a highly controlled way, specific biomolecules to the surface of AuNPs such as: (a) biofunctional spacers; (b) cell penetrating peptides: membrane translocating agents (cell penetrating peptides, CPPs) that exploit more than one mechanism of endocytosis to overcome the lipophilic barrier of the cellular membranes and deliver large molecules and even small particles inside the cell; (c) siRNA complementary to a master regulator gene. As spacer, poly(ethylene glycol) (PEG) spacers, with a thiol end to bond covalently to the gold nanoparticle and carboxilic acid (thiol-PEG-COOH) and azide (thiol-PEG-N $\mathrm{N}_{3}$ ) functional groups in the other end were used to increase solubility and biocompatibility. AuNPs functionalized with CPPs, such as TAT and RGD peptides, were used to better reach the cell cytoplasm and evade retention in sub-cellular organelles. As proof-of-concept, the protooncogene $c-M y c$ was targeted, and the siRNA was bond covalently (thiol-siRNA) and ionically (naked siRNA) to AuNPs and the effect compared [28]. The differences between the ionic and covalent approach for the siRNA binding are further discussed in detailed (see Section 3). 


\section{1) The "NanoVehicles"}
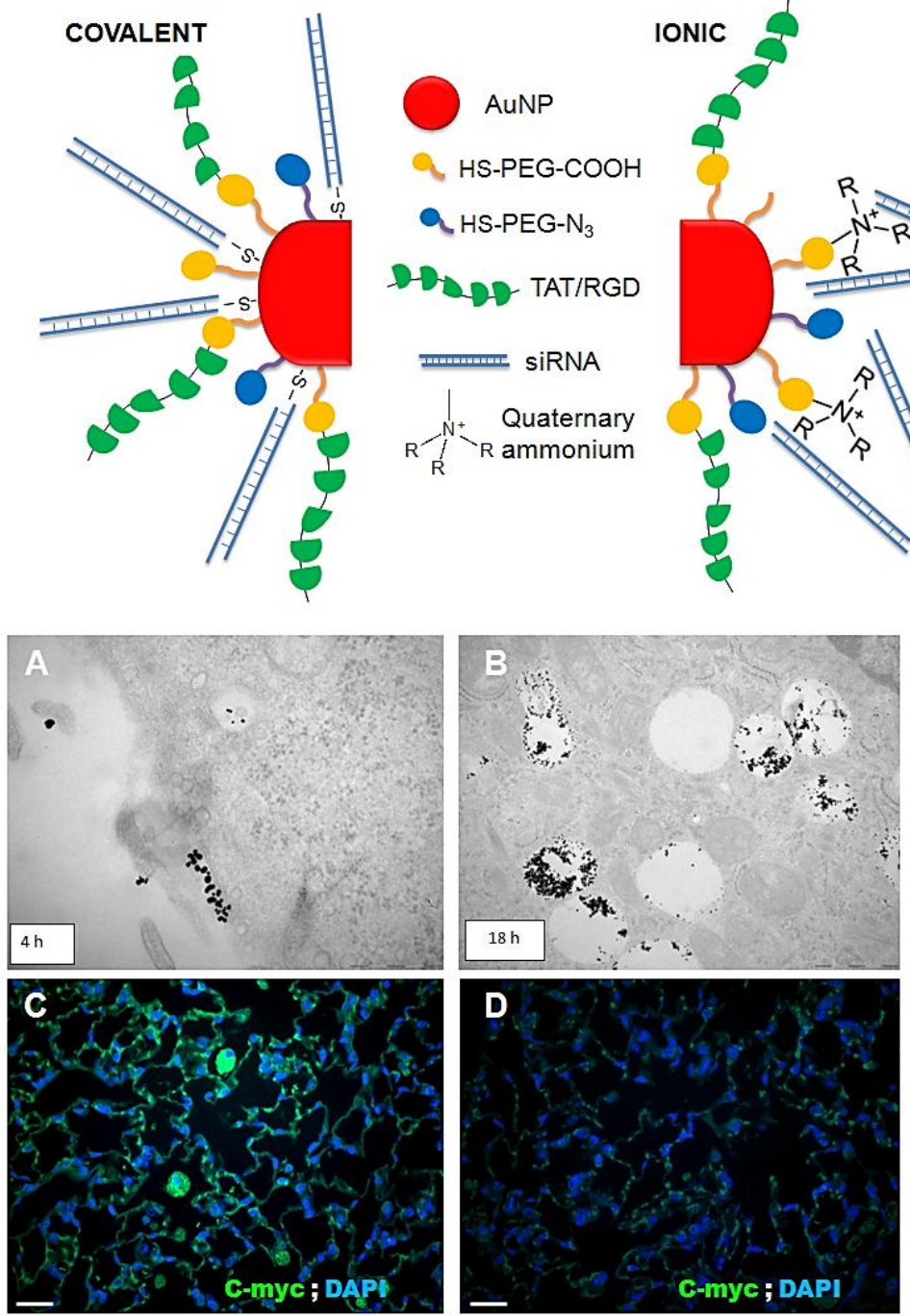

\section{2) The "Hosts"}
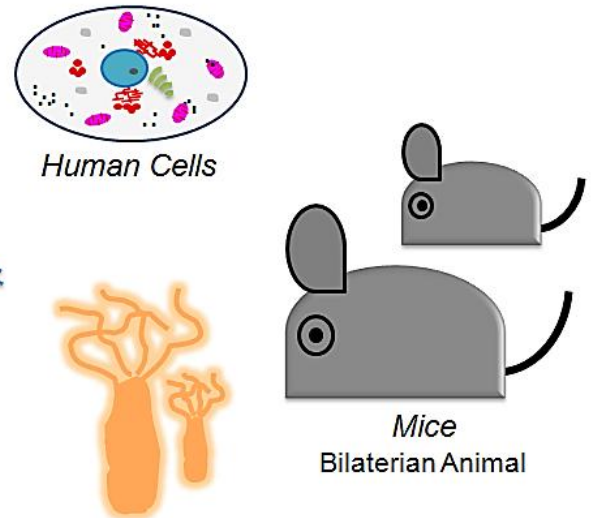

Hydra

Dipoblastic Animal

Figure 4. Regulation of gene expression via multifunctional siRNA-gold nanoparticles. (1) The "NanoVehicles": Covalent approach: the use of thiolated siRNA for the binding to the nanoparticle through the strong interaction gold-thiol; Ionic approach: binding of the negatively charged siRNA through ionic interactions to the modified surface of gold nanoparticle. (2) The "Hosts": The nanoparticles were tested in a cancer cell line (HeLa) and in two animal models: Hydra vulgaris and C57BL/6j mice. (A,B) TEM images of lung epithelial cells. Mice were treated with NPcov@RGD@myc-siRNA by intratracheal instillation. At 4 hours (A) after instillation, NPs are located in ruffles of lung epithelial cell membranes and a few NPs are in the vesicles. At 18 hours (B), huge amounts of NPs are found in vesicles or free in cytoplasm (scale bars $500 \mathrm{~nm}$ ). (C,D) c-myc protein expression on alveolar epithelial cells in lung tissue after 48 hours treatment. (C) Mice instillated with NP-cov@RGD, (D) mice instillated with NP-cov@RGD@myc-siRNA. The c-MYC protein was detected by Alexa-488-conjugated anti-c-MYC antibody (green), and cell nuclei were DAPI stained (blue). Scale bars $200 \mu \mathrm{m}$. (E) Molecular assessment of RNAi efficiency in mice. The $c$-Myc expression levels were determined using $\beta$-actin as reference gene. Data marked with asterisks are statistically significant relative to the corresponding NP-ion/cov without siRNA (*, $\mathrm{P} \leq 0.001 ; * *, \mathrm{P} \leq 0.01)$. Reproduced and adapted with permission [28]. Copyright 2015, American Chemical Society.

In addition to mediating RNAi, siRNA molecules have also the potential to potently induce the innate immune system, which constitutes an important challenge - the differentiation between therapeutic 
effects caused by target-specific, RNAi-mediated gene silencing and those caused by nonspecific stimulation (i.e. inflammation/toxicity) of the innate immune system [47]. Further work has been reported on the innate immune response (as measured by interferon- $\beta$ levels) to densely functionalized siRNA-AuNP to be significantly less (up to a 25-fold decrease) when compared to a lipoplex carrying the same DNA sequence. The authors proposed that the enzymes involved in recognizing foreign nucleic acids and triggering the immune response are impeded due to the local surface environment of the particle, in particular high charge density [48].

\subsection{Magnetic Nanoparticles for RNAi}

Magnetic nanoparticles (MNPs) have emerged as nanotheranostics systems for gene silencing, tumour targeting/imaging and drug delivery [49]. MNPs have been frequently exploited as platforms for tracking the delivery of siRNA, as they can be used to image biodistribution by magnetic resonance imaging (MRI). Thus far, the most promising application of in vivo tumour therapy using MNPs has been reported by Namiki and co-workers [50]. The authors reported a new nanoformulation based on an oleic acid-coated magnetic nanocrystal core and a cationic lipid shell (Figure 5). This smart system can be magnetically guided to deliver and silence genes in vitro and in mice bearing gastric tumours. After systemically injecting the nanoformulation to tumour and applying a magnetic field, a 50\% reduction in tumour mass was achieved.

Another study reporting the use of MNPs as tools for magnetofection [51] and consequently for the enhancement of siRNA delivery using external magnetic fields have also been widely described $[23,52-55]$. 

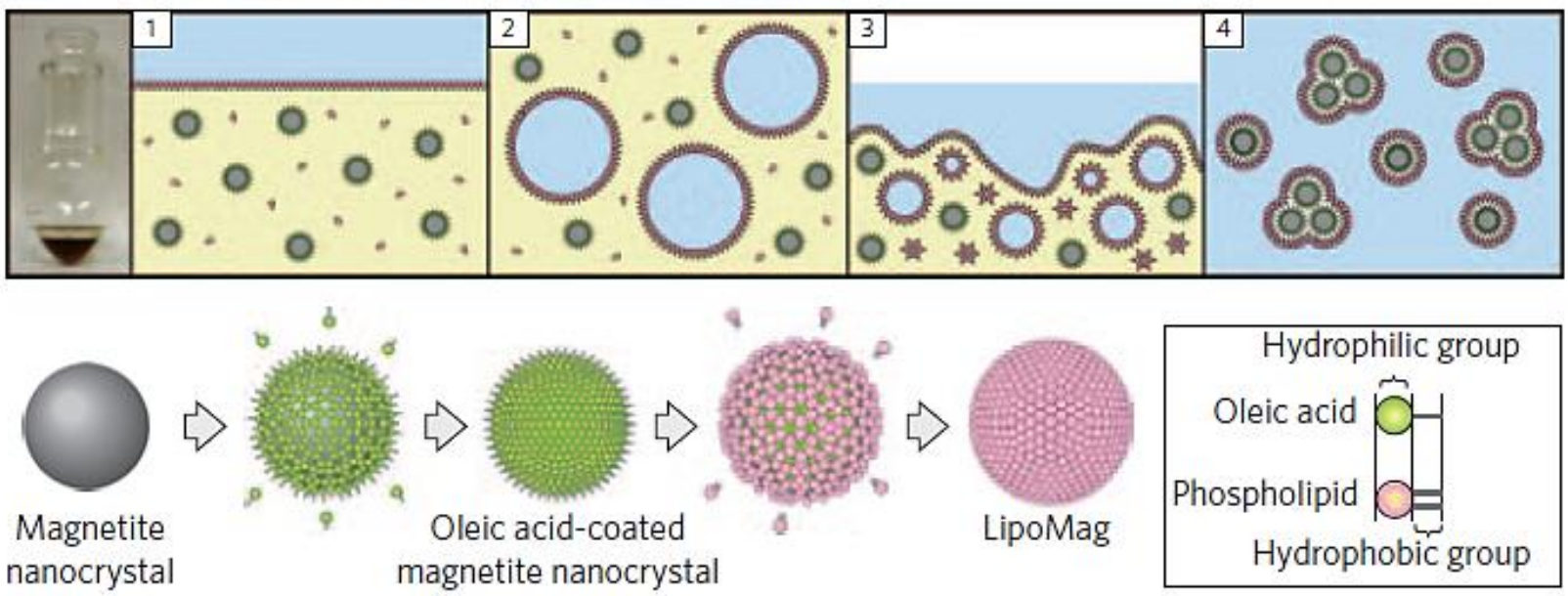

\section{Evaporated magnetic liposomes (using non-coated magnetic nanocrystals)}

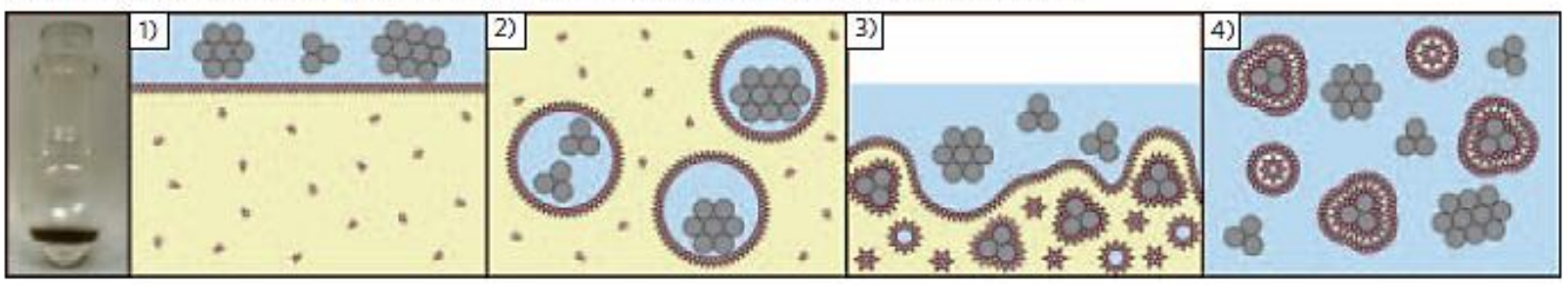

Figure 5. A novel magnetic crystal-lipid nanostructure for magnetically guided in vivo gene delivery. Schematic showing the preparation (upper) and assembly (middle) of LipoMag and reverse-phase evaporated magnetic liposomes (lower). Oleic acid-coated magnetic nanocrystal cores and the lipid shells form through hydrophobic interactions. Reproduced with permission [50]. Copyright 2015, Nature Publishing Group.

Superparamagnetic iron oxide nanoparticles (SPIONs) are another example of siRNA-magnetic carriers, which are also widely studied MR contrast agents useful in both imaging and drug delivery applications [56-58]. The large surface area of SPIONs makes them perfect candidates for functional modification, enabling the conjugation of targeting molecules, drugs, and imaging contrasts agents. For instance, Kumar et al. synthesized multifunctional MNPs by attaching a near-infrared (NIR) optical dye Cy5.5 and a peptide that targets the tumour specific antigen mucin-1 to cross-linked dextran coated SPIONs [59]. The authors tested this tumour-targeted nanodrug to specifically shuttle siRNA to human breast tumours. Following delivery into subcutaneous mouse models of breast cancer, the nanodrug showed preferential tumour uptake that could be visualized by MRI and NIR optical imaging (NIRF). Medarova et al. also reported an important study using a magnetic nanoparticles labelled with a NIR dye and covalently linked to siRNA molecules to use as dualpurpose probes for in vivo siRNA transfection and the simultaneous imaging of its accumulation in tumours by high-resolution MRI and in vivo NIRF (Figure 6). This study represents one of the first steps toward the advancement of siRNA uptake and imaging strategies in the same delivery system, essential for cancer therapy [18]. 
A
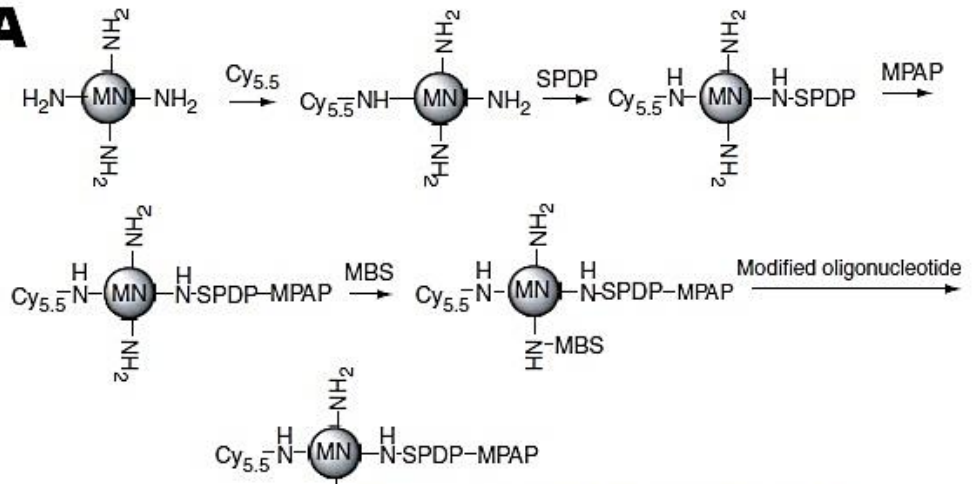

고-MBS-S-( $\left(\mathrm{CH}_{2}\right)_{6}$-GAACUUCAGGGUCAGCUUGCUU

$\downarrow$ Annealing

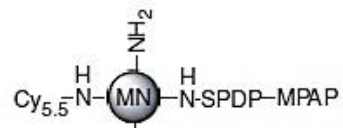

ż-MBS-S- $\left(\mathrm{CH}_{2}\right)_{6}$-GAACUUCAGGGUCAGCUUGCUU
U/CUUUGAAGUCCCAGUCGAACG
B

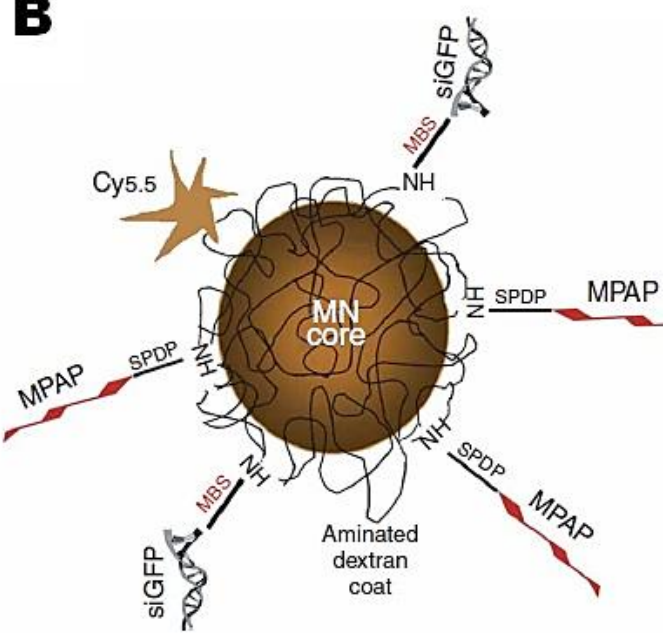

C

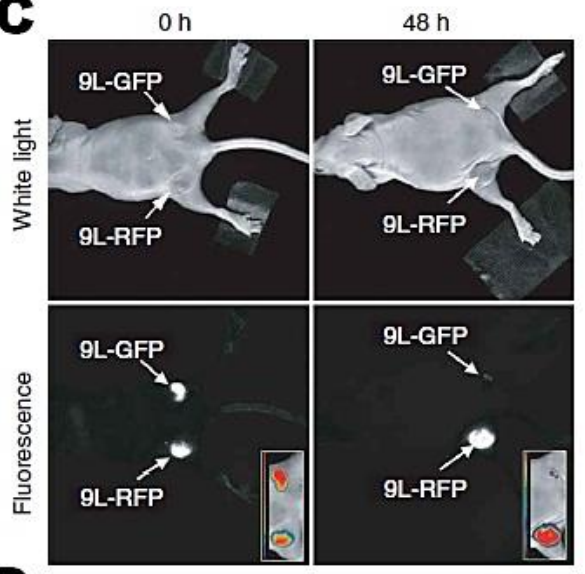

D

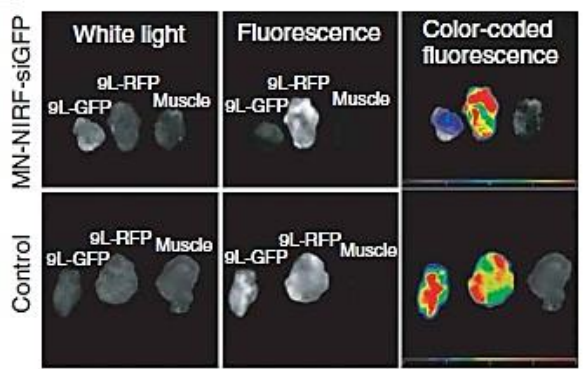

E
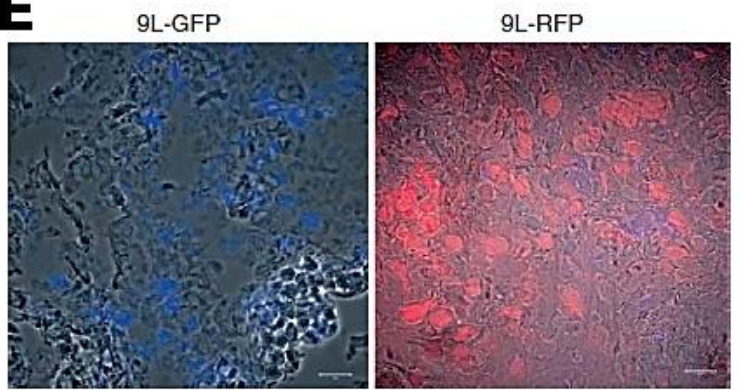

F

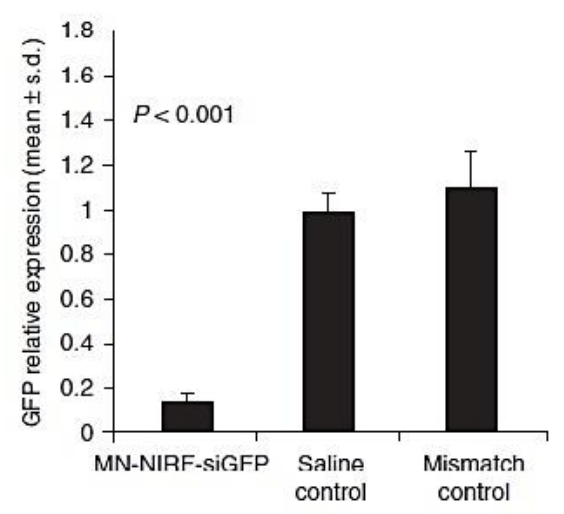

Figure 6. In vivo imaging of siRNA delivery and silencing in tumours. (A) Step-by-step synthesis of the MN-NIRF-siGFP probe, by the sequential conjugation of three different entities onto magnetic nanoparticles. (B) The resultant probe consisted of magnetic nanoparticles labeled with near-infrared Cy5.5 dye (NIRF) and linked through two different linkers to membrane translocation peptides (MPAP) and siRNA molecules targeting GFP (siGFP). In vivo imaging of MN-NIRF-siGFP silencing in tumours. (C) In vivo NIRF optical imaging of mice bearing bilateral 9L-GFP and 9L-RFP tumours $48 \mathrm{~h}$ after intravenous probe injection. (D) Correlative ex vivo fluorescence optical imaging showed a significant drop in fluorescence intensity in 9L-GFP tumours $(\mathrm{P}=0.0036)$. There was no evidence of silencing in saline injected controls. (E) Confocal microscopy of frozen tumour sections indicated the presence of the probe in both 9-GFP and 9L-RFP tumours (blue). Scale bar, $20 \mathrm{~mm}$. (F) Quantitative RT-PCR analysis of GFP expression performed on total RNA extracted from 9LGFP tumours from mice injected with either MN-NIRF-siGFP, a mismatch control or saline solution. Reproduced and adapted with permission [18]. Copyright 2015, Nature Publishing Group. 


\subsection{Mesoporous Silica Nanoparticles for siRNA delivery}

Mesoporous silica nanoparticles (MSNs) are another important inorganic material that have been used for siRNA delivery [60]. The large surface area of the pores allows the particles to be filled with large amounts of small molecules of siRNA. The first study about siRNA MSNs was reported in 2009 by $X i a$ et al., evaluating the role of polyethyleneimine coating in the enhancement of the cellular uptake of MSNs for the safe delivery of siRNA and DNA constructs [61]. After that, several MSN based systems for cancer therapy have been reported to deliver siRNAs in cells, usually through endocytosis [31,62-65].

For instance, $L i$ et al. described the synthesis of MSN functionalized with a cationic polymer (PEI) and a fusogenic peptide used to enhance endosomal escape and consequently improving siRNAinduced silencing gene expression both in vitro and in vivo [65] (Figure 7).

Another application of MSNs is their use to enhance efficacy of chemotherapy. Hom et al. have exploited the large capacity of MSNs to efficiently load a cancer chemotherapeutic, such as doxorubicin (Dox) together with Bcl2-siRNAs. The authors observed that both Bcl2-siRNA and Dox were released into cells. In order to silence the multi-drug resistant pump of Bcl2 gene, enhancing the effect of doxorubicin [64]. 
M-MSNs M-MSN_siRNA M-MSN_siRNA@PEI M-MSN_siRNA@PEI-KALA

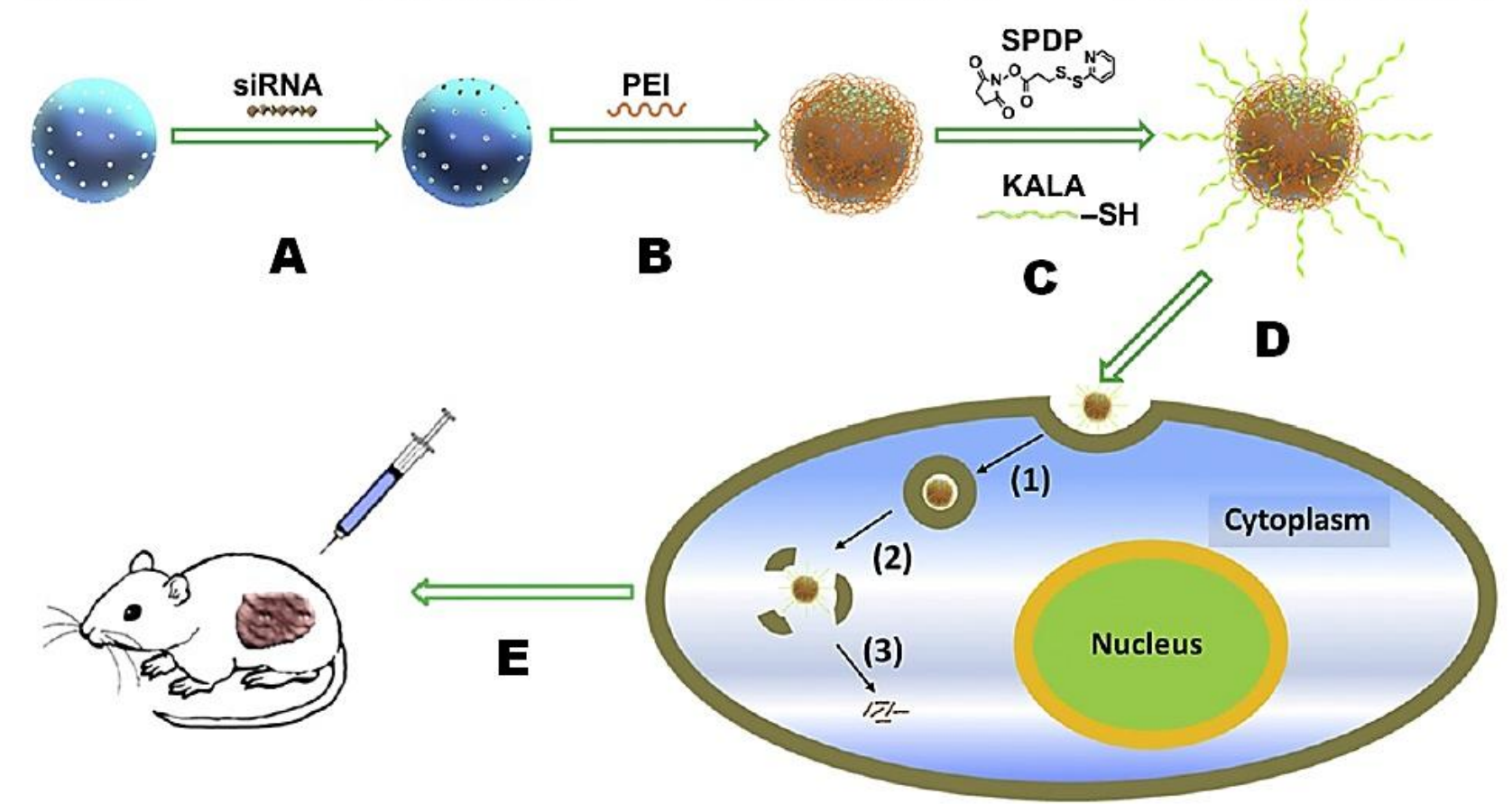

\section{In vivo Cancer Treatment}

F

10 Days
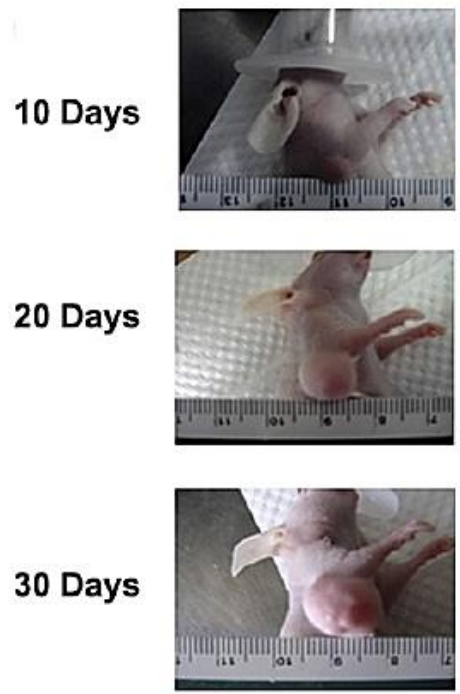

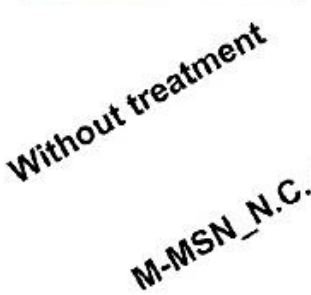
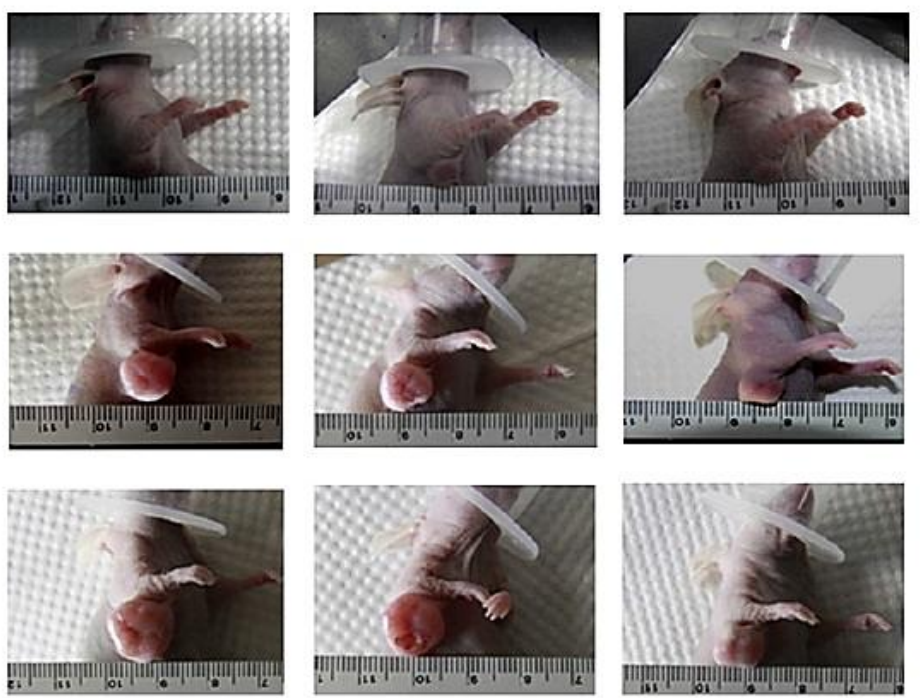

Figure 7. A mesoporous silica nanoparticle-PEI-fusogenic peptide system for siRNA delivery in cancer therapy. Flowchart illustrating the preparation of siRNA delivery vectors based on magnetic mesoporous silica nanoparticles (M-MSNs): (A) Encapsulating siRNA molecules into the mesopores of M-MSNs (MMSN_siRNA); (B) Synthesizing PEI-embedded M-MSN_siRNA composite (M-MSN_siRNA@PEI); (C) Conjugating KALA peptides onto the surface of M-MSN_siRNA@PEI (M-MSN_siRNA@PEI-KALA). (D) In vitro gene silencing process initiated by M-MSN_siRNA@PEI-KALA: (1) the internalization of nanocarriers into cells; (2) the endo-lysosomal escape of delivery vehicles; (3) the release of siRNA into cytoplasm from the vectors. (E) In vivo cancer treatment through injecting M-MSN_siRNA@PEI-KALA delivery vehicles into tumour region. In each step, the blue sphere with white dots represented M-MSNs, the brown double helix represented siRNA, the orange random coil represented PEI and the light greenwave line represented KALA 
peptide. (F) Representative photos of the A549 tumours in mice, which were taken at days 10, 20 and 30.

\subsection{Quantum-Dots (QDs) as vehicles for siRNA}

The first study reporting about siRNA QDs was described in 2007 by Tan et al. The authors reported the QD-based nanoparticles for targeted silencing of HER2/neu gene via RNAi [66]. After this study, siRNA-QDs as light-emitting nanoparticles [67] have been extensively used for gene silencing approaches [21,68-70]. One of the most promising features of siRNA-QDs is the proton-sponge effect. In more detail, Yezhelyev et al. developed multifunctional semi-conductor nanoparticles for siRNA delivery and imaging based on the use of QDs and proton-absorbing polymeric coatings (proton-sponges) (Figure 8). The "proton-sponge effect" occurs when unprotonated species can absorb protons as they are pumped into the lysosome, resulting in more protons being pumped in leading to an increased influx of $\mathrm{Cl}^{-}$ions and water, resulting in swelling and rupture of the lysosomal membrane with subsequent release of its contents into the cytoplasm (Figure 8). The authors demonstrated a dramatic improvement in gene silencing efficiency and simultaneous reduction in cellular toxicity, when compared with existing transfection agents using the proton sponge effect. These nanoparticles were particularly designed to address longstanding barriers in siRNA delivery such as cellular penetration, endosomal release, carrier unpacking, and intracellular transport. These particular nanoparticles are also dual-modality optical and electron-microscopy probes, allowing realtime tracking and ultrastructural localization of QDs during the delivery and transfection processes [70]. 
A

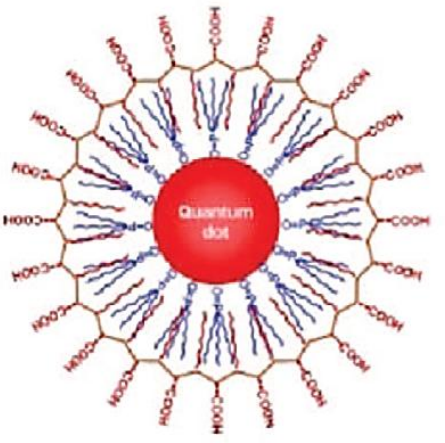
${ }_{2} \mathrm{HN}-\mathrm{CH}_{2}-\mathrm{CH}_{2}-\mathrm{N}\left(\mathrm{CH}_{3}\right)_{2}$ + EDAC

2. siRNA adsorption

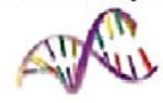

B

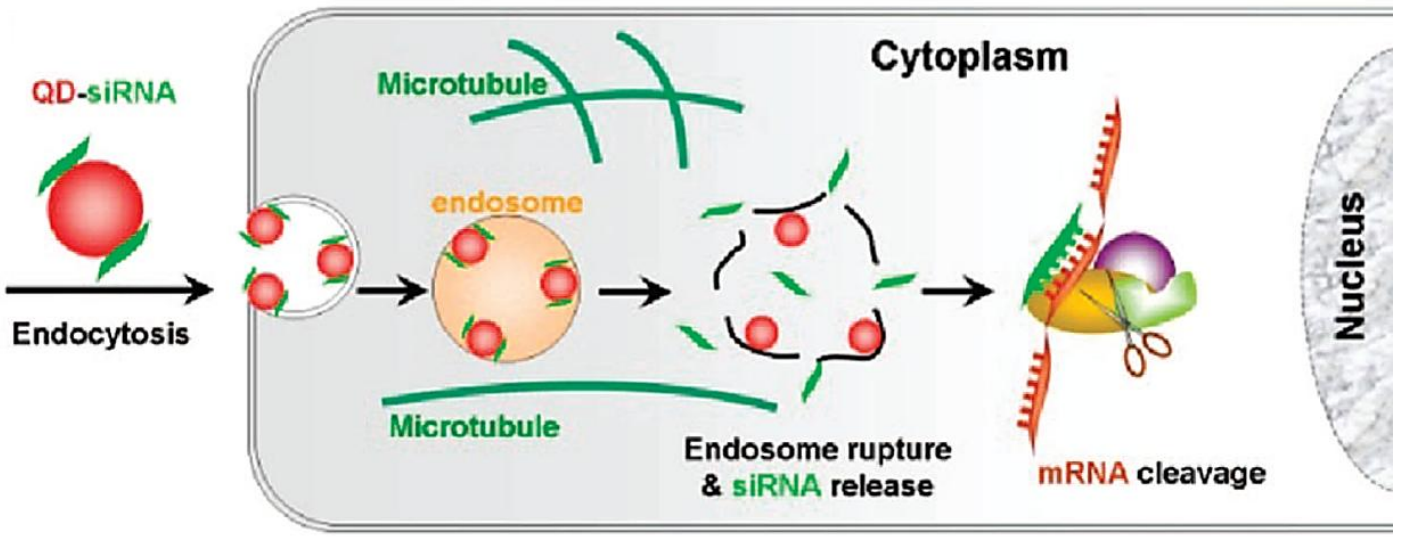

C

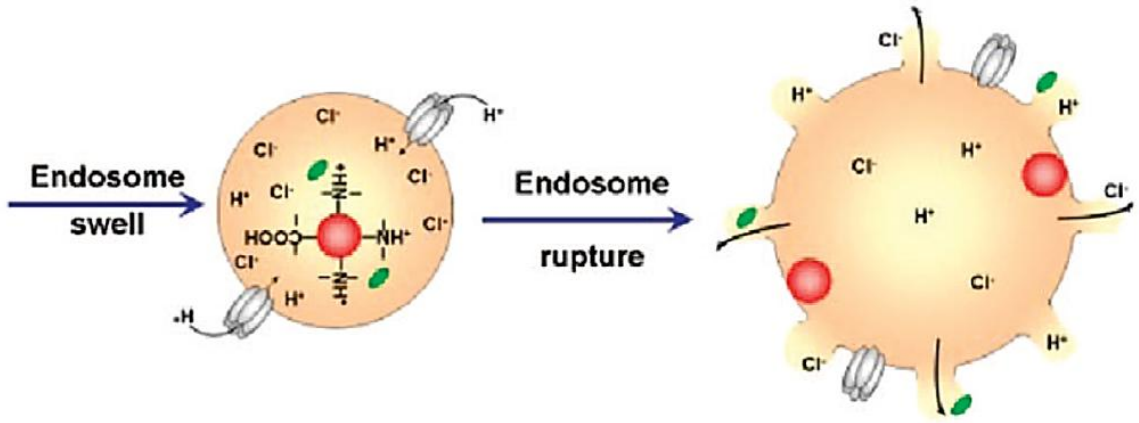

Figure 8. Rational design of proton-sponge coated quantum dots and their use as a multifunctional nanoscale carrier for siRNA delivery and intracellular imaging. (A) Chemical modification of polymerencapsulated QDs to introduce tertiary amine groups, and adsorption of siRNA on the particle surface by electrostatic interactions. (B) Schematic diagram showing the steps of siRNA-QD in membrane binding, cellular entry, endosomal escape, capturing by RNA binding proteins, loading to RISC, and target degradation. (C) Schematic illustration of the proton-sponge effect showing the involvement of the membrane protein ATPase (proton pump), osmotic pressure build-up, and organelle swelling and rupture. For optimized silencing efficiency and cellular toxicity, the QD surface layer is composed of 50\% (molar) carboxylic acids and 50\% tertiary amines. The optimal number of siRNA molecules per particle is approximately two. Reproduced with permission [70]. Copyright 2015, American Chemical Society.

Nevertheless, the major drawback of using QDs as multifunctional imaging probes and delivery systems is their inherent cytotoxicity, as most of the well-established QDs are composed of highly toxic chemical elements, such as cadmium or selenium [71]. Encapsulation of these QDs into polymers may be the key to solving some issues related to acute toxicity but may decrease their intrinsic potential as vehicles for delivery. 
Although nontoxic QDs for imaging and siRNA delivery in vitro have been developed recently

\subsection{Inorganic-organic conjugates as delivery vectors for RNAi}

Although some examples of inorganic-organic systems have been already described in previous sections, it is important to highlight the significance of this type of siRNA delivery vehicles. These conjugates are formed by an inorganic core that provides the system with special properties such as optical and magnetic behaviour, and an organic coating made of different biomolecules such as polymers or lipids, used for increasing biocompatibility while serving as anchor points for the siRNA. Regarding the use of polymers in the organic shell, the most frequently used polymer is PEI due to its positively-charged nature that can bind to siRNA and also induce the disruption of endosomal membrane, facilitating the siRNA release into the cytoplasm [73-75]. In fact, PEI (MW $25 \mathrm{kDa}$ ) has been used very efficiently as delivery vector, although its usage in biological applications is strongly limited because of its toxicity. This new approach of combination with inorganic nanoparticles seeks reducing the amount of PEI needed and therefore its toxicity while exploiting the advantages it presents for siRNA delivery. In an attempt to reducing the toxicity shown by PEI, it has been also reported the use of carbohydrate-derived polymers (i.e. dextran or chitosan [66,76]), and amphiphilic polymers such as PEG [38,77], known for reducing opsonisation and increasing the circulating time of these conjugates.

In the same direction, several groups have developed inorganic-organic conjugates using lipid coatings [39,50] or even dendrimers [78] such as PAMAM [79] that may increase cellular uptake in order to enhance the efficacy of these systems searching for the ideal vector.

More information and examples will be provided in next section regarding the design and functionalization of inorganic nanoparticles.

\section{Functionalization of inorganic nanoparticles with siRNA}

The use of inorganic nanoparticles as carriers for siRNA has expanded amazingly during the last decade, revealing these new materials as excellent candidates for gene therapy in order to replace viral vectors and their inherent disadvantages [80].

The success of the therapy is highly dependent on the effective conjugation between nanoparticles and the siRNA, as well as the nature of this attachment. At a first glance, a strong interaction is desirable 
to maintain stability while the system remains in the bloodstream until reaching the target cells, being internalized and escaping from the endosome if necessary. However, once in the cytosol the siRNA needs to be capable of being incorporated into the RISC complex to initiate the interference mechanism, so it should be completely or partially released from the carrier [81].

Attending to the nature of the interaction between siRNA and inorganic nanoparticles, there are three main approaches: ionic, covalent and encapsulation. Attachment may be established directly to the core of the nanoparticle $[38,82]$ or through intermediates, such as polymers [83,84], dendrimers $[79,85]$ and short linkers $[18,86]$, among others.

\subsection{Ionic approach}

As with other types of nucleic acids, siRNA is negatively charged due to the presence of phosphate groups in its backbone. For this reason the most common and maybe the simplest strategy for conjugation is establishing ionic interactions with cationic species.

Although it may seem to be a weak attachment, by modulating the number of positive charges it is possible to increase the points of interaction and, therefore, the strength of the ionic bond.

The most frequent functional group used are amines as they are positive at values of $\mathrm{pH}$ under their $\mathrm{pKa}$ (such as the physiological $\mathrm{pH}$ ) being able to attach to the siRNA. Besides, it has been described their ability to induce endosomal escape by a mechanism usually known as "proton-sponge effect" (see Figure 9) [87]. A special type of amines are quaternary ammonium groups whose main feature is being positively charged in the whole range of $\mathrm{pH}$ ensuring an effective conjugation in all kind of media. These groups and different cations can be found either on the surface of the nanoparticles or in molecules previously attached ionic or covalently to the carrier. 


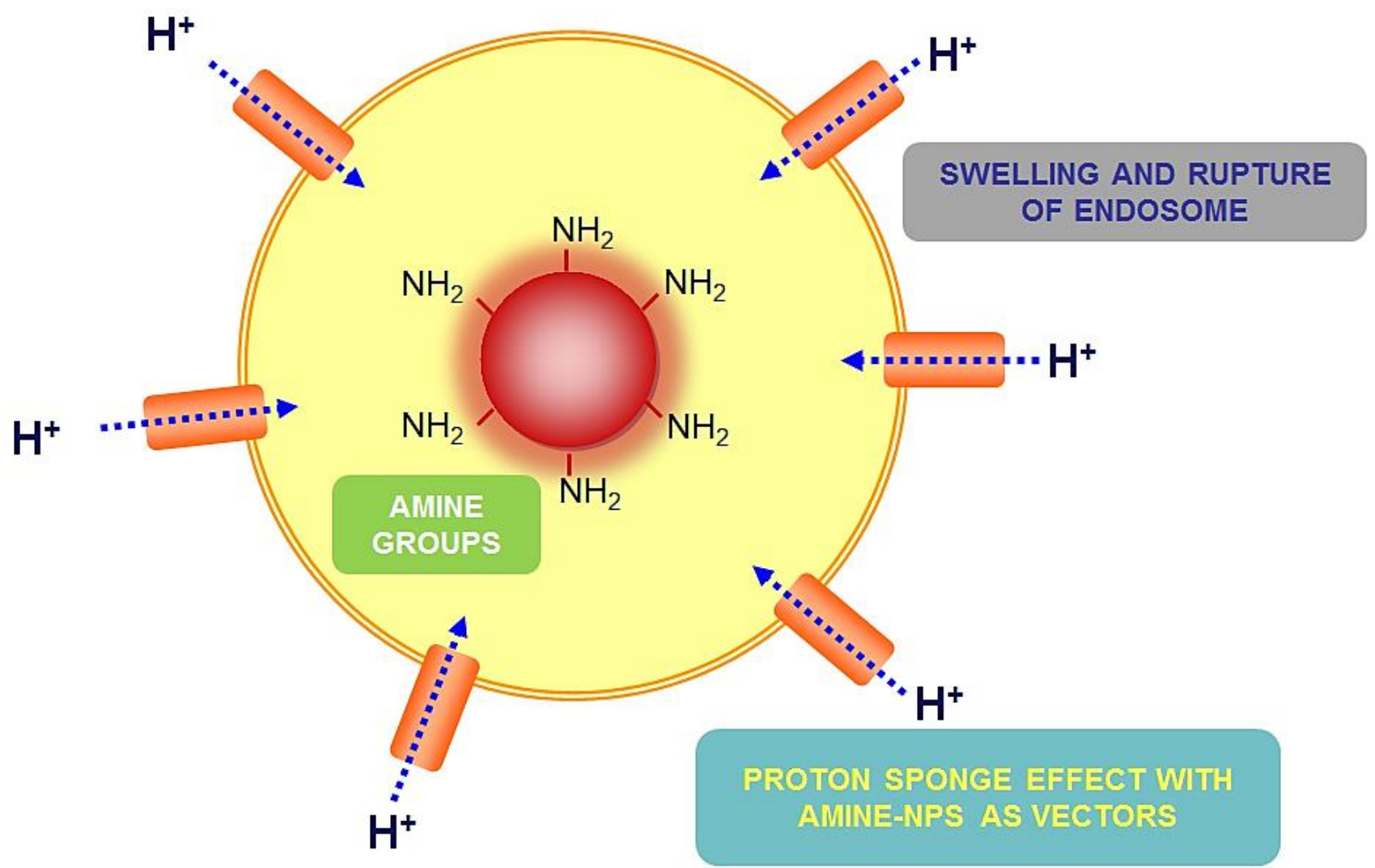

Figure 9. The "proton-sponge effect": unprotonated amines can absorb protons as they are pumped into the lysosome, resulting in more protons being pumped in leading to an increased influx of $\mathrm{Cl}^{-}$ions and water, resulting in swelling and rupture of the lysosomal membrane with subsequent release of its contents into the cytoplasm.

The simplest system consists on the direct conjugation of the siRNA to the core of cationic nanoparticles such as quantum dots coated with silica [82], calcium phosphate nanoparticles [88], carbon nanotubes [89] and layered double hydroxide nanoparticles [90,91].

However, it is more frequent to find hybrid systems composed by the inorganic core and different coatings, which provide the positive charges needed.

The most universal systems reported are based on the functionalization of the nanoparticles with cationic polymers, especially with PEI and polylysine (PLL) with many variations. PEI has been described using different kinds of nanoparticles directly adsorbed on negatively charged materials [74,92] or covalently attached by amination [93]. There are many examples of the functionalization of AuNPs [94,95], MNPs [54,96-98], SiNPs [61,99,100], with PEI of different molecular weights [61,101] or even modified with labile bonds like acetal [102]. In relation to the PLL, this polymer has been used previously modified with a terminal cysteine for the direct attachment to AuNPs [103], conjugated to epoxysilanes [62] and as part of a layer-by-layer system with siRNA [104]. However, more polymers have been used for conjugation, e.g. poly-arginine [105], derivatives of polymaleic acid [70] and ethylmethacrylate [106]. 
Besides, Pierre et al. used a combined functionalization of MNPs with two kinds of polymers, being able to modulate the net charge more effectively [107]. Lately, a new kind of polymer named "chargereversal" has appeared, whose main property is the ability to change their charge as a function of $\mathrm{pH}$, being positive at neutral $\mathrm{pH}$ and negative in acidic conditions. One of the best examples is PAH-Cit, which is also effective in reducing the possible cytotoxicity induced by highly positive species [29,108,109].

Other possibility includes cationic dendrimers [110,111] like in the case of the dendriworms made from magnetic nanoparticles by Bhatia et al. and coated with Poly(amido amine) dendrimer (PAMAM) [79] (Figure 10) or lipidic species such as cholesterol [23], dioleoylphosphatidylethanolamine (DOPE) [45] or the commercially available transfection agent Metafectene® [98], or polyurea dendrimers (PURE-G4) [112].

Last but not least, many other molecules have been described that use other chains like aminoacids (lysine and arginine [68,113]), alkyl chains with either one or two amine groups (Cetyltrimethyl ammonium bromide (CTAB 60) [114], cysteamine [46,115], Hexamethylendiamine (HMDA) [116], 2-aminoethyltrimethylammonium chloride [28]) and protamine [117]. 
A

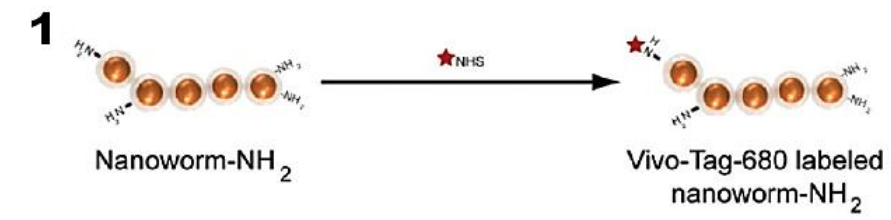

2

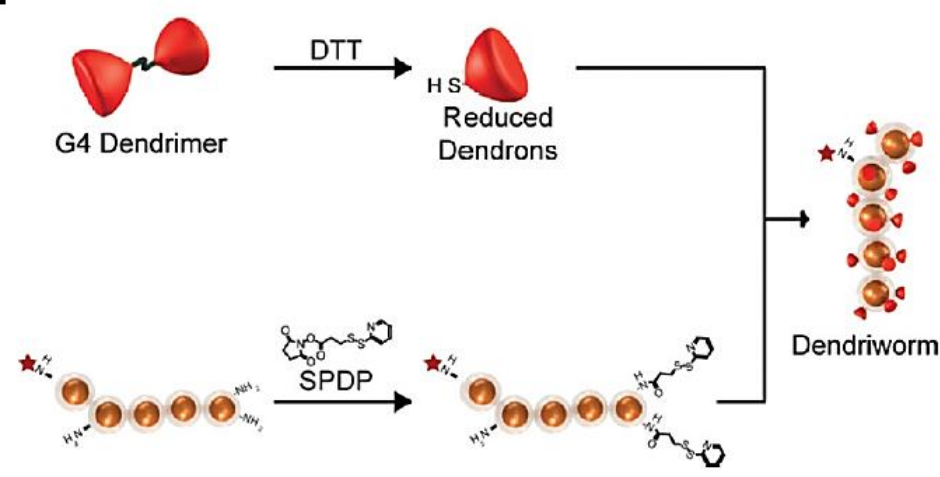

B
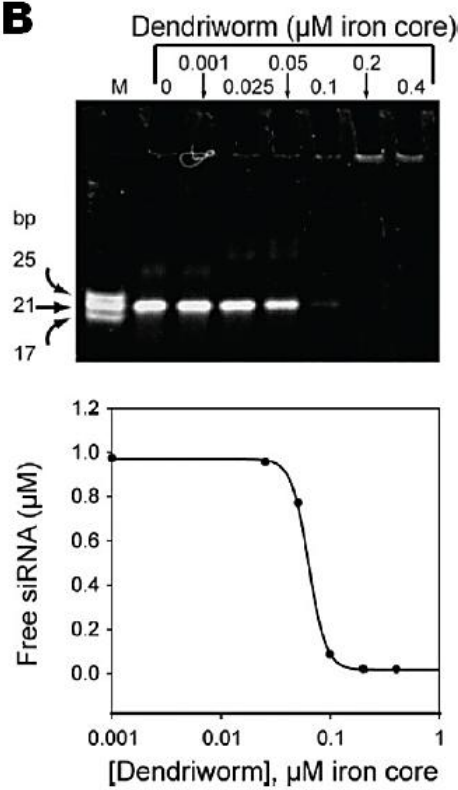
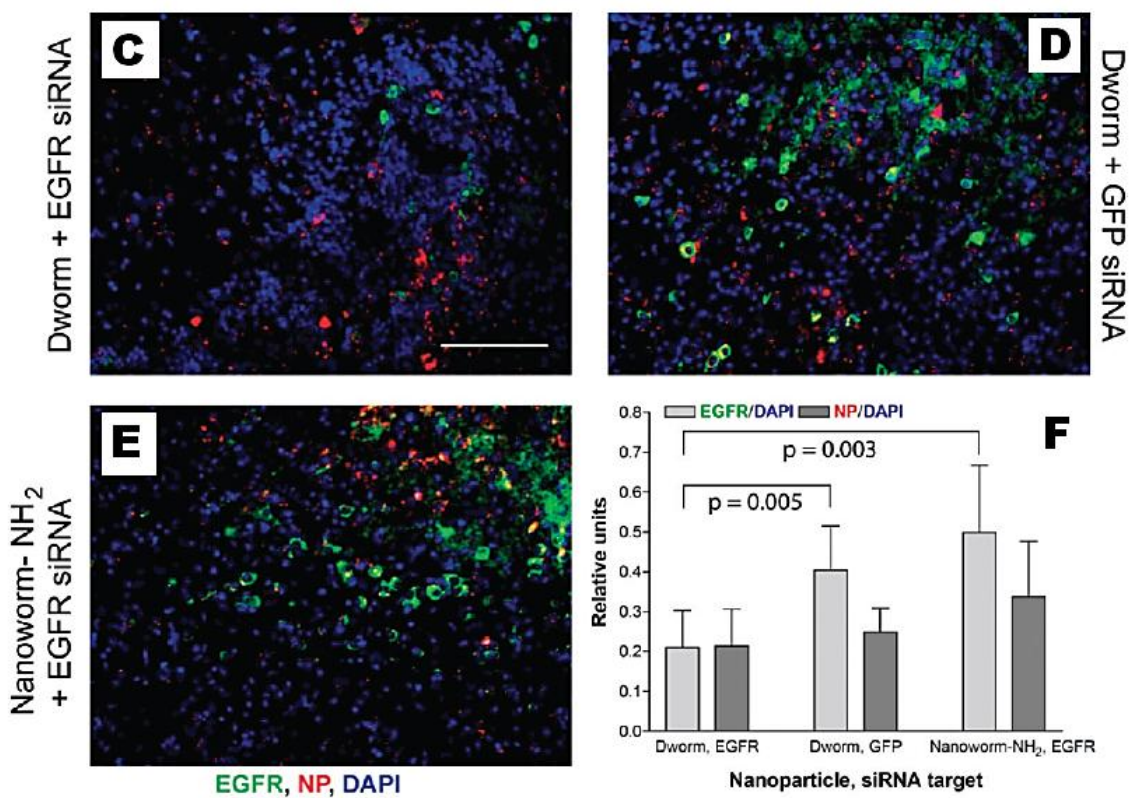

Figure 10. Functional delivery of siRNA in mice using dendriworms. Synthesis and characterization of dendriworms: (A) synthesis scheme; (B) siRNA binding characteristics. Dendriworm and siRNAs were allowed to bind in varying ratios and run on a gel. Strong binding between the dendriworm and siRNA at roughly 1:10 ratio (measured using iron core concentration) prevents siRNAs from entering the gel. In vivo knockdown of EGFR expression in transgenic mice: (C) EGFR siRNA delivered with dendriworms, (D) GFP siRNA delivered with dendriworms, (E) EGFR siRNA delivered with nanoworm- $\mathrm{NH}_{2}$, and (F) quantitative analysis of EGFR expression per cell or NP uptake relative to number of cells (DAPI). Scale bar, $100 \mu \mathrm{m}$. Reproduced with permission [79]. Copyright 2015, American Chemical Society.

\subsection{Covalent approach}

For the covalent approach there are many different options determined by the nature of the nanoparticles and the compounds used as stabilizers of the system. However, all these strategies have 
in common the use of thiolated siRNA, generally synthesized as disulphide and reduced with dithiothreitol (DTT) [21,118] or tris(2-carboxyethyl)phosphine (TCEP) [73] prior to the attachment. An important issue that should be taken into account is the nature of the bond in terms of labile or non-labile and the influence of the attachment of the antisense or the sense strands of the siRNA (see Figure 11) [119].

\section{A Probe Design}

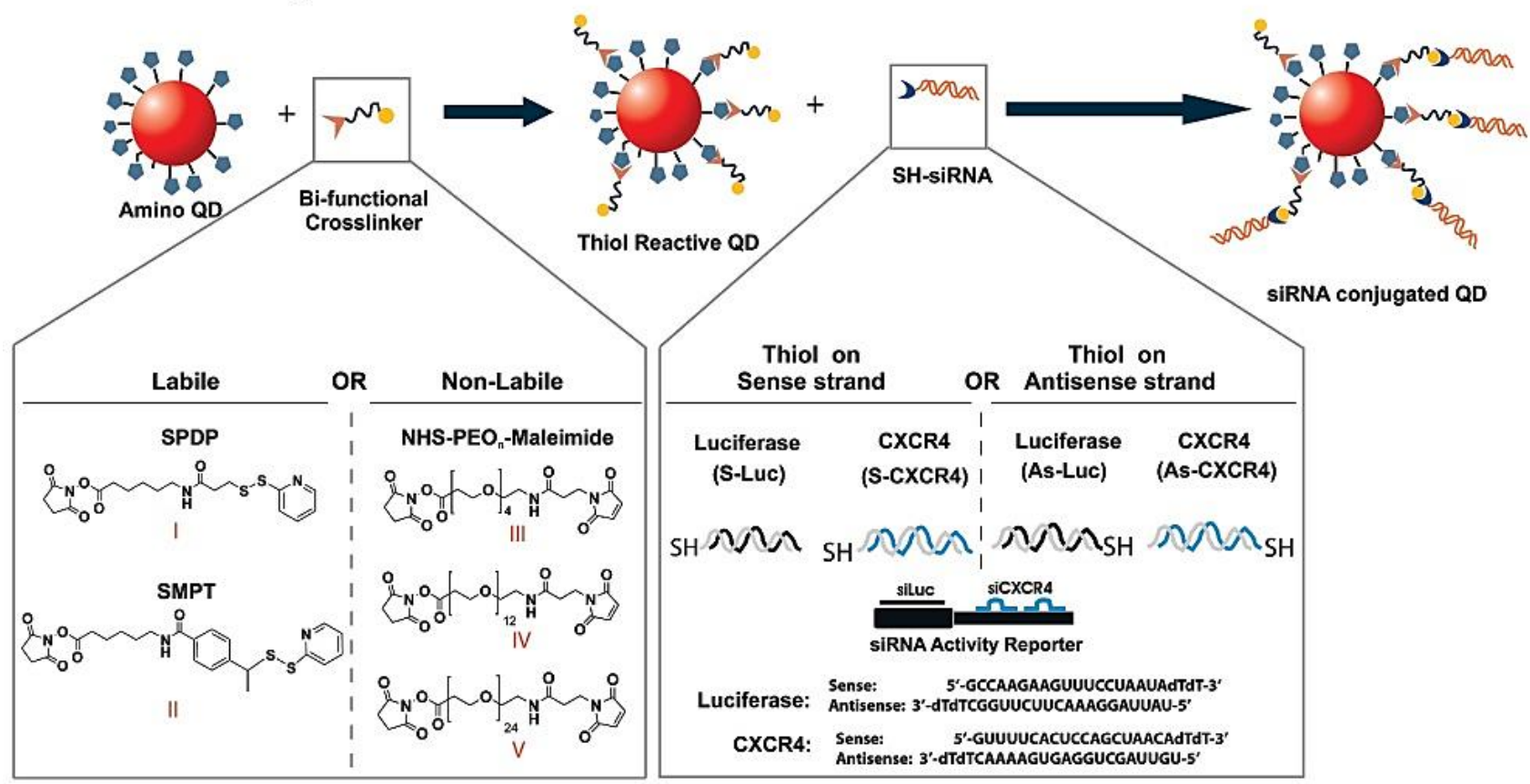

\section{B Probe Characterization}
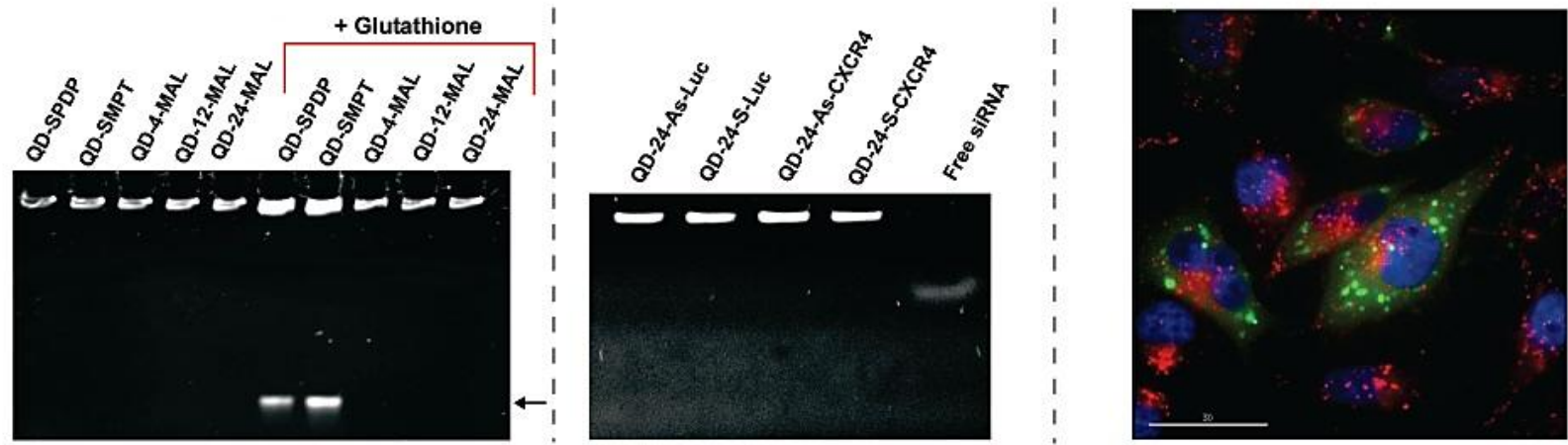

Figure 11. Probing the effect of conjugation strategy on gene silencing by QD-siRNA conjugates. (A) Scheme for probe synthesis. (B) Characterization of the probes. (Left) Gel electrophoresis of QD-siRNA conjugates. Conjugation with labile cross-linkers (SPDP and SMPT) releases the conjugated siRNA upon treatment with glutathione. Arrow indicates unbound siRNA. (Middle) Gel electrophoresis of QD-siRNA with nonlabile maleimide cross-linker indicating the absence of unbound siRNA. (Right) Intracellular delivery of QD-siRNA conjugates by electroporation in modified HeLa (GFP-Ago2/Luc-CXCR4) cells. QD-siRNA conjugates are in red, green is Ago2-GFP, and the nuclei are stained with DAPI (blue). Scale bar, $30 \mu \mathrm{m}$. Reproduced with permission [119]. Copyright 2015, American Chemical Society. 
The most direct strategy is the chemisorption of thiolated siRNA on AuNPs, due to the strong bond

formed between gold and sulphur atoms [120]. Taking advantage of this simple interaction and based on previous functionalization of AuNPs with DNA [121-125], there are plenty of examples describing the analogue conjugation of siRNA with systems of different sizes [126-128] and shapes [39,129].

In fact, we reported the design of two approaches (Figure 12) for the binding of siRNA molecules to multifunctional AuNPs. The binding of the negatively charged siRNA through ionic interactions to the modified gold surface (ionic approach) and the use of thiolated siRNA for the binding to the nanoparticle through the strong interaction gold-thiol (covalent approach) [28]. The two approaches had huge differences in terms of silencing efficacy in vitro, proving that the method for siRNA binding together with the targeting motifs plays a crucial role in the efficiency of gene silencing via RNAi-NPs (Figure 11).

A

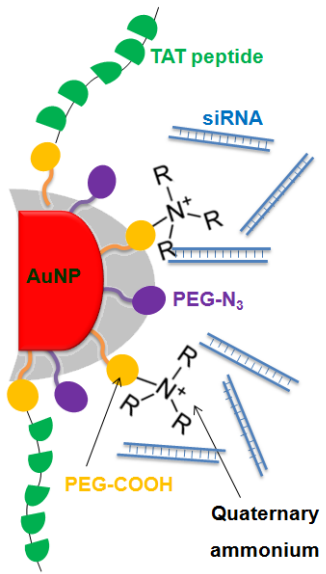

IONIC APPROACH

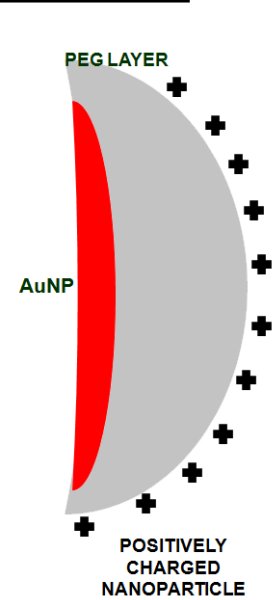

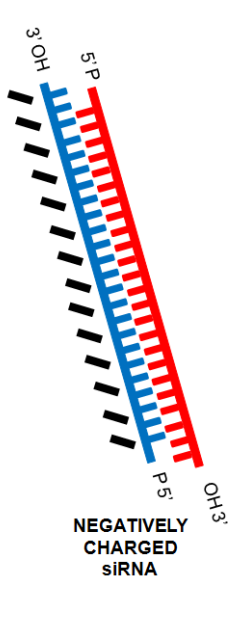
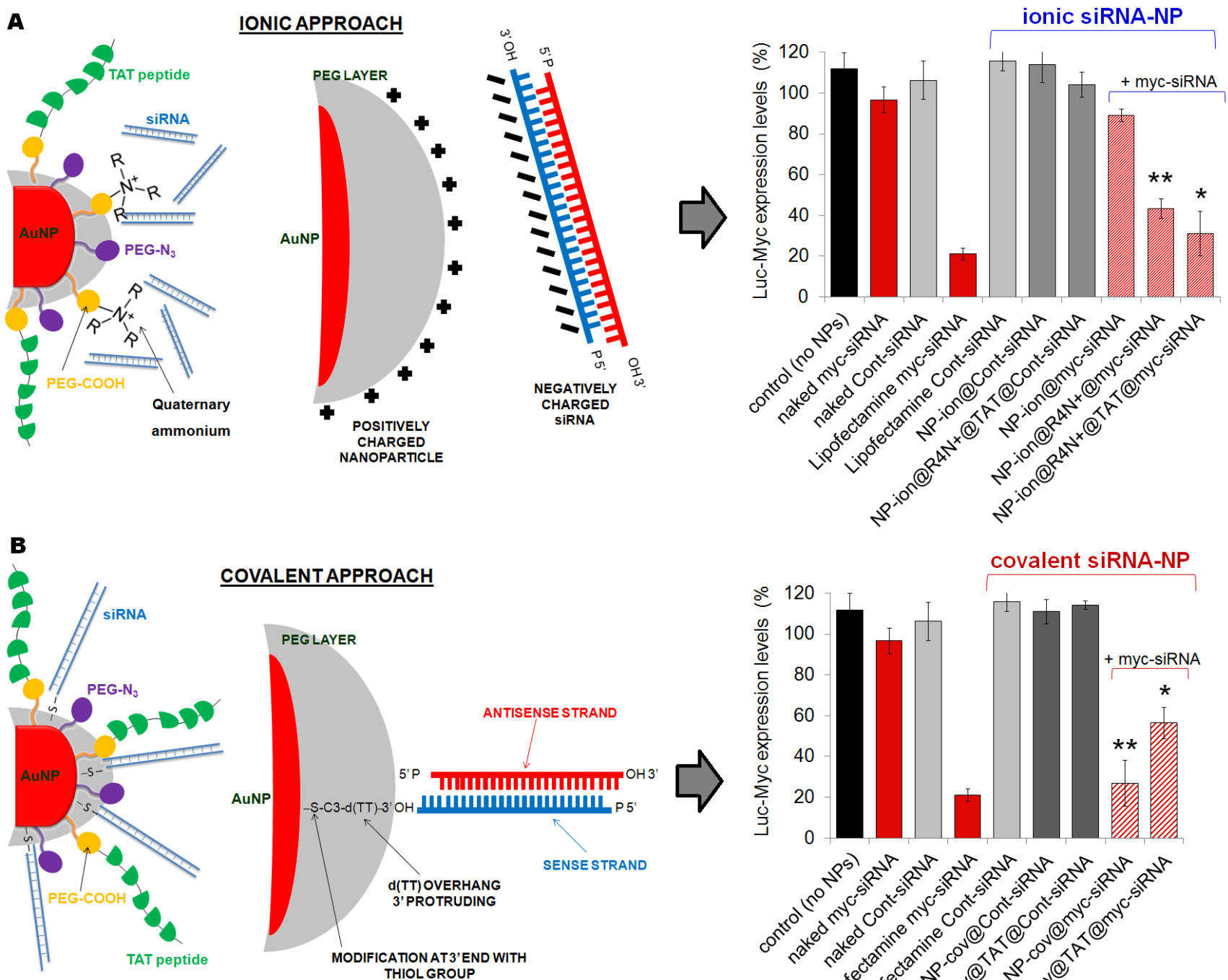

COVALENTAPPROACH
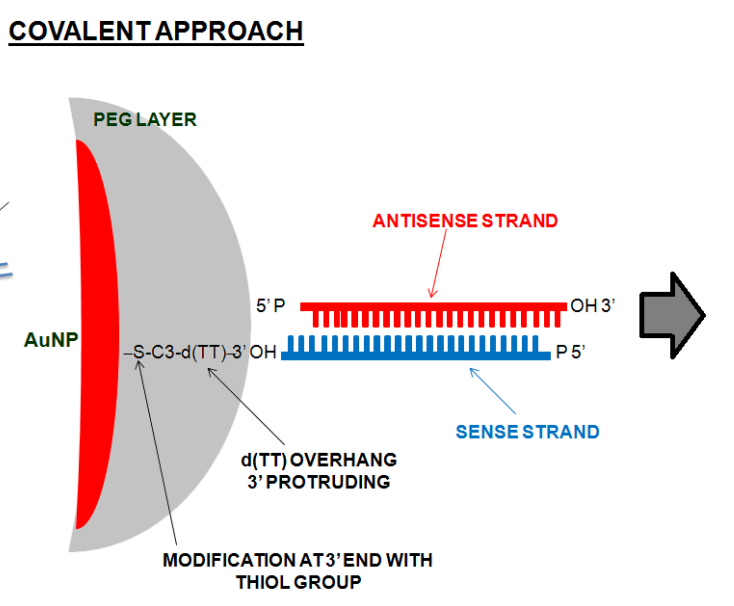

Figure 12. Gold nanoparticles functionalized with multiple biomolecules: PEG, cell penetration peptide (TAT), ammonium quaternary groups, and siRNA. Two different approaches were employed to conjugate the siRNA to the AuNPs: (A) ionic approach, interaction of the negatively charged siRNA to the modified surface of the AuNPs through ionic interactions; (B) covalent approach, use of thiolated siRNA for gold thiol binding to the 
NPs. The graphs show the quantitative assessment of RNAi efficiency. HeLa cells were transfected with the recombinant vector psiCHECK-2, encoding for the fusion protein Renilla luciferase-myc. Decrease of Renilla luciferase activity induced by c-myc-siRNA was expressed as percentage of normal luciferase activity. Unrelated siRNA (cont-siRNA) bound on the AuNPs; naked or lipofectamine delivered siRNA were included as negative and positive RNAi controls, respectively. Data marked with asterisks are statistically significant relative to the corresponding NP-ion/cov with control siRNA as calculated by paired Sample t test (**, P $\leq$ 0.0001; *, P $\leq 0.001)$. Reproduced and adapted with permission [16,28]. Copyright 2015, American Chemical Society and Frontiers.

In addition, the influence of different parameters such as the thiolation degree of the siRNA [130], the strand involved in the attachment [127], the need of increasing the amount of salt to improve the yield of the functionalization [24] and the possible release of the siRNA with DTT or the glutathione present in the cytosol [38], are also to be taken into account.

The remaining strategies for covalent attachment involve compounds with two reactive groups that serve as linkers. The most frequent linker is the Succinimidyl 3-(2-Pyridyldithio)Propionate (SPDP) and all of its derivatives (LC-SPDP and sulfo-LC-SPDP). This compound effectively reacts with amine groups on one end (N-hydroxisuccinimide group forming an amide bond) and thiols on the other (pyridil disulfide group that forms a new disulfide bond). Its use has been described with almost all types of inorganic nanoparticles such as AuNPs [25], MNPs [131], QDs [21,119] and carbon nanotubes $[17,132]$. It has also been reported in the use of products with the same reactive groups as SPDP (i.e. 4-succinimidyloxycarbonyl- $\alpha$-methyl- $\alpha$-[2-pyridyldithio]toluene (SMPT) [119]) or similar (i.e. 3-(2-pyridyl)-dithiopropionic acid pentafluorophenyl ester (PTPPf) [133]), in which different modifications have been introduced. These linkers are very interesting because the disulfide bond they establish with the siRNA is actually a labile bond that can be reduced in the cytosol with the levels of glutathione found inside cells $(\sim 10 \mathrm{mM})$, much higher than levels on the bloodstream, allowing the release at the desired place.

Another option consists of forming non-labile bonds with siRNA by using linkers like mMaleimidobenzoyl-N-hydroxysuccinimide ester (MBS) [18], N-gamma-Maleimidobutyryloxysuccinimide ester (GMBS) [33], Succinimidyl 4-(N-maleimidomethyl)cyclohexane-1-carboxylate (SMCC) [21] and their sulfonated derivatives, which have a terminal maleimide group that react with thiols to form a thioether bond [133]. It has also been studied the influence of nature and length of the chains between the succinimydil group and the maleimide [119]. Following with the formation of non-labile bonds, the linker SIA (Succinimidyl iodoacetate) that has a N-hydroxisuccinimidyl ester and a iodoacetyl group, is interesting once it introduces less atoms in the final structure than others $[56,73]$. 


\subsection{Encapsulation}

Encapsulation is the least common approach, as it can be used with only a few types of inorganic nanoparticles, such as calcium phosphate nanoparticles [44,114,134], which can encapsulate the siRNA when added in the synthesis step. Afterwards, these nanoparticles induce the endosomal escape by disruption of the endosome membrane and upon degradation release the siRNA directly in the cytosol (Figure 13) [134].
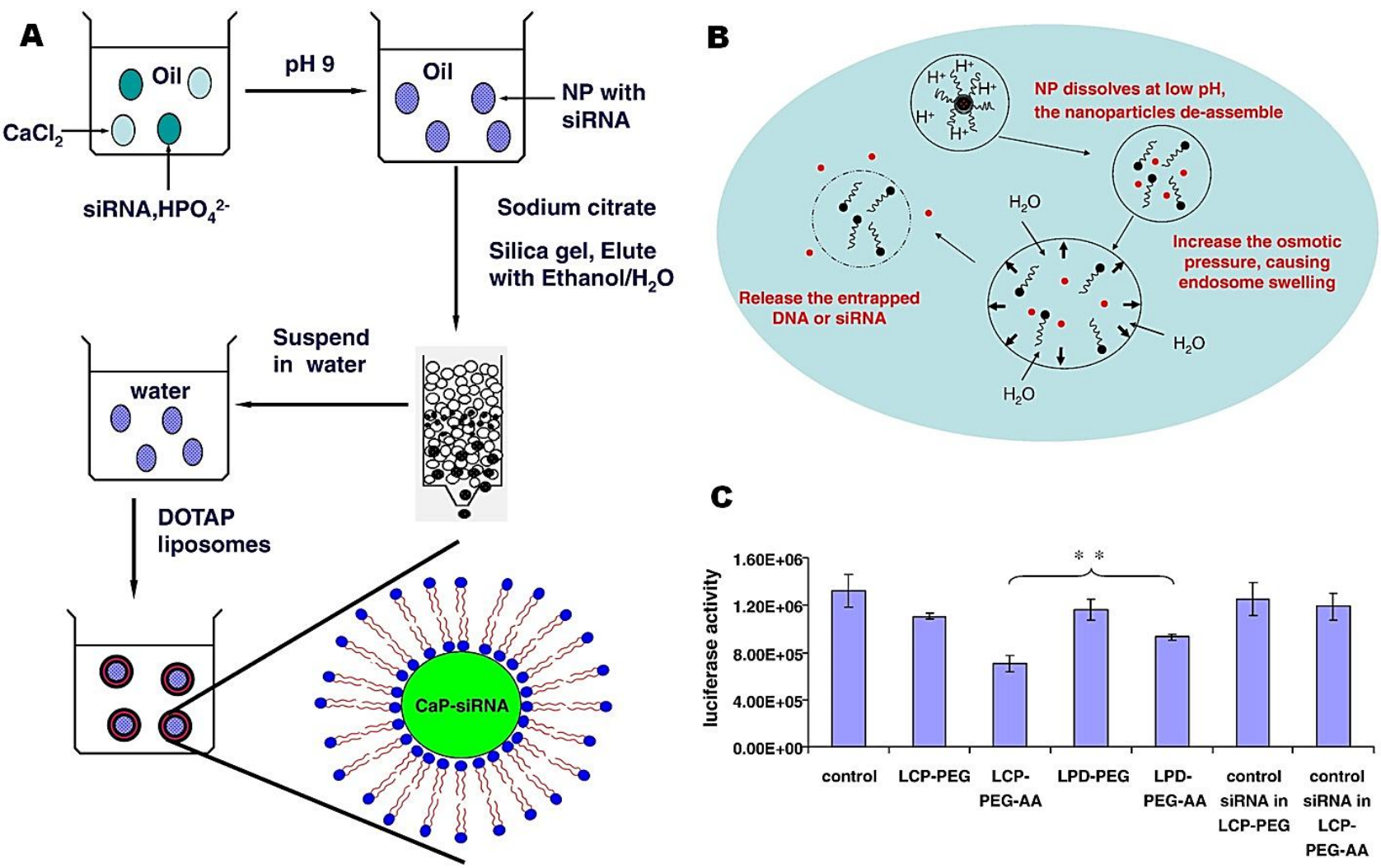

Figure 13. Biodegradable calcium phosphate nanoparticle with lipid coating for systemic siRNA delivery. (A) The formation process of liposome/calcium/phosphate (LCP) nanoparticles. (B) The hypothesized release process of siRNA entrapped in LCP after endocytosis to the endosome. There are four steps for siRNA released from LCP: 1) The LCP enters the cell through endocytosis and stays in the endosome; 2) The CaP core is dissolved at low $\mathrm{pH}$, causing NP de-assembly; 3) The dissolved calcium and phosphate ions increase the osmotic pressure and cause endosome swelling and 4) The endosome bursts and releases the siRNA, calcium and phosphate ions into the cytoplasm. (C) In vivo luciferase gene silencing effects of different formulations at the dose of $1.2 \mathrm{mg} / \mathrm{kg}$. The luciferase activity in H-460 cells was measured after $24 \mathrm{~h}$ of the I.V. injection with different siRNA formulations. Reproduced and adapted with permission [134]. Copyright 2015, Elsevier.

Other types of nanoparticles capable to encapsulate siRNA are mesoporous silica nanoparticles with large pores $[31,135,136]$ embedding the siRNA inside them under strong dehydrating conditions [63,137]. Carrying the siRNA encapsulated shows some advantages over ionic adsorption [65], including avoiding the use of large amounts of positively charged substances that can increase toxicity 
and the fact that more groups are available on the surface for the effective attachment of targeting molecules, thus improving the system's specificity.

Lastly, although not very frequent, there are also a few reports on the encapsulation of siRNA inside carbon nanotubes [138,139].

\section{Evaluation of silencing strategies in vitro}

The methods for evaluating the success and degree of silencing diverge greatly. A variety of techniques that determine multiple degrees of cellular complexity, such as the transcript level, the protein level and the physiological level, are important to fully understand how effective a strategy employed is at producing a silencing effect. Vogel et al. have shown that the abundance of detected transcripts can only partially predict protein levels, often by as little as $40 \%$. A further consideration for evaluation is that not all transcripts and proteins are created equally; many exhibit a wide range of stability and turnover properties (Figure 14) [140].

A

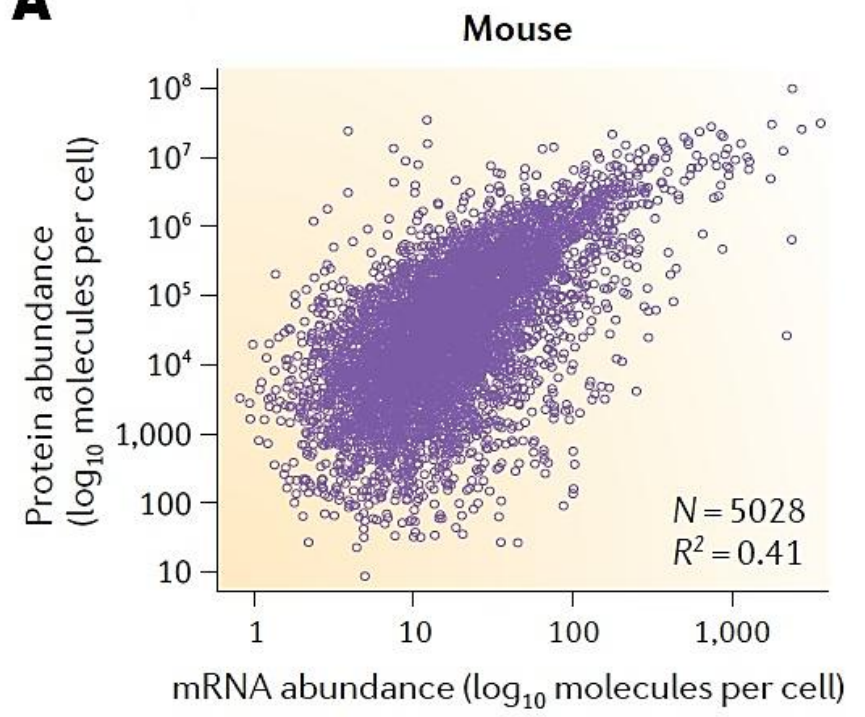

B

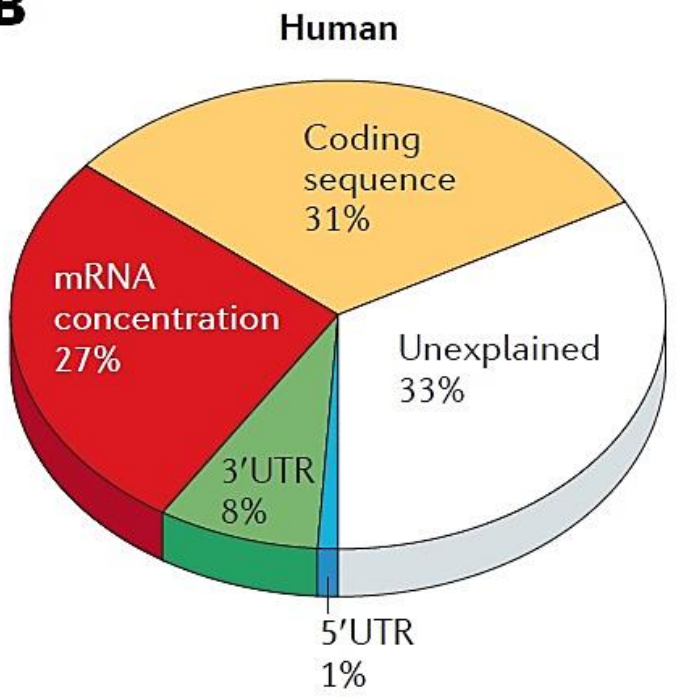

Figure 14. mRNA transcript abundance only partially correlates with protein abundance, typically explaining approximately one- to two-thirds of the variance in steady-state protein levels, depending on the organism. This trend is evident in data from NIH3T3 mouse fibroblast cells (A) and from a human DAOY medulloblastoma cell line (B), where $\sim 30-40 \%$ of the variance in protein abundance is explained by mRNA abundance. A similarly large fraction of variance can be explained by other factors, which is indicative of post-transcriptional and translational regulation and protein degradation. Reproduced with permission [140]. Copyright 2015, Nature Publishing Group.

In mammalian cells, approximately two molecules of transcript are produced per hour [141], in contrast to transcript translation, which can produce tens of copies of proteins per hour. This 
exemplifies the need, when studying silencing strategies, to determine effects not only at the transcript

\begin{abstract}
level, but also at the protein level.
\end{abstract}

\title{
4.1. The Transcript level
}

Typically, various modifications of Polymerase Chain Reaction (PCR) are employed when assessing the transcript level. The data supplied provide information on the increase or decrease of the target gene. A recent paper by Acharya et al. used AuNPs functionalised with a KDEL peptide and loaded with siRNA against the gene NOX4 in C2C12 cells [142]. The authors showed that the AuNPs were actively uptaken and subsequently reduced the levels of the NOX4 transcript levels by as much as 55\% in myoblasts after 24 hours. However, they did not investigate whether this level of knockdown was paralleled at the protein level, which is necessary to ensure that the siRNA is acting at different levels of the cells molecular machinery. In 2012, Han et al. used chitosan conjugated AuNPs and siRNA to knockdown the multidrug resistance $1(M D R l)$ gene encoding the drug exporter P-glycoprotein (P-gp) in HeLa and MCF-7 cells [109]. To assess the knockdown they used semiquantative RT-PCR, and found up to $80 \%$ knockdown. Although significant at the transcript level, the authors did not directly verify whether this high level of knockdown affects the MDR-1 protein expression. Instead, the authors indirectly used doxorubicin as a measure of protein knockdown, as the P-gp acts as a drug efflux pump. They found fluorescently labelled doxorubicin at more than double the amount within cells treated with the siRNA-AuNPs, in contrast to control; showing a correlation between the knockdown of the MDR-1 mRNA and the amount to which doxorubicin is uptaken (Figure 15). However, there does appear to be a weakening of the effect when moving from the transcript, to protein, to physiological level. 
A

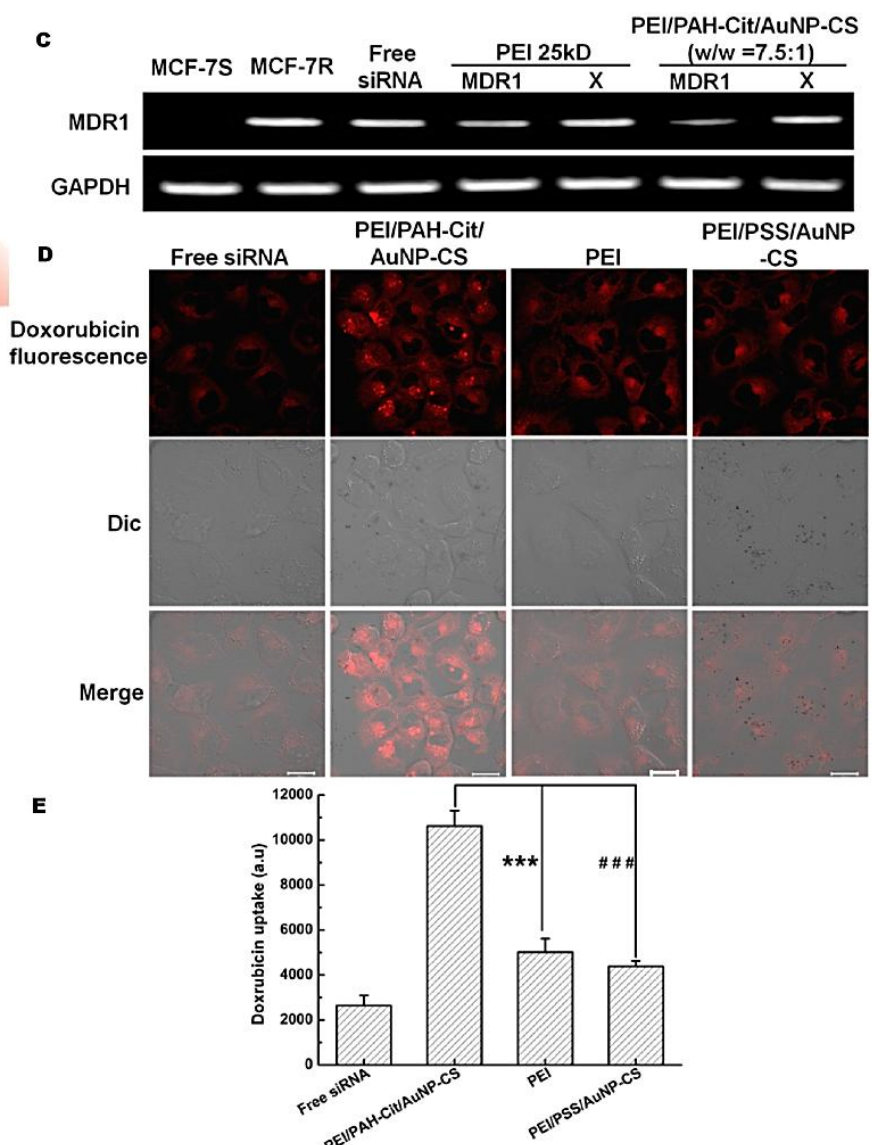

Figure 15. Enhanced siRNA delivery and silencing gold chitosan nanosystem with surface chargereversal polymer assembly. (A) Assembly steps for siRNA/PEI/PAH-Cit/AuNP-CS complexes and $\mathrm{pH}$ responsive release of siRNA. (B) TEM images of AuNP-CS, PAH-Cit/AuNPCS, and PEI/PAH-Cit/AuNP-CS. Insets: Higher magnification micrographs of the assembled nanoparticles. (C) MDR1 knockdown efficacy detected by semiquantitative RT-PCR. (D) CLSM images of MCF-7R cells incubated with naked MDR1 targeted siRNA, PEI/PAH-Cit/AuNP-CS, PEI, and PEI/PSS/AuNP-CS complexed with MDR1 targeted siRNA. MCF-7R cells were exposed to free siRNA or vector-complexed siRNA for $48 \mathrm{~h}$, incubated with doxorubicin (red) for $24 \mathrm{~h}$, and then subjected to CLSM imaging. Scale bar, $20 \mu \mathrm{m}$. (E) Quantitative analysis of intracellular doxorubicin uptake. Reproduced and adapted with permission [109]. Copyright 2015, American Chemical Society.

\subsection{The Protein level}

Many examples of silencing have used luciferase activity as an indicator of success [25,29,38,45,46]. Although very useful for assessing the concept of AuNPs for silencing, it is of limited scope for knockdown studies seeking to target native proteins. The same is true for studies that use GFP as a reporter gene. As GFP is not a native protein, it has limited used for further studies, which would ideally aim at altering native protein levels by using silencing machinery, such as siRNA, miRNA or small molecules $[24,25,38]$. When verifying protein knockdown, alternative techniques would need to be used such as western blots [143], flow cytometry [45] and In-Cell westerns [144]. A recent study by Zhao et al. reported the development of AuNPs loaded with siRNA against the epidermal growth factor receptor (EGFR) gene, and observed a knockdown efficiency of between 16-38\% in MCF-7 
cells via flow cytometry (Figure 16) [145]. The use of the flow cytometer allowed for the distinction between populations of cells, with a better assessment of the siRNA knockdown; in contrast to western blots, which use a pooled protein sample from a cellular population.

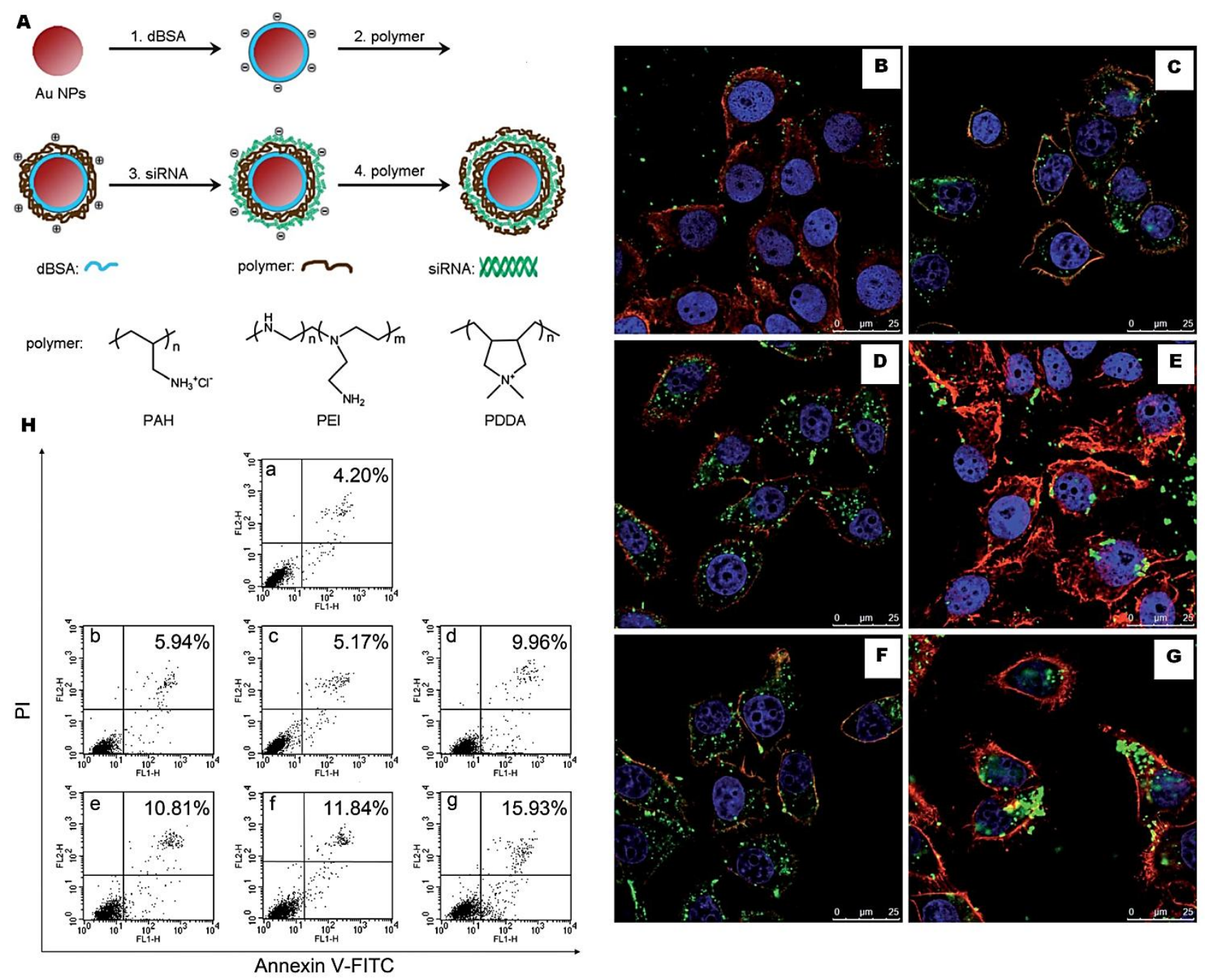

Figure 16. Surface engineering of gold nanoparticles for in vitro siRNA delivery. (A) Schematic illustration showing the preparation process of the AuNP-based siRNA vectors together with chemical structures of positively charged polyelectrolytes, i.e., PAH, PEI, and PDDA. Confocal fluorescence microscopy images of MCF-7 cells treated with AuNP-PAH-1 (B), AuNP-PAH-2 (C), AuNP-PAH-3 (D), AuNP-PAH-4 (E), FAMlabelled siRNA-Lipofectamine $2000(\mathbf{F})$, and FAM-labelled siRNA-PAH $(\mathbf{G})$, respectively. The cell nuclei were stained with Hoechst 33258 (blue), and the cell membrane was stained with Rhodamine phalloidin (red). The FAM-labelled siRNA appear in green. (H) Apoptosis rates of MCF-7 cells treated with no siRNA (a), and NC siRNA loaded by Lipofectamine 2000 (b), AuNP-PAH-3 (c), and PAH (d), respectively, together with those recorded from the cells treated with EGFR siRNA delivered by Lipofectamine (e), AuNP-PAH-3 (f), and PAH (g), respectively. Reproduced and adapted with permission [145]. Copyright 2015, Royal Society of Chemistry.

Western blots are still routinely used to evaluate the efficacy of silencing using siRNA. For example, siRNA conjugated AuNPs was used against the hepatoma-derived growth factor (HDGF) [146], showing considerable reduction of HDGF protein levels in contrast to a scrambled siRNA sequence. 
However, the authors used an additional [3H]-thymidine incorporation assay (a method to measure cell proliferation), treatment with the AuNPs loaded with the functional siRNA significantly arrested the cell cycle. The adoption of several techniques, such as western blots and cell functional assays, allows for parallel assessment of protein amount and protein function, thus elucidating both the efficiency and effect of the silencing on the cell.

With increasing levels of complexity the initial efficacy of silencing may be weakened by a numerous intracellular mechanisms, such transcript turnover, post-translational modification, protein half-life and many other intercellular interactions. To fully understand how the silencing target is affected, it is vital to assess the functionality at multiple levels, such the transcript, protein or whole cell level before testing in vivo.

\section{In vivo delivery of siRNA: promises and challenges}

RNAi, and more specifically siRNA, have emerged as powerful tools for sequence-specific posttranscriptional gene silencing. Nevertheless, the in vivo delivery of siRNAs to the specific target cell represents the most challenging bottleneck of RNAi translation into clinical therapeutics. While RNAi works well in the laboratory, it has proven to be somewhat problematic in vivo [147]. In fact, recent pre-clinical trials have tempered the excitement and triggered extensive efforts to overcome some of the major obstacles/limitations of siRNA technology, namely cytoplasmic and systemic delivery of siRNAs, renal clearance, target site accumulation after administration, heterogeneous vascular perfusion and diffusion, endosomal escape and siRNA recognition by RISC [148,149].

The success of RNAi therapy is highly dependent on the effective conjugation of siRNA to the nanoparticles, but also on several factors that affect RNAi efficiency, such as route of administration, circulation time and stability, tissue extravasation, targeting and cell internalization and endosomal escape, as delineated below.

Route of administration: Systemic delivery of therapeutic agents is the most convenient application route that can potentially reach any target site non-invasively. However, systemic administration of siRNA represents a huge challenge since unmodified siRNAs tend to accumulate in the kidneys (40fold more than in other organs), whereas siRNA containing nanoparticles often become entrapped in the liver [150]. Thus, siRNA therapeutics designed for these tissues can be delivered by local administration of siRNA, which encounters fewer cellular barriers. Nevertheless, numerous disease target sites, such as liver and spleen, require systemic administration of siRNAs into the circulatory system and circulation throughout the vasculature prior to specific tissue accumulation [151]. For 
specific applications that require targeted systemic delivery, nanocarriers may be functionalized with cell-specific ligands that allow receptor-mediated uptake into target cells, such as tumour cells. Also, depending on the target tissue, alternatives to injection into circulation may be considered. The local application of nanoparticles at or near the target sites might be the method of choice for the multitude of pathologies.

Recently, the in vivo targeting of lung tumours using siRNA/RGD-AuNPs in a lung cancer syngeneic orthotopic murine model resulted in successful targeting in the lung following direct intratracheal delivery (Figure 17) [27]. Intratracheal instillation is a non-invasive and highly efficacious route of administration with high clinical value, and was used to improve NPs distribution in the lungs, and avoid liver/spleen non-specific accumulation associated with the systemic administration. In this model, significant $c-M y c$ oncogene down-regulation followed by tumour growth inhibition and prolonged survival of lung tumour-bearing mice was attained, possibly via $\alpha v \beta 3$ integrin interaction. The authors suggest that RGD AuNPs-mediated delivery of siRNA by intratracheal instillation in mice leads to successful suppression of tumour cell proliferation and respective tumour size reduction, without any signal of inflammation [27]. 
A
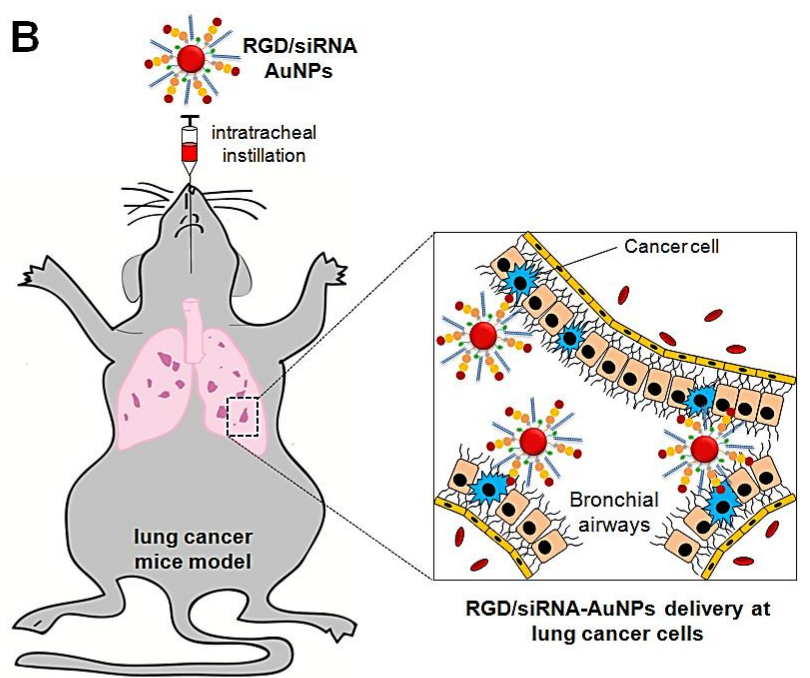

lung cancer cells
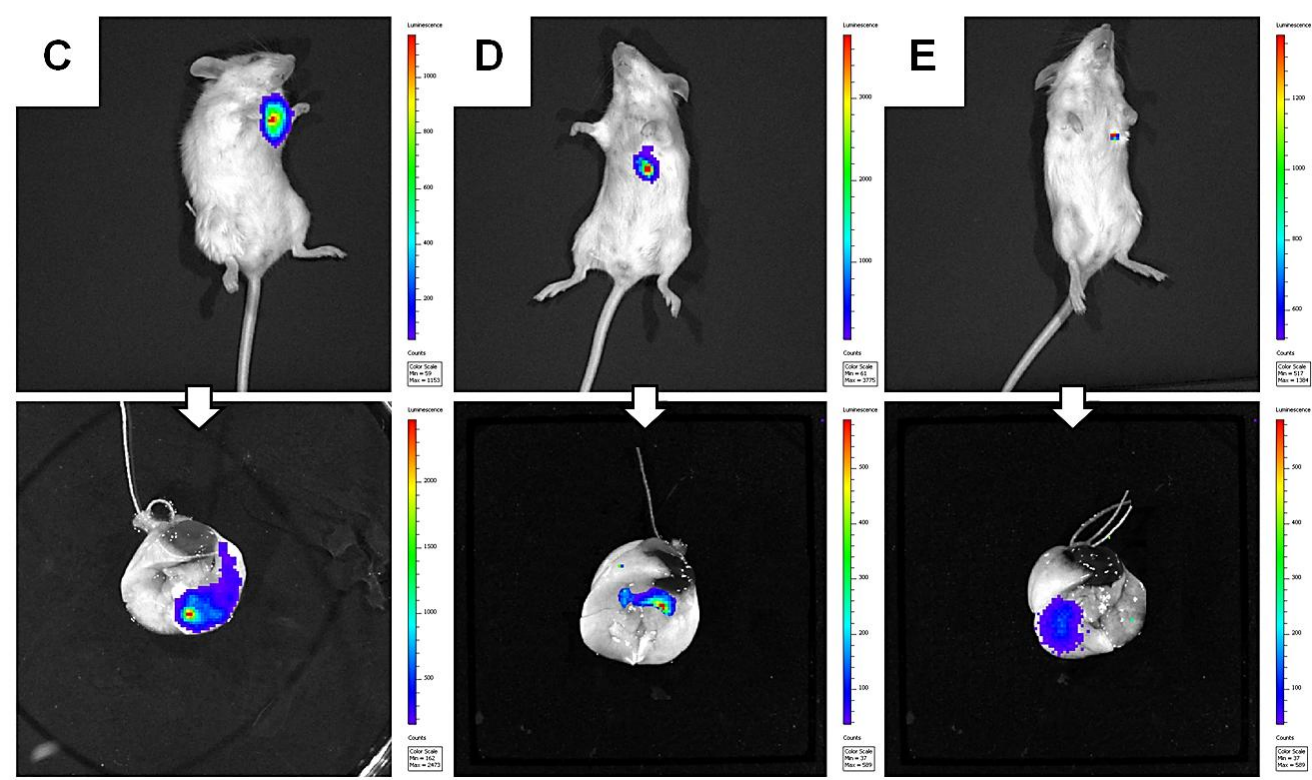

Figure 17. Inflammatory response and therapeutic siRNA silencing through RGD-nanoparticles in a lung cancer syngeneic orthotopic mouse model. (A) Engineered nanoparticles modified with RGD and siRNA can represent a delivery system of siRNA and a useful tool for sequence-specific gene silencing in a lung cancer mouse model. (B) AuNPs@PEG@RGD@siRNA are administered by intratracheal instillation and directly delivered to bronchial airways, where the can efficiently target tumour cells, by anchor through RGD receptors, such as $\alpha v \beta 3$ integrins, expressed in lung tumour cells. Bioluminescent imaging of B6 albino mice injected with luciferase-CMT/167 adenocarcinoma cells was performed to serially assed tumour size in each mouse, with luciferase activity as a measure for the tumour burden. Images show lung cancer mice and respective control lungs with no treatment (C), or with AuNPs@PEG@RGD (D) and AuNPs@PEG@RGD@siRNA (E) treatment. These bioluminescence images clearly depict a tumour regression (80-90\% decrease) in AuNPs@PEG@RGD@siRNA treated group. Reproduced and adapted with permission [27]. Copyright 2015, Elsevier.

In fact, local delivery can prevent most of the systemic toxicity while simultaneously enabling effective concentration and retention of the therapeutic agent. Continuous release of siRNA into the local cell/tissue microenvironment can be accomplished by formulating siRNA into biocompatible, biodegradable and immunologically inert matrices, like hydrogels [152-154]. These hydrogels can be further engineered to interact with specific tissues and to control the nanoparticles' release kinetics 
and stability. Intelligent hydrogel-based matrix designs would enable the programming of the nanoparticles' release kinetics to occur in response to extrinsic factors such as light, temperature or $\mathrm{pH}$. This can be combined with the ability to track the release using optical imaging, making these hydrogels ideal candidates for the local delivery of siRNAs [154-156].

Implantable or locally injectable NP-embedded hydrogels can be exploited to deliver siRNAs to target tissues. Nanoparticles can also be delivered subcutaneously by intradermal injection [157], epidermal electroporation [158] or via microneedles [159] but also as topical applications using hydrogel scaffolds or patches [154].

Circulation time and stability: Nanoparticles can be modified to protect and shield the siRNAs from endogenous clearance mechanisms. Compared to conventional transfection agents, nanoparticleconjugated siRNAs have been shown to be less susceptible to degradation by nuclease activity, to exhibit greater cellular uptake and to have a higher siRNA effective concentration, all of which have accelerated siRNA research into this delivery method over the past few years. Unfortunately, linking the siRNA to a nanoparticle alone does not protect it from clearance. Blood serum components interact with siRNA-nanoparticles and mark them for uptake via the mononuclear phagocyte system (MPS), especially by Kupffer cells in the liver [14,150]. The use of nanoparticles composed of hydrophilic polymers including acrylic acid, acrylamide, and maleic anhydride polymers and copolymers, as well as allylamine, ethyleneimine, oxazoline (for example, Polyethylene glycol, Polyethylenimine, Poly(acrylic acid), Poly(vinyl alcohol), Poly(N-isopropylacrylamide)) inhibits serum protein binding and clearance by immune cells which thereby drastically increases their circulation time $[14,160]$. This method is used to increase circulation time by reducing the nonspecific interaction of nanoparticles with serum proteins or unspecific immune cells or targeted tissue/organs $[14,160]$. In fact, the great majority of siRNA-NP conjugates require functionalization with PEG molecules to achieve equivalent stability to DNA-NPs, which may have something to do with the capacity loading of the different molecules due to singular hydrophobicity and/or hydrophilicity, molecular weight and charge density properties between RNA and DNA [161].

Renal clearance: Renal clearance is another challenge as naked siRNA, with average diameter of less than $10 \mathrm{~nm}$, is rapidly excreted from the blood compartment through renal clearance [148]. To avoid renal clearance, nanocarriers chemically modified to increase the retention time of the siRNAs in the circulatory system (e.g. cationic polymers) are frequently proposed [162,163]. The interaction of siRNA with serum components may affect their delivery, some serum proteins in the bloodstream can tag the delivery vehicles for uptake via the MPS. Actually, the stimulatory or anti-stimulatory action is 
typically due to binding of proteins in the blood, which influence the nanoparticles uptake by cells and

the interaction with other blood components [14]. This can be overcome by shielding the surface of the delivery vehicle with hydrophilic polymers including acrylic acid, and maleic anhydride polymers and copolymers, as wells as allylamine, ethyleneimine, oxazoline (for example, Polyethylene glycol, Polyethylenimine, Poly(acrylic acid), Poly(vinyl alcohol), Poly(N-isopropylacrylamide)).

Tissue/Tumour extravasation: In vivo delivery of siRNAs also shows some limitations concerning vascular extravasation and diffusion in target tissues, since it is required that the siRNA or nanocarrier extravasate from the blood stream into the extracellular matrix, and then diffuse to reach all cells[164]. For instance, several solid tumours have defective vasculature and poor lymphatic drainage, due to their rapid growth, resulting in an enhanced permeability and retention (EPR) effect, facilitating the delivery of therapeutics to this region $[165,166]$. This effect allows nanocarriers to accumulate specifically at the tumour site [167]. Tumour cells are supplied by blood capillaries that perfuse the cells of the tissue, and nanocarriers can passively accumulate or anchor through targeting moieties to biomarkers overexpress by tumour cells.

Nanoparticles' size is critical for efficient tissue or tumour delivery. Nanoparticles in the size range of 10-100 $\mathrm{nm}$ are generally accepted as efficient delivery agents, determined by in vivo clearance, biodistribution and toxicity. Particles of less than $10 \mathrm{~nm}$ are subject to renal clearance, while larger particles $>15 \mu \mathrm{m}$ are removed from the circulation by the reticulo-endothelial system (RES) in the liver and spleen [58,59]. The RES (also known as macrophage or mononuclear phagocyte systems), is a network of cells located throughout the body that support the elimination of small particles, also involved in the identification of foreign substances in blood and tissues [168]. Because of the effective elimination of NPs by the RES, the optimal delivery of NPs to target sites through intravascular delivery constitutes a challenge. Therefore, the size of nanoparticles and their payload should be large enough to prevent rapid leakage in blood capillaries but at the same time small enough to escape from the scavenge of macrophages in the RES, such as the liver and spleen or being cleared out by the kidneys. Appropriately sized nanoparticles can be chemically modified to increase their retention time in the circulatory system, using cationic polymers as described [162,163] or directly engineered to target phagocytic cells to increase uptake and antigen presentation [169].

Usually, nanocarriers with $\leq 400 \mathrm{~nm}$ in diameter can easily extravasate and accumulate in the leaky vasculature of solid tumours [148,170]. Taking advantage of the EPR effect several nanocarriers ( $100 \mathrm{~nm}$ diameter) for in vivo siRNA delivery have been produced, especially by steric stabilization of nanoparticles via PEGylation and also with active targeting ligands, such as antibodies, peptides, aptamers [24,30,171-174]. 
Targeting and cellular uptake: Once the siRNA is inside the target tissue it has to reach the target cells while excluding healthy cells. Nanoparticles can be functionalized with cell-specific ligands that allow receptor-mediated uptake into target cells, for example markers which are overexpressed on tumour or immune cells. Additionally, the surface charge on the nanoparticle is a crucial factor that affects cellular internalization and also determines potential in vivo circulation. Positively charged particles have been shown to exhibit increased internalization compared to neutral or negatively charged nanoparticles. In general, positively charged particles are more efficiently taken up because of electrostatic interactions between the positively charged particle surface and the negatively charged cellular membrane. Conversely, nanoparticles with negative surface charges typically exhibit low cellular internalization; however these nanoparticles can circulate longer in vivo and thus, better accumulate at tumour sites [175,176].

Endosomal escape: In order to activate the RNAi pathway, siRNAs must be successfully delivered into the cytoplasm, a process challenged by the large size and hydrophilicity of the nanoparticles, limiting their ability to cross the cell membrane in the absence of a transfection agent. Moreover, the cellular uptake of nanoparticles (endocytosis) as well as their subsequent discharge (exocytosis) is affected by their shape, size and charge. Generally, small $(<200 \mathrm{~nm})$ positively charged nanoparticles adsorb to the negatively charged plasma membrane, followed by clathrin-dependent endocytosis. In contrast, larger particles (>200 $\mathrm{nm}$ ) enter the cell by receptor- and clathrin-independent endocytosis [177]. The uptake pathway can greatly influence the interaction/effect of particles on cellular responses.

Therefore, from a cell's point of view, a critical step which also requires novel materials, is the endosomal release of siRNA after transfection across the cell membrane. Most of the described systems get trapped in the lysosomes compromising functionality and effectiveness of their siRNA cargo. Once the nanoparticle is taken up by the target cells via endocytosis, its release from the endosome into the cytoplasm is the next challenge. Many of the described systems/vehicles get trapped in the endosome, which fuses with lysosomes (i.e. endolysosome) thereby destroying the siRNAs. Therefore, the endosomal escape or siRNA accessibility to form the RNA-induced silencing complex (RISC) requires substantially more circulation time, as well as specific targeting via fusogenic peptides that promote endosomal escape [178] or lysosomotropic compounds/surfactants [179] that promote lysosomal release (see Figure 18). 


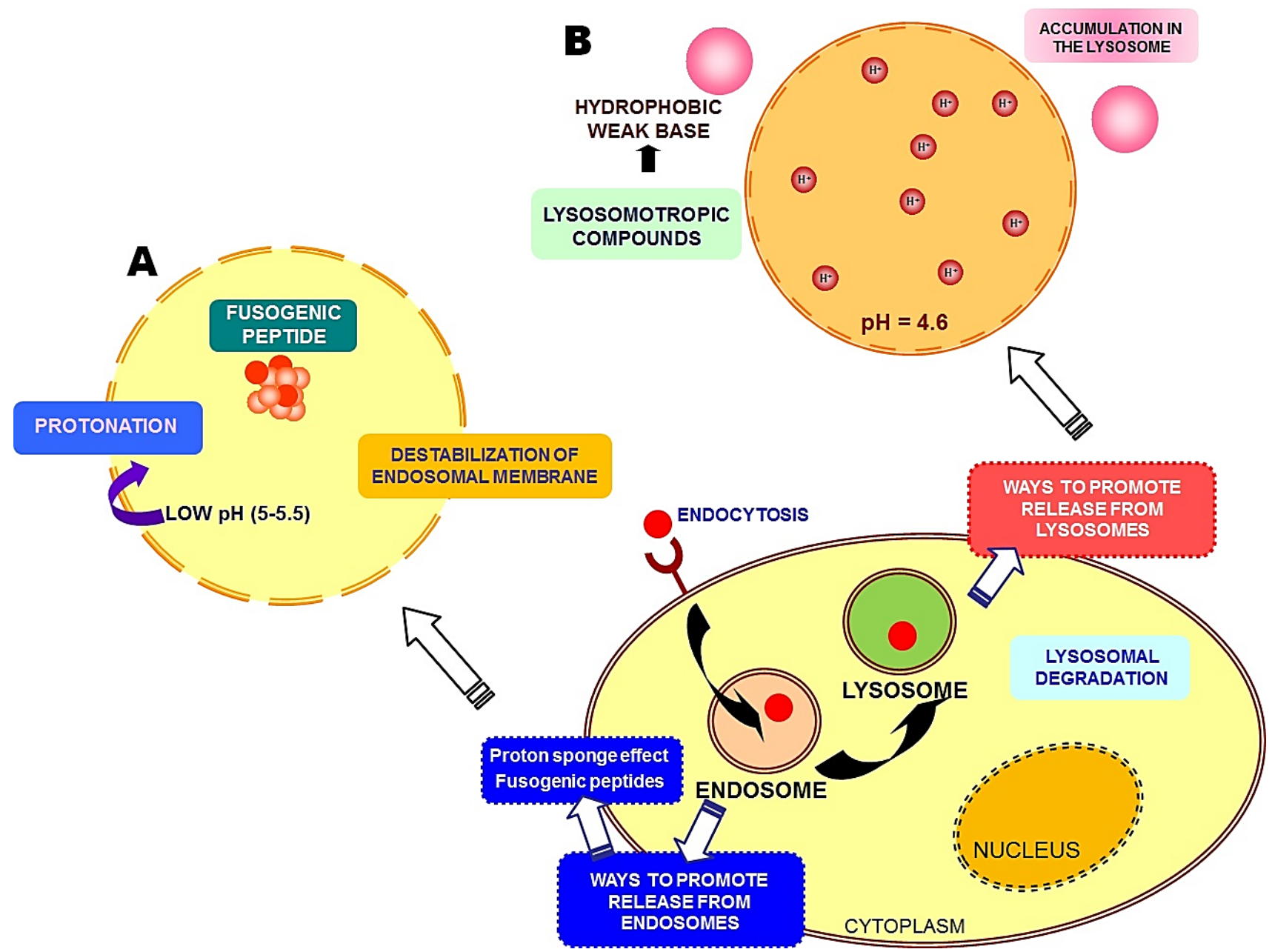

Figure 18. Fusogenic peptides (A) versus lysosomotropic compounds/surfactants (B) for endosomal escape and lysosomal release, respectively. These two types of compounds can greatly enhance the gene silencing of siRNA-containing nanoparticles.

\section{The fate of inorganic nanovectors for gene silencing}

Even the most successful siRNA vector might be useless if it induces undesirable toxicity on either a cellular or systemic level. In the case of nanomaterials engineered for gene silencing, it appears obvious that the introduction, the persistence and the transformation of inorganic nanoparticles into the cytoplasmic environment may represent a risk for cell homeostasis and viability. For such reasons, it would be warmly desirable that the nanomaterials employed might be metabolised to innocuous byproducts or harmlessly excreted from the cells in a reasonable period of time after having completed their function. Over the last decade maximising the silencing efficiency of siRNA-conjugated nanoparticles has been the major concern of researchers operating in this field, while limited attention has been dedicated to understand the fate of these nanovectors after siRNA delivery in vitro and in vivo. As consequence, our knowledge about the metabolism (transformation, degradation) of siRNA- 
conjugated NPs is still in its infancy and hence requests intensive investigation before reaching clinical trials.

As rule of thumb, after biomolecule delivery the fate of inorganic nanovectors is strictly related to the physico-chemical properties of nanostructures such as size, charge, chemical composition and coating. Besides the intrinsic properties of nanomaterials, internalization routes and intracellular localization also play a key role in determining nanovector fate and clearance. For instance, NPs often ultimate their intracellular journey in the lysosomes, and within these organelles their fate depend on the resistance to the unfavourable environment created by combined effects of acidic $\mathrm{pH}$, digestive enzymes and chelating agents.

It is generally accepted that gold NPs present high stability against oxidation, which makes them less prone to degradation in biological compartments [180]. Consequently, these nanoparticles are often secreted apparently intact from cells, preserving their chemico-physical properties. Bartczak et al. investigated the endothelial cell clearance of two types of peptide-coated gold nanoparticles of similar size and charge but different functional coatings [181]. The authors demonstrated that peptide capping influenced NP exocytosis profiles. These variations in exocytosis profiles strongly correlated with different nanoparticle uptake mechanisms and the fate of particles in the cells. In addition, the authors demonstrated that excreted Au NPs conserved their colloidal stability after exocytosis. Recently, Marchesano et al performed the first study of siRNA functionalized gold nanoparticles trafficking at whole animal level, using the aquatic invertebrate $H$. vulgaris [182]. In more details, the authors demonstrated that AuNPs could be internalised through a multitude of routes (membrane translocation, endocytosis and vesicle loading) independently from the siRNA cargo, while the efficiency of uptake was strictly dependent on the surface charge. A dynamic study performed entirely at ultrastructural level showed AuNP accumulation into lysosomes $24 \mathrm{~h}$ post incubation, and more interestingly revealed different exocytosis mechanisms, including membrane shedding, lysosomal release and for the first time nanovesicle mediated secretion, likely through exosomes. In contrast to gold nanoparticles, the degradation of other inorganic nanovectors is well documented. A striking multiscale approach, proposed by Levy et al., was employed to profile the intracellular processing and degradation of MNPs in mouse over three months. The authors reported that after injection MNPs presented a change of the magnetic behaviour and the loss of their superparamagnetic properties. At subcellular scale, they proved that large clusters of MNPs accumulated prevalently into lysosomes of tissue-resident macrophages (spleen, liver, adipose tissue) and gradually degraded over time, whereas iron was recycled into ferritin storage proteins [183]. Regarding colloidal mesoporous silica nanoparticles (MSNs), a first study on the biodegradation has been carried out in situ by using a simulated biological fluid (SBF). Long-term incubation in SBF produced a progressive degradation of 
silica nanostructrures. Interestingly, the authors reported that a PEG-shell can effectively slow down

the degradation of the mesopore system suggesting that these NPs are highly promising candidate for targeted and controlled drug release [184]. Subsequently, Zhai et al, demonstrated that the degradation of MSNs took place initially both in the cytoplasm and the lysosomes, and subsequently only in the lysosomes of human umbilical vein endothelial cells (HUVEC). Noteworthy, the silicon content in culture medium increased as function of NP degradation indicating that HUVEC excreted the degradation product from the intracellular environment [185].

While it is generally assumed that the fate of gold, iron oxide and silica nanoparticles does not pose a real threat, heavy metal (e.g. Cadmium, Cd; Indium, In) release from semiconductor nanocrystals may severely limit the use of QDs for biomolecule delivery. It is well documented, in fact, that capped and uncapped nanocrystals undergo degradation producing harmful effects in vitro and in vivo [186-189]. For instance, surface oxidation through a variety of pathways led to the formation of reduced $\mathrm{Cd}$ on the QD surface and release of free cytotoxic ions. Most of these reactions occur in endosomes, lysosomes and peroxisomes [184]. Therefore, despite the above-mentioned successful approaches of gene silencing based on QDs, long-term toxicity of these conjugates may be a problem and needs to be carefully evaluated in order to achieve a critical assessment of risk versus benefit of the use of QDs for RNAi.

\section{Conclusions and future perspectives: where we are for the next 15 years?}

Some of the nanomaterials and strategies described here will most likely revolutionize our understanding in how siRNA nanoparticles can interact and influence or be influenced by biological mechanisms. This will in turn push forward the clinical practice through their integration in future therapy platforms. However, further research into the fundamental mechanisms of in vivo gene therapy using these nanoconjugates could unveil new dimensions of nanoparticle-mediated gene silencing that will have thoughtful consequences for understanding gene regulation, and could also affect the development of functional genomic and therapeutic applications. In vivo transfection/administration will also require optimization for both passive and active targeting mechanisms.

Moreover, another important issue that remains unclear is how safe siRNA nanoparticles will be tracked following incubation/injection/implantation, and in particular how clearance and recycling of these materials occurs in long-lasting and sustained release platforms. Future in vivo work will need to cautiously consider the accurate option of chemical modifications to incorporate into the nanoparticles to avoid off-target effects. Some limitations for the correct design and application of nanoparticles, such as pharmacokinetics and pharmacodynamics, biodistribution, and side effects of the nanotherapy; 
safety profile of nanomaterials before and after conjugation and toxicity, needs to be clarified to validate efficient clinical appliance. This is especially important for the establishment of a regulatory approval of these siRNA nanoconjugates. It is, therefore, imperative to learn how advances in nanosystem's capabilities are being used to identify new diagnostic and therapy tools driving the development of personalized medicine in different disease states and pathologies and recognize how to translate nanotherapy data into an actionable clinical strategy and discuss it with industry leaders. Last but definitely not least, personalized materials for the delivery of siRNA nanoparticles are needed. The archetype for diseases' treatment has to change from relatively nonspecific nanodelivery agents to tuned, selective, cellular/molecular and mechanism-based devices. No studies reported so far use tuned materials to respond either to cellular microenvironment in specific pathologies, different stages of disease or tune materials to different dosages in order not to overload cells with siRNAs. In fact, most of the current approaches lack control over some critical features such as stimuli responsiveness and biodegradation for siRNA release in light of the microenvironment conditions nor the disease type and stages. We believe this will definitely represent the next 15 years on siRNA delivery using nanotechnology.

\section{Acknowledgments}

This work has been funded by ERANET-NANOSCIERA NANOTRUCK project. JC acknowledges Marie Curie International Outgoing Fellowship (FP7-PEOPLE-2013-IOF, Project no. 626386). JMF acknowledges SAF2014-54763-C2-2-R project (Spanish Government), European Regional and Social Development Funds, Aragón Autonomous Government (DGA) through Research Groups and ERCStarting Grant 239931-NANOPUZZLE.

\section{References}

[1] Fire, A., Xu, S., Montgomery, M. K., Kostas, S. A., Driver, S. E., and Mello, C. C., Nature 391 (1998) 806-811.

[2] Elbashir, S. M., Harborth, J., Lendeckel, W., Yalcin, A., Weber, K., and Tuschl, T., Nature 411 (2001) $494-498$.

[3] Ghildiyal, M. and Zamore, P. D., Nature Reviews Genetics 10 (2009) 94-108.

[4] Luteijn, M. J. and Ketting, R. F., Nature Reviews Genetics 14 (2013) 523-534.

[5] Bartel, D. P., Cell 116 (2004) 281-297.

[6] Tomari, Y. and Zamore, P. D., Genes \& Development 19 (2005) 517-529.

[7] Meister, G. and Tuschl, T., Nature 431 (2004) 343-349.

[8] Baker, M., Nature 464 (2010) 1225. 
[9] Tabernero, J., Shapiro, G. I., LoRusso, P. M., Cervantes, A., Schwartz, G. K., Weiss, G. J., Paz-Ares, L., Cho, D. C., Infante, J. R., Alsina, M., Gounder, M. M., Falzone, R., Harrop, J., White, A. C. S., Toudjarska, I., Bumcrot, D., Meyers, R. E., Hinkle, G., Svrzikapa, N., Hutabarat, R. M., Clausen, V. A., Cehelsky, J., Nochur, S. V., Gamba-Vitalo, C., Vaishnaw, A. K., Sah, D. W. Y., Gollob, J. A., and Burris, H. A., Cancer Discovery 3 (2013) 406-417.

[10] Chen, S., Ge, X. M., Chen, Y. H., Lv, N., Liu, Z. G., and Yuan, W., Drug Design Development and Therapy 7 (2013) 117-125.

[11] Lares, M. R., Rossi, J. J., and Ouellet, D. L., Trends in Biotechnology 28 (2010) 570-579.

[12] Kim, D. H. and Rossi, J. J., Nature Reviews Genetics 8 (2007) 173-184.

[13] Davidson, B. L. and Mccray, P. B., Nature Reviews Genetics 12 (2011) 329-340.

[14] Kanasty, R., Dorkin, J. R., Vegas, A., and Anderson, D., Nature Materials 12 (2013) 967-977.

[15] Conde, J., Edelman, E. R., and Artzi, N., Adv.Drug Deliv.Rev. (2014).

[16] Conde, J., Dias, J. T., Grazu, V., Moros, M., Baptista, P. V., and de la Fuente, J. M., Front Chem. 2 (2014) 48.

[17] Liu, Z., Winters, M., Holodniy, M., and Dai, H. J., Angewandte Chemie-International Edition 46 (2007) 20232027.

[18] Medarova, Z., Pham, W., Farrar, C., Petkova, V., and Moore, A., Nature Medicine 13 (2007) 372-377.

[19] Malvindi, M. A., Brunetti, V., Vecchio, G., Galeone, A., Cingolani, R., and Pompa, P. P., Nanoscale 4 (2012) 486-495.

[20] Li, J., Yang, Y., and Huang, L., Journal of Controlled Release 158 (2012) 108-114.

[21] Derfus, A. M., Chen, A. A., Min, D. H., Ruoslahti, E., and Bhatia, S. N., Bioconjugate Chemistry 18 (2007) 1391-1396.

[22] Bigall, N. C., Curcio, A., Leal, M. P., Falqui, A., Palumberi, D., Di Corato, R., Albanesi, E., Cingolani, R., and Pellegrino, T., Advanced Materials 23 (2011) 5645-+.

[23] Jiang, S., Eltoukhy, A. A., Love, K. T., Langer, R., and Anderson, D. G., Nano Letters 13 (2013) 1059-1064.

[24] Giljohann, D. A., Seferos, D. S., Prigodich, A. E., Patel, P. C., and Mirkin, C. A., J.Am.Chem.Soc. 131 (2009) 2072-2073.

[25] Lee, J. S., Green, J. J., Love, K. T., Sunshine, J., Langer, R., and Anderson, D. G., Nano.Lett. 9 (2009) $2402-$ 2406.

[26] Conde, J., Tian, F., Hernandez, Y., Bao, C., Baptista, P. V., Cui, D., Stoeger, T., and de la Fuente, J. M., Nanoscale (2015)

[27] Conde, J., Tian, F., Hernandez, Y., Bao, C., Cui, D., Janssen, K. P., Ibarra, M. R., Baptista, P. V., Stoeger, T., and de la Fuente, J. M., Biomaterials 34 (2013) 7744-7753.

[28] Conde, J., Ambrosone, A., Sanz, V., Hernandez, Y., Marchesano, V., Tian, F., Child, H., Berry, C. C., Ibarra, M. R., Baptista, P. V., Tortiglione, C., and de la Fuente, J. M., ACS Nano. (2012).

[29] Guo, S., Huang, Y., Jiang, Q., Sun, Y., Deng, L., Liang, Z., Du, Q., Xing, J., Zhao, Y., Wang, P. C., Dong, A., and Liang, X. J., ACS Nano. 4 (2010) 5505-5511.

[30] Davis, M. E., Zuckerman, J. E., Choi, C. H., Seligson, D., Tolcher, A., Alabi, C. A., Yen, Y., Heidel, J. D., and Ribas, A., Nature 464 (2010) 1067-1070. 
[31] Na, H. K., Kim, M. H., Park, K., Ryoo, S. R., Lee, K. E., Jeon, H., Ryoo, R., Hyeon, C., and Min, D. H., Small 8 (2012) 1752-1761.

[32] Meng, H., Mai, W. X., Zhang, H. Y., Xue, M., Xia, T., Lin, S. J., Wang, X., Zhao, Y., Ji, Z. X., Zink, J. I., and Nel, A. E., ACS Nano 7 (2013) 994-1005.

[33] Chang, Y. T., Liao, P. Y., Sheu, H. S., Tseng, Y. J., Cheng, F. Y., and Yeh, C. S., Advanced Materials 24 (2012) 3309-3314.

[34] Li, S. L., Liu, Z. H., Ji, F. T., Xiao, Z. J., Wang, M. J., Peng, Y. J., Zhang, Y. L., Liu, L., Liang, Z. B., and Li, F., Molecular Therapy-Nucleic Acids 1 (2012).

[35] J. Conde, F. Tian, P.V. Baptista, and J.M. de la Fuente, Multifunctional Gold Nanocarriers for Cancer Theranostics - From bench to bedside and back again?, in: Nano-Oncologicals: New Targeting And Delivery Approaches. Springer International Publishing AG., 2014.

[36] Kesharwani, P., Gajbhiye, V., and Jain, N. K., Biomaterials 33 (2012) 7138-7150.

[37] Daka, A. and Peer, D., Advanced Drug Delivery Reviews 64 (2012) 1508-1521.

[38] Oishi, M., Nakaogami, J., Ishii, T., and Nagasaki, Y., Chemistry Letters 35 (2006) 1046-1047.

[39] Braun, G. B., Pallaoro, A., Wu, G., Missirlis, D., Zasadzinski, J. A., Tirrell, M., and Reich, N. O., ACS Nano. (2009).

[40] Conde, J., Rosa, J., and Baptista, P. V., Protocol Exchange - Nature Publishing group doi:10.1038/protex.2013.088 (2013).

[41] Conde, J., Larguinho, M., Cordeiro, A., Raposo, L. R., Costa, P. M., Santos, S., Diniz, M. S., Fernandes, A. R., and Baptista, P. V., Nanotoxicology. 8 (2014) 521-532.

[42] Rosa, J., Conde, J., de la Fuente, J. M., Lima, J. C., and Baptista, P. V., Biosens.Bioelectron. 36 (2012) $161-167$.

[43] Conde, J., Rosa, J., de la Fuente, J. M., and Baptista, P. V., Biomaterials 34 (2013) 2516-2523.

[44] Li, P. C., Li, D., Zhang, L. X., Li, G. P., and Wang, E. K., Biomaterials 29 (2008) 3617-3624.

[45] Kong, W. H., Bae, K. H., Jo, S. D., Kim, J. S., and Park, T. G., Pharmaceutical Research 29 (2012) $362-374$.

[46] Lee, S. H., Bae, K. H., Kim, S. H., Lee, K. R., and Park, T. G., Int.J.Pharm. 364 (2008) 94-101.

[47] Whitehead, K. A., Dahlman, J. E., Langer, R. S., and Anderson, D. G., Annual Review of Chemical and Biomolecular Engineering 2 (2011) 77-96.

[48] Massich, M. D., Giljohann, D. A., Seferos, D. S., Ludlow, L. E., Horvath, C. M., and Mirkin, C. A., Molecular Pharmaceutics 6 (2009) 1934-1940.

[49] Lu, A. H., Salabas, E. L., and Schuth, F., Angewandte Chemie-International Edition 46 (2007) 1222-1244.

[50] Namiki, Y., Namiki, T., Yoshida, H., Ishii, Y., Tsubota, A., Koido, S., Nariai, K., Mitsunaga, M., Yanagisawa, S., Kashiwagi, H., Mabashi, Y., Yumoto, Y., Hoshina, S., Fujise, K., and Tada, N., Nature Nanotechnology 4 (2009) 598-606.

[51] Scherer, F., Anton, M., Schillinger, U., Henkel, J., Bergemann, C., Kruger, A., Gansbacher, B., and Plank, C., Gene Therapy 9 (2002) 102-109.

[52] David, S., Marchais, H., Herve-Aubert, K., Bedin, D., Garin, A. S., Hoinard, C., and Chourpa, I., International Journal of Pharmaceutics 454 (2013) 660-667.

[53] Lopez, X. Y., Castillo, B., Badillo, V., and Barletta, G., Abstracts of Papers of the American Chemical Society 243 (2012). 
[54] Lim, J., Clements, M. A., and Dobson, J., Plos One 7 (2012).

[55] Cho, Y. S., Yoon, T. J., Jang, E. S., Hong, K. S., Lee, S. Y., Kim, O. R., Park, C., Kim, Y. J., Yi, G. C., and Chang, K., Cancer Letters 299 (2010) 63-71.

[56] Veiseh, O., Kievit, F. M., Fang, C., Mu, N., Jana, S., Leung, M. C., Mok, H., Ellenbogen, R. G., Park, J. O., and Zhang, M. Q., Biomaterials 31 (2010) 8032-8042.

[57] Lee, J. H., Lee, K., Moon, S. H., Lee, Y., Park, T. G., and Cheon, J., Angewandte Chemie-International Edition 48 (2009) 4174-4179.

[58] Peng, X. H., Qian, X. M., Mao, H., Wang, A. Y., Chen, Z., Nie, S. M., and Shin, D. M., International Journal of Nanomedicine 3 (2008) 311-321.

[59] Kumar, M., Yigit, M., Dai, G. P., Moore, A., and Medarova, Z., Cancer Research 70 (2010) 7553-7561.

[60] Tang, F. Q., Li, L. L., and Chen, D., Advanced Materials 24 (2012) 1504-1534.

[61] Xia, T. A., Kovochich, M., Liong, M., Meng, H., Kabehie, S., George, S., Zink, J. I., and Nel, A. E., ACS Nano 3 (2009) 3273-3286.

[62] Hartono, S. B., Gu, W. Y., Kleitz, F., Liu, J., He, L. Z., Middelberg, A. P. J., Yu, C. Z., Lu, G. Q., and Qiao, S. Z., ACS Nano 6 (2012) 2104-2117.

[63] Li, X., Xie, Q. R., Zhang, J. X., Xia, W. L., and Gu, H. C., Biomaterials 32 (2011) 9546-9556.

[64] Hom, C., Lu, J., Liong, M., Luo, H. Z., Li, Z. X., Zink, J. I., and Tamanoi, F., Small 6 (2010) 1185-1190.

[65] Li, X., Chen, Y. J., Wang, M. Q., Ma, Y. J., Xia, W. L., and Gu, H. C., Biomaterials 34 (2013) 1391-1401.

[66] Tan, W. B., Jiang, S., and Zhang, Y., Biomaterials 28 (2007) 1565-1571.

[67] Conde, J., Rosa, J., Lima, J. C., and Baptista, P. V., International Journal of Photoenergy 2012 (2012) 1-11.

[68] Li, J. M., Zhao, M. X., Su, H., Wang, Y. Y., Tan, C. P., Ji, L. N., and Mao, Z. W., Biomaterials 32 (2011) 7978 7987.

[69] Zhao, Y., Zhao, L. J., Zhou, L. J., Zhi, Y., Xu, J. M., Wei, Z., Zhang, K. X., Ouellette, B. F. F., and Shen, H. B., Journal of Nanoscience and Nanotechnology 10 (2010) 5137-5143.

[70] Yezhelyev, M. V., Qi, L. F., O'Regan, R. M., Nie, S., and Gao, X. H., Journal of the American Chemical Society 130 (2008) 9006-9012.

[71] Su, Y. Y., He, Y., Lu, H. T., Sai, L. M., Li, Q. N., Li, W. X., Wang, L. H., Shen, P. P., Huang, Q., and Fan, C. H., Biomaterials 30 (2009) 19-25.

[72] Subramaniam, P., Lee, S. J., Shah, S., Patel, S., Starovoytov, V., and Lee, K. B., Advanced Materials 24 (2012) 4014-4019.

[73] Veiseh, O., Kievit, F. M., Mok, H., Ayesh, J., Clark, C., Fang, C., Leung, M., Arami, H., Park, J. O., and Zhang, M. Q., Biomaterials 32 (2011) 5717-5725.

[74] Elbakry, A., Zaky, A., Liebl, R., Rachel, R., Goepferich, A., and Breunig, M., Nano.Lett. 9 (2009) $2059-2064$.

[75] Shen, J. L., Kim, H. C., Su, H., Wang, F., Wolfram, J., Kirui, D., Mai, J. H., Mu, C. F., Ji, L. N., Mao, Z. W., and Shen, H. F., Theranostics 4 (2014) 487-497.

[76] Xie, Y., Qiao, H. Z., Su, Z. G., Chen, M. L., Ping, Q. N., and Sun, M. J., Biomaterials 35 (2014) 7978-7991.

[77] Kim, H. J., Takemoto, H., Yi, Y., Zheng, M., Maeda, Y., Chaya, H., Hayashi, K., Mi, P., Pittella, F., Christie, R. J., Toh, K., Matsumoto, Y., Nishiyama, N., Miyata, K., and Kataoka, K., ACS Nano 8 (2014) 8979-8991. 
[78] Kim, S. T., Chompoosor, A., Yeh, Y. C., Agasti, S. S., Solfiell, D. J., and Rotello, V. M., Small 8 (2012) 3253 3256.

[79] Agrawal, A., Min, D. H., Singh, N., Zhu, H. H., Birjiniuk, A., von Maltzahn, G., Harris, T. J., Xing, D. Y., Woolfenden, S. D., Sharp, P. A., Charest, A., and Bhatia, S., ACS Nano 3 (2009) 2495-2504.

[80] Marshall, E., Science 286 (1999) 2244-2245.

[81] Sapsford, K. E., Algar, W. R., Berti, L., Gemmill, K. B., Casey, B. J., Oh, E., Stewart, M. H., and Medintz, I. L., Chemical Reviews 113 (2013) 1904-2074.

[82] Klein, S., Zolk, O., Fromm, M. F., Schrodl, F., Neuhuber, W., and Kryschi, C., Biochemical and Biophysical Research Communications 387 (2009) 164-168.

[83] Zhang, H. Y., Lee, M. Y., Hogg, M. G., Dordick, J. S., and Sharfstein, S. T., ACS Nano 4 (2010) $4733-4743$.

[84] Qian, J. and Gao, X. H., Acs Applied Materials \& Interfaces 5 (2013) 2845-2852.

[85] Taratula, O., Garbuzenko, O., Savla, R., Wang, Y. A., He, H. X., and Minko, T., Current Drug Delivery 8 (2011) 59-69.

[86] Neves, V., Heister, E., Costa, S., Tilmaciu, C., Flahaut, E., Soula, B., Coley, H. M., McFadden, J., and Silva, S. R. P., Nanotechnology 23 (2012).

[87] Akinc, A., Thomas, M., Klibanov, A. M., and Langer, R., Journal of Gene Medicine 7 (2005) 657-663.

[88] Klesing, J., Chernousova, S., Kovtun, A., Neumann, S., Ruiz, L., Gonzalez-Calbet, J. M., Vallet-Regi, M., Heumann, R., and Epple, M., Journal of Materials Chemistry 20 (2010) 6144-6148.

[89] Santosh, M., Panigrahi, S., Bhattacharyya, D., Sood, A. K., and Maiti, P. K., Journal of Chemical Physics 136 (2012).

[90] Ladewig, K., Niebert, M., Xu, Z. P., Gray, P. P., and Lu, G. Q. M., Biomaterials 31 (2010) 1821-1829.

[91] Wong, Y. Y., Markham, K., Xu, Z. P., Chen, M., Lu, G. Q., Bartlett, P. F., and Cooper, H. M., Biomaterials 31 (2010) 8770-8779.

[92] Zhang, L. Y., Wang, T. T., Li, L., Wang, C. G., Su, Z. M., and Li, J., Chemical Communications 48 (2012) $8706-$ 8708 .

[93] Huang, Y. P., Lin, I. J., Chen, C. C., Hsu, Y. C., Chang, C. C., and Lee, M. J., Nanoscale Research Letters 8 (2013).

[94] Song, W. J., Du, J. Z., Sun, T. M., Zhang, P. Z., and Wang, J., Small 6 (2010) 239-246.

[95] Lee, Y., Lee, S. H., Kim, J. S., Maruyama, A., Chen, X., and Park, T. G., J.Control Release 155 (2011) 3-10.

[96] Wu, C., Gong, F. M., Pang, P. F., Shen, M., Zhu, K. S., Cheng, D., Liu, Z. H., and Shan, H., Plos One 8 (2013).

[97] Liu, G., Xie, J., Zhang, F., Wang, Z. Y., Luo, K., Zhu, L., Quan, Q. M., Niu, G., Lee, S., Ai, H., and Chen, X. Y., Small 7 (2011) 2742-2749.

[98] Mykhaylyk, O., Vlaskou, D., Tresilwised, N., Pithayanukul, P., Moller, W., and Plank, C., Journal of Magnetism and Magnetic Materials 311 (2007) 275-281.

[99] Chen, M., Zhang, X. Q., Man, H. B., Lam, R., Chow, E. K., and Ho, D. A., Journal of Physical Chemistry Letters 1 (2010) 3167-3171.

[100] Lee, H., Sung, D., Veerapandian, M., Yun, K., and Seo, S. W., Analytical and Bioanalytical Chemistry 400 (2011) 535-545. 
[101] Meng, H. A., Liong, M., Xia, T. A., Li, Z. X., Ji, Z. X., Zink, J. I., and Nel, A. E., ACS Nano 4 (2010) 45394550 .

[102] Shim, M. S., Kim, C. S., Ahn, Y. C., Chen, Z. P., and Kwon, Y. J., Journal of the American Chemical Society 132 (2010) 8316-8324.

[103] Huschka, R., Barhoumi, A., Liu, Q., Roth, J. A., Ji, L., and Halas, N. J., ACS Nano 6 (2012) 7681-7691.

[104] Lee, S. K., Han, M. S., Asokan, S., and Tung, C. H., Small 7 (2011) 364-370.

[105] Saha, K., Agasti, S. S., Kim, C., Li, X. N., and Rotello, V. M., Chemical Reviews 112 (2012) 2739-2779.

[106] Bhattarai, S. R., Muthuswamy, E., Wani, A., Brichacek, M., Castaneda, A. L., Brock, S. L., and Oupicky, D., Pharmaceutical Research 27 (2010) 2556-2568.

[107] Boyer, C., Priyanto, P., Davis, T. P., Pissuwan, D., Bulmus, V., Kavallaris, M., Teoh, W. Y., Amal, R., Carroll, M., Woodward, R., and St Pierre, T., Journal of Materials Chemistry 20 (2010) 255-265.

[108] Alhaddad, A., Adam, M. P., Botsoa, J., Dantelle, G., Perruchas, S., Gacoin, T., Mansuy, C., Lavielle, S., Malvy, C., Treussart, F., and Bertrand, J. R., Small 7 (2011) 3087-3095.

[109] Han, L., Zhao, J., Zhang, X., Cao, W. P., Hu, X. X., Zou, G. Z., Duan, X. L., and Liang, X. J., ACS Nano 6 (2012) 7340-7351.

[110] Herrero, M. A., Toma, F. M., Al-Jamal, K. T., Kostarelos, K., Bianco, A., Da Ros, T., Bano, F., Casalis, L., Scoles, G., and Prato, M., Journal of the American Chemical Society 131 (2009) 9843-9848.

[111] Battigelli, A., Wang, J. T. W., Russier, J., Da Ros, T., Kostarelos, K., Al-Jamal, K. T., Prato, M., and Bianco, A., Small 9 (2013) 3610-3619.

[112] Restani, R. B., Conde, J., Baptista, P. V., Cidade, M. T., Bragança, A. M., Morgado, J., Correia, I. J., AguiarRicardo, A., and Bonifacio, V. D. B., RSC Advances 4 (2014) 54872-54878.

[113] Li, J. M., Wang, Y. Y., Zhao, M. X., Tan, C. P., Li, Y. Q., Le, X. Y., Ji, L. N., and Mao, Z. W., Biomaterials 33 (2012) 2780-2790.

[114] Bonoiu, A. C., Mahajan, S. D., Ding, H., Roy, I., Yong, K. T., Kumar, R., Hu, R., Bergey, E. J., Schwartz, S. A., and Prasad, P. N., Proceedings of the National Academy of Sciences of the United States of America 106 (2009) 5546-5550.

[115] Lee, M. Y., Park, S. J., Park, K., Kim, K. S., Lee, H., and Hahn, S. K., ACS Nano 5 (2011) 6138-6147.

[116] Wang, X. H., Ren, J. S., and Qu, X. G., Chemmedchem 3 (2008) 940-945.

[117] Qi, L. F., Wu, L. X., Zheng, S., Wang, Y. L., Fu, H. L., and Cui, D. X., Biomacromolecules 13 (2012) 2723 2730 .

[118] Mok, H., Veiseh, O., Fang, C., Kievit, F. M., Wang, F. Y., Park, J. O., and Zhang, M. Q., Molecular Pharmaceutics 7 (2010) 1930-1939.

[119] Singh, N., Agrawal, A., Leung, A. K. L., Sharp, P. A., and Bhatia, S. N., Journal of the American Chemical Society 132 (2010) 8241-8243.

[120] Sperling, R. A. and Parak, W. J., Philos.Transact.A Math.Phys.Eng Sci. 368 (2010) 1333-1383.

[121] Conde, J., Doria, G., de la Fuente, J. M., and Baptista, P. V., Methods Mol.Biol. 906 (2012) 71-87.

[122] Conde, J., de la Fuente, J. M., and Baptista, P. V., Nanotechnology. 21 (2010) 505101.

[123] Conde, J., de la Fuente, J. M., and Baptista, P. V., J.Nanobiotechnology. 8 (2010) 5. 
[124] Alivisatos, A. P., Johnsson, K. P., Peng, X. G., Wilson, T. E., Loweth, C. J., Bruchez, M. P., and Schultz, P. G., Nature 382 (1996) 609-611.

[125] Mirkin, C. A., Letsinger, R. L., Mucic, R. C., and Storhoff, J. J., Nature 382 (1996) 607-609.

[126] Zheng, D., Giljohann, D. A., Chen, D. L., Massich, M. D., Wang, X. Q., Iordanov, H., Mirkin, C. A., and Paller, A. S., Proceedings of the National Academy of Sciences of the United States of America 109 (2012) 1197511980.

[127] Kong, W. H., Bae, K. H., Hong, C. A., Lee, Y., Hahn, S. K., and Park, T. G., Bioconjugate Chemistry 22 (2011) 1962-1969.

[128] Patel, P. C., Hao, L. L., Yeung, W. S. A., and Mirkin, C. A., Molecular Pharmaceutics 8 (2011) 1285-1291.

[129] Lu, W., Zhang, G. D., Zhang, R., Flores, L. G., Huang, Q., Gelovani, J. G., and Li, C., Cancer Research 70 (2010) 3177-3188.

[130] Rosi, N. L., Giljohann, D. A., Thaxton, C. S., Lytton-Jean, A. K., Han, M. S., and Mirkin, C. A., Science 312 (2006) 1027-1030.

[131] Wang, P., Yigit, M. V., Medarova, Z., Wei, L. L., Dai, G. P., Schuetz, C., and Moore, A., Diabetes 60 (2011) 565-571.

[132] Kam, N. W. S., Liu, Z., and Dai, H. J., Journal of the American Chemical Society 127 (2005) 12492-12493.

[133] Jung, J. J., Solanki, A., Memoli, K. A., Kamei, K., Kim, H., Drahl, M. A., Williams, L. J., Tseng, H. R., and Lee, K., Angewandte Chemie-International Edition 49 (2010) 103-107.

[134] Li, J., Chen, Y. C., Tseng, Y. C., Mozumdar, S., and Huang, L., Journal of Controlled Release 142 (2010) 416421.

[135] Ashley, C. E., Carnes, E. C., Epler, K. E., Padilla, D. P., Phillips, G. K., Castillo, R. E., Wilkinson, D. C., Wilkinson, B. S., Burgard, C. A., Kalinich, R. M., Townson, J. L., Chackerian, B., Willman, C. L., Peabody, D. S., Wharton, W., and Brinker, C. J., ACS Nano 6 (2012) 2174-2188.

[136] Ashley, C. E., Carnes, E. C., Phillips, G. K., Padilla, D., Durfee, P. N., Brown, P. A., Hanna, T. N., Liu, J. W., Phillips, B., Carter, M. B., Carroll, N. J., Jiang, X. M., Dunphy, D. R., Willman, C. L., Petsev, D. N., Evans, D. G., Parikh, A. N., Chackerian, B., Wharton, W., Peabody, D. S., and Brinker, C. J., Nature Materials 10 (2011) 389-397.

[137] Wang, M. Q., Li, X., Ma, Y. J., and Gu, H. C., International Journal of Pharmaceutics 448 (2013) 51-57.

[138] Mogurampelly, S. and Maiti, P. K., Journal of Chemical Physics 138 (2013).

[139] Ladeira, M. S., Andrade, V. A., Gomes, E. R. M., Aguiar, C. J., Moraes, E. R., Soares, J. S., Silva, E. E., Lacerda, R. G., Ladeira, L. O., Jorio, A., Lima, P., Leite, M. F., Resende, R. R., and Guatimosim, S., Nanotechnology 21 (2010).

[140] Vogel, C. and Marcotte, E. M., Nature Reviews Genetics 13 (2012) 227-232.

[141] Eden, E., Geva-Zatorsky, N., Issaeva, I., Cohen, A., Dekel, E., Danon, T., Cohen, L., Mayo, A., and Alon, U., Science 331 (2011) 764-768.

[142] Acharya, S. and Hill, R. A., Nanomedicine-Nanotechnology Biology and Medicine 10 (2014) 329-337.

[143] Yang, Y., Li, J., Liu, F., and Huang, L., Molecular Therapy 20 (2012) 609-615.

[144] Hoffman, G. R., Moerke, N. J., Hsia, M., Shamu, C. E., and Blenis, J., Assay and Drug Development Technologies 8 (2010) 186-199. 
[145] Zhao, E. Y., Zhao, Z. X., Wang, J. C., Yang, C. H., Chen, C. J., Gao, L. Y., Feng, Q., Hou, W. J., Gao, M. Y., and Zhang, Q., Nanoscale 4 (2012) 5102-5109.

[146] Arvizo, R. R., Giri, K., Moyano, D., Miranda, O. R., Madden, B., McCormick, D. J., Bhattacharya, R., Rotello, V. M., Kocher, J. P., and Mukherjee, P., Plos One 7 (2012).

[147] Conde, J. and Artzi, N., Trends Biotechnol. 33 (2015) 141-144.

[148] Zhou, J., Shum, K. T., Burnett, J. C., and Rossi, J. J., Pharmaceuticals.(Basel) 6 (2013) 85-107.

[149] Miele, E., Spinelli, G. P., Miele, E., Di Fabrizio, E., Ferretti, E., Tomao, S., and Gulino, A., International Journal of Nanomedicine 7 (2012) 3637-3657.

[150] Burnett, J. C. and Rossi, J. J., Chemistry \& Biology 19 (2012) 60-71.

[151] Whitehead, K. A., Langer, R., and Anderson, D. G., Nat.Rev.Drug Discov. 8 (2009) 129-138.

[152] Conde, J., Oliva, N., and Artzi, N., Proc.Natl.Acad.Sci.U.S.A (2015).

[153] Ramakrishnan, S., Cancer Biol.Ther. 11 (2011) 849-851.

[154] Segovia, N., Pont, M., Oliva, N., Ramos, V., Borros, S., and Artzi, N., Adv.Healthc.Mater. (2014).

[155] Artzi, N., Oliva, N., Puron, C., Shitreet, S., Artzi, S., bon, Ramos A., Groothuis, A., Sahagian, G., and Edelman, E. R., Nat.Mater. 10 (2011) 704-709.

[156] Artzi, N., Shazly, T., Baker, A. B., Bon, A., and Edelman, E. R., Advanced Materials 21 (2009) 3399-+.

[157] Kourtis, I. C., Hirosue, S., de Titta, A., Kontos, S., Stegmann, T., Hubbell, J. A., and Swartz, M. A., Plos One 8 (2013).

[158] Buchan, S., Gronevik, E., Mathiesen, I., King, C. A., Stevenson, F. K., and Rice, J., Journal of Immunology 174 (2005) 6292-6298.

[159] Zaric, M., Lyubomska, O., Touzelet, O., Poux, C., Al-Zahrani, S., Fay, F., Wallace, L., Terhorst, D., Malissen, B., Henri, S., Power, U. F., Scott, C. J., Donnelly, R. F., and Kissenpfennig, A., Acs Nano 7 (2013) 2042-2055.

[160] Wang, J., Lu, Z., Wientjes, M. G., and Au, J. L., AAPS.J. 12 (2010) $492-503$.

[161] Gary, D. J., Puri, N., and Won, Y. Y., Journal of Controlled Release 121 (2007) 64-73.

[162] Gao, S., Dagnaes-Hansen, F., Nielsen, E. J. B., Wengel, J., Besenbacher, F., Howard, K. A., and Kjems, J., Molecular Therapy 17 (2009) 1225-1233.

[163] Zuckerman, J. E., Choi, C. H. J., Han, H., and Davis, M. E., Proceedings of the National Academy of Sciences of the United States of America 109 (2012) 3137-3142.

[164] Gil, P. R. and Parak, W. J., ACS Nano. 2 (2008) 2200-2205.

[165] Conde, J., Doria, G., and Baptista, P., J.Drug Deliv. 2012 (2012) 751075.

[166] Conde, J., de la Fuente, J. M., and Baptista, P. V., Front Pharmacol. 4 (2013) 134.

[167] Minelli, C., Lowe, S. B., and Stevens, M. M., Small 6 (2010) 2336-2357.

[168] Li, S. D. and Huang, L., Biochimica et Biophysica Acta-Biomembranes 1788 (2009) 2259-2266.

[169] Franca, A., Aggarwal, P., Barsov, E. V., Kozlov, S. V., Dobrovolskaia, M. A., and Gonzalez-Fernandez, A., Nanomedicine 6 (2011) 1175-1188.

[170] Moghimi, S. M., Hunter, A. C., and Murray, J. C., Pharmacological Reviews 53 (2001) 283-318. 
[171] Wong, C., Stylianopoulos, T., Cui, J. A., Martin, J., Chauhan, V. P., Jiang, W., Popovic, Z., Jain, R. K., Bawendi, M. G., and Fukumura, D., Proceedings of the National Academy of Sciences of the United States of America 108

[172] Bartlett, D. W., Su, H., Hildebrandt, I. J., Weber, W. A., and Davis, M. E., Proceedings of the National Academy of Sciences of the United States of America 104 (2007) 15549-15554.

[173] Perrault, S. D. and Chan, W. C. W., Proceedings of the National Academy of Sciences of the United States of America 107 (2010) 11194-11199.

[174] Leucuta, S. E., Current Drug Delivery 10 (2013) 208-240.

[175] Alexis, F., Pridgen, E., Molnar, L. K., and Farokhzad, O. C., Molecular Pharmaceutics 5 (2008) 505-515.

[176] Thiele, L., Merkle, H. P., and Walter, E., Pharmaceutical Research 20 (2003) 221-228.

[177] Conner, S. D. and Schmid, S. L., Nature 422 (2003) 37-44.

[178] Oliveira, S., van, Rooy, I, Kranenburg, O., Storm, G., and Schiffelers, R. M., Int.J.Pharm. 331 (2007) $211-214$.

[179] Villamil Giraldo, A. M., Appelqvist, H., Ederth, T., and Ollinger, K., Biochem.Soc.Trans. 42 (2014) 1460-1464.

[180] Arvizo, R., Bhattacharya, R., and Mukherjee, P., Expert Opinion on Drug Delivery 7 (2010) 753-763.

[181] Bartczak, D., Nitti, S., Millar, T. M., and Kanaras, A. G., Nanoscale 4 (2012) 4470-4472.

[182] Marchesano, V., Hernandez, Y., Salvenmoser, W., Ambrosone, A., Tino, A., Hobmayer, B., de la Fuente, J. M., and Tortiglione, C., ACS Nano 7 (2013) 2431-2442.

[183] Levy, M., Luciani, N., Alloyeau, D., Elgrabli, D., Deveaux, V., Pechoux, C., Chat, S., Wang, G., Vats, N., Gendron, F., Factor, C., Lotersztajn, S., Luciani, A., Wilhelm, C., and Gazeau, F., Biomaterials 32 (2011) 39883999.

[184] Chang, E., Thekkek, N., Yu, W. W., Colvin, V. L., and Drezek, R., Small 2 (2006) 1412-1417.

[185] Zhai, W. Y., He, C. L., Wu, L., Zhou, Y., Chen, H. R., Chang, J., and Zhang, H. F., Journal of Biomedical Materials Research Part B-Applied Biomaterials 100B (2012) 1397-1403.

[186] Ambrosone, A., Marchesano, V., Mazzarella, V., and Tortiglione, C., Nanotoxicology 8 (2014) 508-520.

[187] Yong, K. T., Law, W. C., Hu, R., Ye, L., Liu, L. W., Swihart, M. T., and Prasad, P. N., Chemical Society Reviews 42 (2013) 1236-1250.

[188] Lovric, J., Cho, S. J., Winnik, F. M., and Maysinger, D., Chemistry \& Biology 12 (2005) 1227-1234.

[189] Ambrosone, A., Mattera, L., Marchesano, V., Quarta, A., Susha, A. S., Tino, A., Rogach, A. L., and Tortiglione, C., Biomaterials 33 (2012) 1991-2000. 


\section{Graphical Abstract}

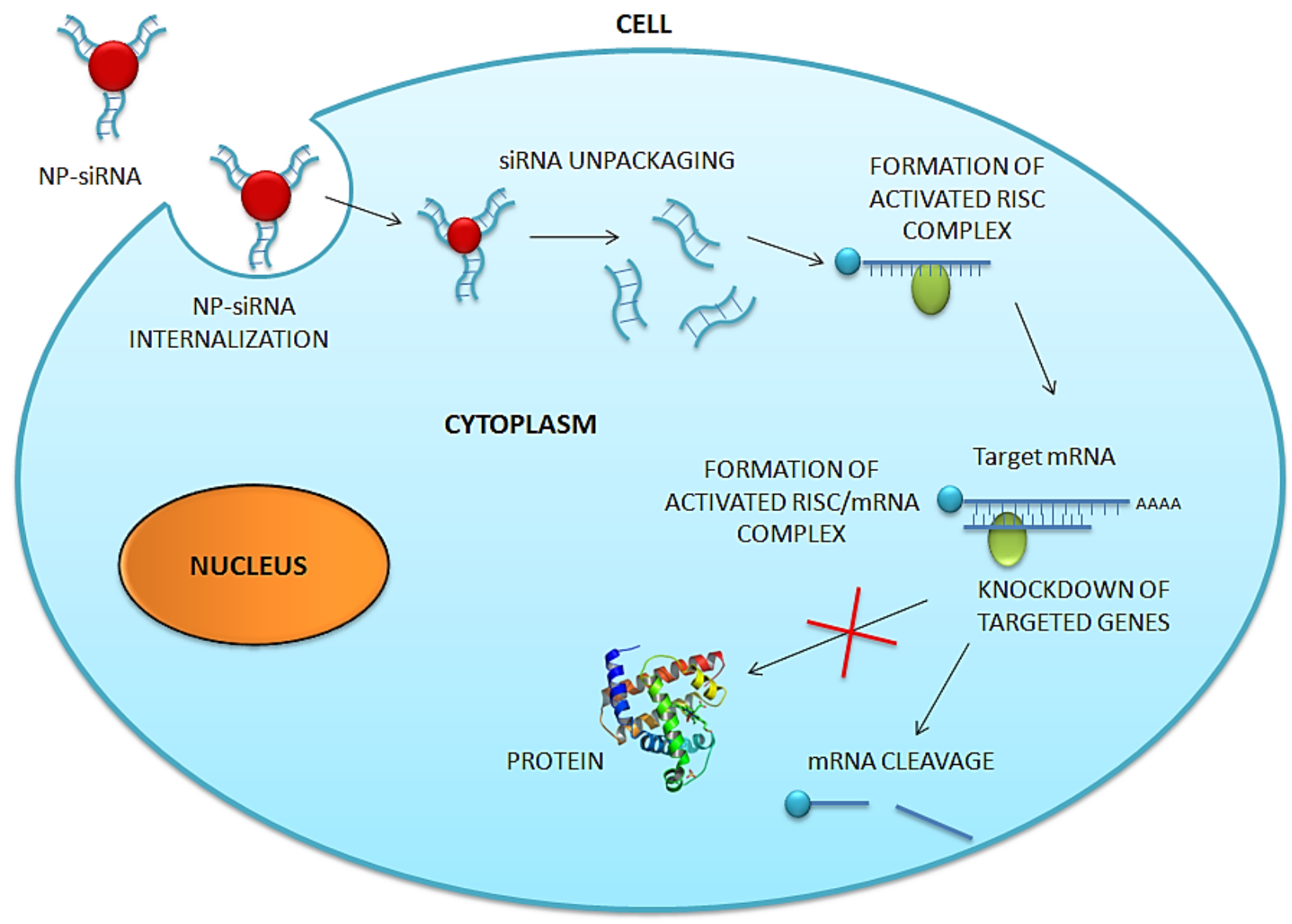


Table 1. Examples of nanoparticle-based siRNA delivery systems.

\begin{tabular}{|c|c|c|c|c|c|}
\hline Nanoparticle type & $\begin{array}{c}\text { Conjugation } \\
\text { type }\end{array}$ & Target gene & Biological system & $\begin{array}{l}\text { Efficiency of silencing/ } \\
\text { detection method }\end{array}$ & Ref \\
\hline \multirow{2}{*}{ Magnetic NP } & Covalent binding & $\begin{array}{l}\text { GFP/RFP/ } \\
\text { survivin }\end{array}$ & $\begin{array}{l}\text { 9LGliosarcoma } \\
\text { cells } \\
\text { mouse }\end{array}$ & $\begin{array}{l}50 \% \text {-fluorescence intensity } \\
>80 \% \text {-qRT-PCR }\end{array}$ & [18] \\
\hline & $\begin{array}{l}\text { Absorption via } \\
\text { lipids }\end{array}$ & luciferase & HeLa cells & $90 \%$ - enzymatic activity & [28] \\
\hline $\begin{array}{l}\text { Magnetic } \\
\text { nanobeads }\end{array}$ & $\begin{array}{l}\text { Surface } \\
\text { absorption }\end{array}$ & GFP & HeLa cells & n.d. -fluorescence intensity & [22] \\
\hline \multirow{6}{*}{ Gold NP } & $\begin{array}{l}\text { Gold-thiol } \\
\text { conjugation }\end{array}$ & luciferase & HeLa cells & $>70 \%$-enzymatic activity & [29] \\
\hline & $\begin{array}{l}\text { Gold-thiol } \\
\text { conjugation }\end{array}$ & luciferase & HeLa cells & $>90 \%$-enzymatic activity & [30] \\
\hline & Covalent binding & $\mathrm{c}-\mathrm{Myc}$ & $\begin{array}{l}\text { HeLa cells } \\
\text { Hydra } \\
\text { mouse }\end{array}$ & $\begin{array}{l}80 \% \text {-enzymatic activity } \\
80 \% \text {-qRT-PCR } \\
70 \% \text {-qRT-PCR }\end{array}$ & {$[24,27,31]$} \\
\hline & Ionic interaction & Lamin $\mathrm{A} / \mathrm{C}$ & HeLa cells & $80 \%$-immunoblot & [32] \\
\hline & $\begin{array}{l}\text { Gold-thiol } \\
\text { conjugation }\end{array}$ & $\mathrm{c}-\mathrm{Myc}$ & $\begin{array}{l}\text { LA4-cells } \\
\text { mouse }\end{array}$ & $\begin{array}{l}80 \% \text {-qRT-PCR } \\
80-90 \% \text {-bioluminescence } \\
\text { imaging }\end{array}$ & [27] \\
\hline & $\begin{array}{l}\text { Ciclodextrin/ } \\
\text { adamantin } \\
\text { interaction }\end{array}$ & RRM2 & human & $\begin{array}{l}\text { 30-70\% -qRT-PCR, } \\
\text { immunolocalization }\end{array}$ & [25] \\
\hline $\begin{array}{l}\text { Mesoporous silica } \\
\text { NP }\end{array}$ & $\begin{array}{l}\text { Pore/surface } \\
\text { adsorption }\end{array}$ & GFP/VEGF & $\begin{array}{l}\text { HeLa cells } \\
\text { MDA-MB-231 } \\
\text { cells } \\
\text { mouse } \\
\end{array}$ & $\begin{array}{l}80 \% \text {-fluorescence intensity } \\
60 \% \text {-RT-PCR } \\
80 \% \text {-fluorescence intensity } \\
\text { RT-PCR } \\
\end{array}$ & [23] \\
\hline $\begin{array}{l}\text { Mesoporous silica } \\
\text { NP } \\
\text { (+doxorubicin) }\end{array}$ & Adsorption & $\begin{array}{l}\text { Pgp (ABC drug } \\
\text { efflux } \\
\text { transporter) }\end{array}$ & $\begin{array}{l}\text { MCF-7 cells } \\
\text { mouse }\end{array}$ & $\begin{array}{l}50 \% \text { - immunoblot } \\
\text { 10-90\% -tumor weight, } \\
\text { immunoblot, qRT-PCR }\end{array}$ & [33] \\
\hline $\begin{array}{l}\text { Gold nanorods- } \\
\text { mesoporous silica }\end{array}$ & Covalent binding & GFP & HeLa cells & $60 \%$-fluorescence intensity & [34] \\
\hline $\begin{array}{l}\text { Calcium } \\
\text { Phosphate NP }\end{array}$ & Encapsulation & luciferase & $\begin{array}{l}\mathrm{H} 460 \text { cells } \\
\text { mouse }\end{array}$ & $\begin{array}{l}50 \% \text { enzymatic activity } \\
50 \% \text { enzymatic activity }\end{array}$ & [20] \\
\hline Quantum dots & Adsorption & $\begin{array}{l}\text { BACE1 } \\
\text { (b-secretase) }\end{array}$ & SK-N-SH cells & $50 \%$-immunoblot & [35] \\
\hline $\begin{array}{l}\text { Single walled } \\
\text { carbon nanotubes }\end{array}$ & Covalent binding & $\begin{array}{l}\text { CXCR4 } \\
\text { (cell surface } \\
\text { co-receptor) } \\
\text { CD4 }\end{array}$ & $\begin{array}{l}\text { T cells } \\
\text { peripheral blood } \\
\text { mononuclear cells }\end{array}$ & $\begin{array}{l}50 \%-90 \% \text { qRT-PCR } \\
60 \% \text { qRT-PCR }\end{array}$ & [17] \\
\hline
\end{tabular}


Table 2. Inorganic nanoparticles in clinical trials.

\begin{tabular}{|c|c|c|c|c|c|}
\hline $\begin{array}{c}\text { Delivery } \\
\text { vehicle }\end{array}$ & $\begin{array}{c}\text { Target } \\
\text { gene } \\
\end{array}$ & Disease & Phase & Status & $\begin{array}{c}\text { ClinicalTrials.gov } \\
\text { ID } \\
\end{array}$ \\
\hline $\begin{array}{l}\text { Gold + Iron } \\
\text { Oxide-Silica } \\
\end{array}$ & NA & $\begin{array}{l}\text { Coronary Artery Disease } \\
\text { Atherosclerosis }\end{array}$ & 1 & Completed & NCT01436123 \\
\hline Gold + silica & NA & $\begin{array}{l}\text { Stable Angina } \\
\text { Heart Failure } \\
\text { Atherosclerosis } \\
\text { Multivessel Coronary Artery Disease }\end{array}$ & $\begin{array}{l}1 \\
2\end{array}$ & Completed & NCT01270139 \\
\hline Gold & NA & Stomach Diseases & 0 & Recruiting & NCT01420588 \\
\hline Silica & NA & $\begin{array}{l}\text { Head and Neck Cancer } \\
\text { Melanoma } \\
\text { Prostate Cancer } \\
\text { Cervical Cancer } \\
\text { Uterine Cancer }\end{array}$ & 0 & Recruiting & NCT02106598 \\
\hline \multirow{12}{*}{$\begin{array}{l}\text { Iron oxide } \\
\text { (magnetic) }\end{array}$} & NA & Head and Neck Cancer & 0 & Recruiting & NCT01895829 \\
\hline & NA & Leukemia & - & Completed & NCT01411904 \\
\hline & NA & Brain Neoplasms & 1 & Completed & NCT00769093 \\
\hline & NA & Multiple Sclerosis & 0 & Recruiting & NCT01973517 \\
\hline & NA & $\begin{array}{l}\text { Papillary Carcinoma of Thyroid } \\
\text { Metastatic to Regional Lymph Node } \\
\text { Metastatic Medullary Thyroid Cancer } \\
\text { Follicular Thyroid Cancer Lymph } \\
\text { Node Metastasis }\end{array}$ & 0 & Recruiting & NCT01927887 \\
\hline & NA & Cancer of Lymph Node & 0 & Recruiting & NCT01815333 \\
\hline & NA & $\begin{array}{l}\text { Myocardial Infarction } \\
\text { Inflammation }\end{array}$ & 2 & Recruiting & NCT01995799 \\
\hline & NA & Pancreatic Cancer & 4 & Recruiting & NCT00920023 \\
\hline & NA & $\begin{array}{l}\text { Bladder Cancer } \\
\text { Genitourinary Cancer } \\
\text { Prostate Cancer }\end{array}$ & - & Completed & NCT00147238 \\
\hline & NA & Myocardial Infarction & - & Completed & NCT01323296 \\
\hline & NA & $\begin{array}{l}\text { Myocardial Infarction } \\
\text { Inflammation }\end{array}$ & - & - & NCT01127113 \\
\hline & NA & Renal Transplant Rejection & - & Recruiting & NCT02006108 \\
\hline
\end{tabular}

NA: not applicable 
Table 3. RNAi-based drugs in clinical trials. Adapted from [14].

\begin{tabular}{|c|c|c|c|c|c|}
\hline $\begin{array}{l}\text { Delivery } \\
\text { vehicle }\end{array}$ & Target gene & Disease & Phase & Status & $\begin{array}{c}\text { ClinicalTrials.gov } \\
\text { ID }\end{array}$ \\
\hline \multirow{9}{*}{ Lipid-based } & $c-M y c$ & Hepatocellular Carcinoma & $\begin{array}{l}1 \\
2\end{array}$ & Recruiting & NCT02314052 \\
\hline & $c-M y c$ & $\begin{array}{l}\text { Solid Tumors } \\
\text { Multiple Myeloma } \\
\text { Non-Hodgkins Lymphoma }\end{array}$ & 1 & Recruiting & NCT02110563 \\
\hline & HSP47 & $\begin{array}{l}\text { Moderate to Extensive Hepatic } \\
\text { Fibrosis }\end{array}$ & 1 & Recruiting & NCT02227459 \\
\hline & $P L K 1$ & $\begin{array}{l}\text { Colorectal, Pancreas, Gastric, } \\
\text { Breast and Ovarian Cancers } \\
\text { With Hepatic Metastases }\end{array}$ & 1 & Completed & NCT01437007 \\
\hline & EphA2 & Advanced Cancers & 1 & $\begin{array}{l}\text { Not yet } \\
\text { recruiting }\end{array}$ & NCT01591356 \\
\hline & $A p o B$ & Hypercholesterolaemia & 1 & Completed & NCT00927459 \\
\hline & $\begin{array}{l}V P 24, V P 35, \\
\text { Zaire Ebola } \\
\text { L-polymerase }\end{array}$ & Ebola-virus infection & 1 & Recruiting & NCT01518881 \\
\hline & KSP, VEGF & Solid tumors & 1 & Completed & NCT01158079 \\
\hline & $T T R$ & $\begin{array}{l}\text { Transthyretin-mediated } \\
\text { amyloidosis }\end{array}$ & 2 & Recruiting & NCT01617967 \\
\hline \multirow{6}{*}{ Naked siRNAs } & \begin{tabular}{|l}
$\begin{array}{l}\text { K6a }(\mathrm{N} 171 \mathrm{~K} \\
\text { mutation })\end{array}$ \\
\end{tabular} & Pachyonychia congenita & 1 & Completed & NCT00716014 \\
\hline & VEGFRI & $\begin{array}{l}\text { Age-related macular } \\
\text { degeneration, choroidal } \\
\text { neovascularization }\end{array}$ & 2 & Completed & NCT00395057 \\
\hline & CASP2 & $\begin{array}{l}\text { Optic atrophy, non-arteritic } \\
\text { anterior ischaemic optic } \\
\text { neuropathy }\end{array}$ & 1 & Completed & NCT01064505 \\
\hline & P53 & Kidney injury, acute renal failure & 1 & Completed & NCT00554359 \\
\hline & RTP801 & $\begin{array}{l}\text { Choroidal neovascularization, } \\
\text { diabetic retinopathy, diabetic } \\
\text { macular edema }\end{array}$ & 2 & Completed & NCT01445899 \\
\hline & $\begin{array}{l}\text { RSV } \\
\text { nucleocapsid }\end{array}$ & $\begin{array}{l}\text { Respiratory syncytial virus } \\
\text { infections }\end{array}$ & 2 & Completed & NCT00658086 \\
\hline \multirow{2}{*}{$\begin{array}{l}\text { bacteria/viral } \\
\text { vectors }\end{array}$} & \begin{tabular}{|l|} 
Conserved \\
regions of HBV
\end{tabular} & HBV (human hepatitis B virus) & 1 & Recruiting & NCT01872065 \\
\hline & CTNNB1 & Familial adenomatous polyposis & $\begin{array}{l}1 \\
2\end{array}$ & Recruiting & - \\
\hline
\end{tabular}


Click here to download high resolution image

\section{"W50.0.}

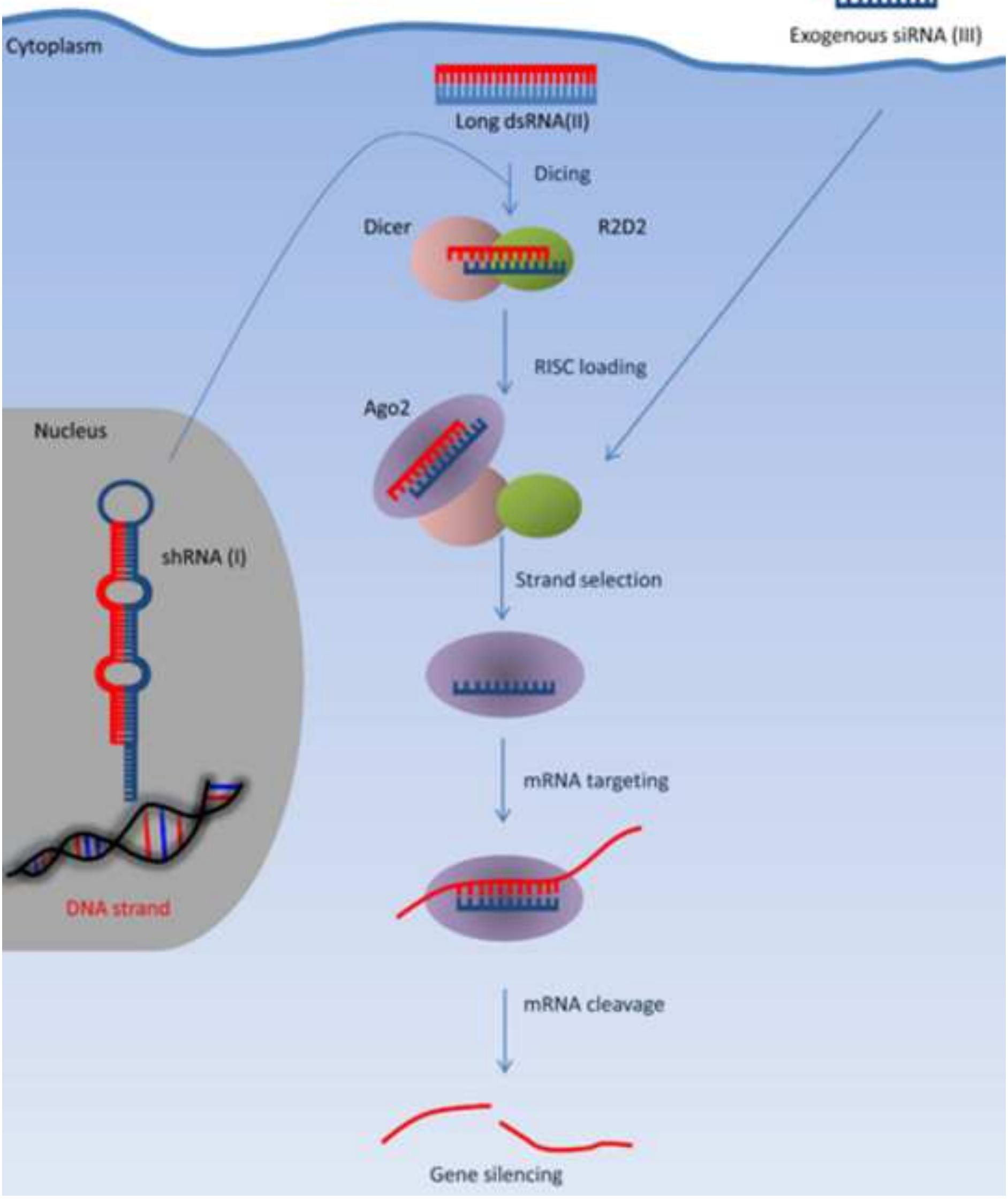


Click here to download high resolution image

Fire \& Mello

RNAi mechanism

C. elegans

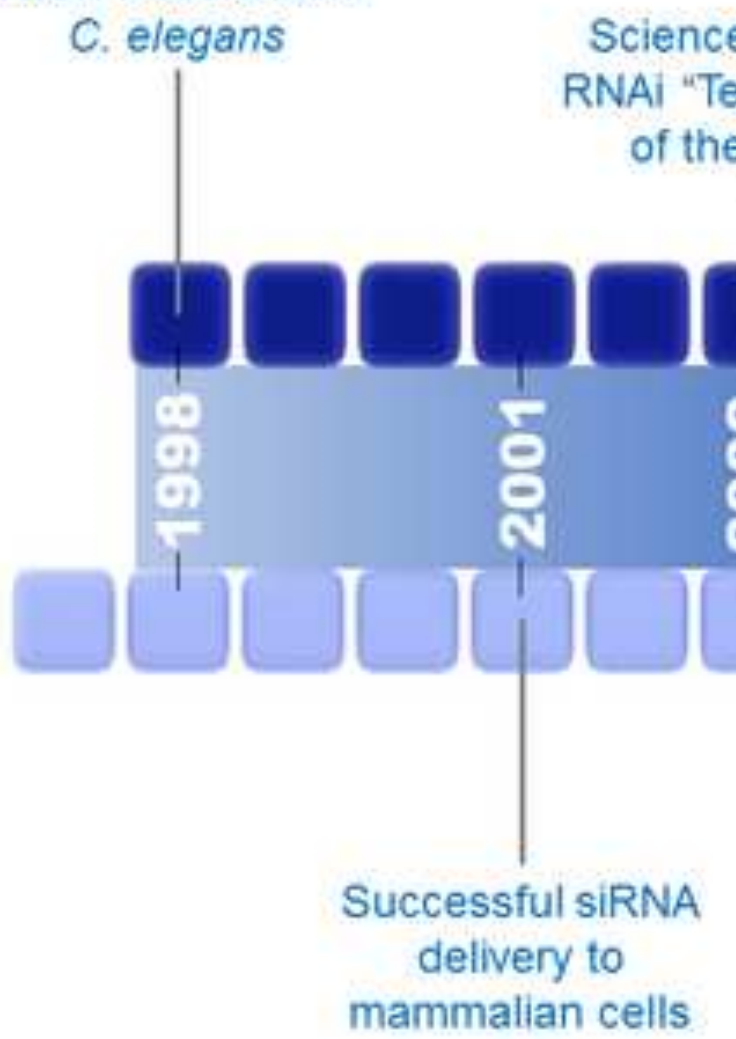

$1^{\text {st }}$ siRNA-gold

NP delivery

Luciferase

knockdown in

human cells

\section{y}

\section{$1^{\text {st }}$ siRNA-}

\section{magnetic NP}

in vivo delivery

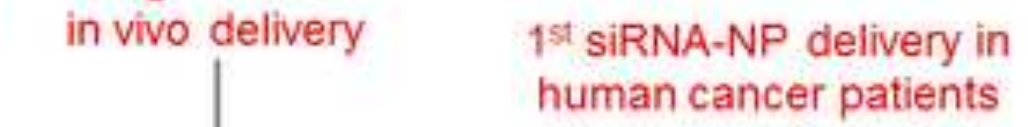

$1^{\text {st }}$ siRNA-NP delivery in

human cancer patients
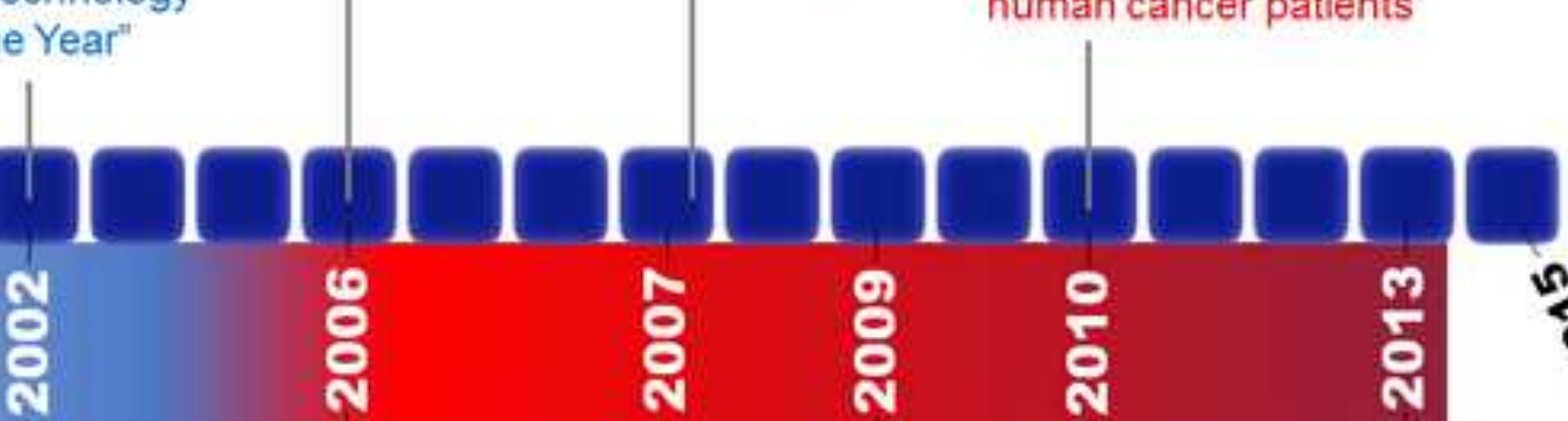

है ह
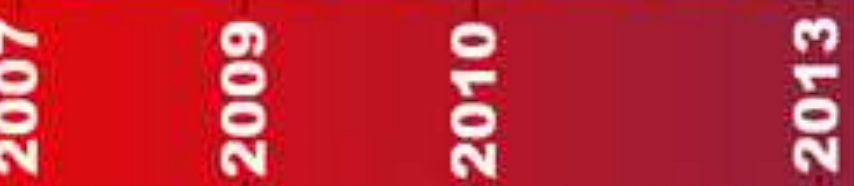

\& 


\section{Figure 3}

Click here to download high resolution image

A

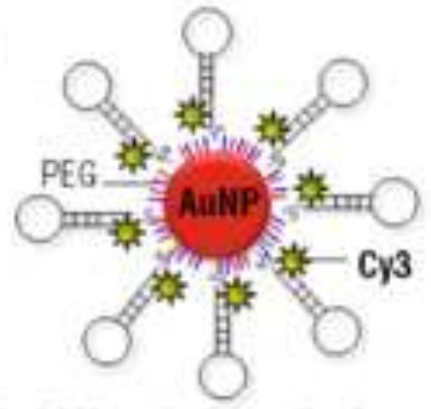

Gold Nanobeacon Antisense

to silenc EGFP

\section{ANTISENSE APPROACH}

HUMAN CELL.

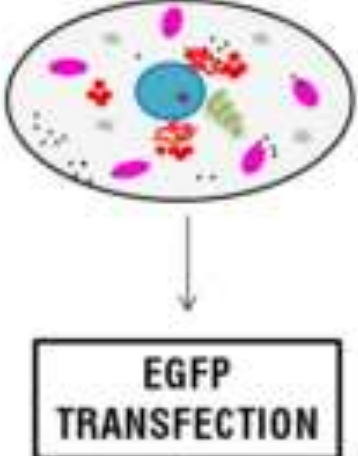

B

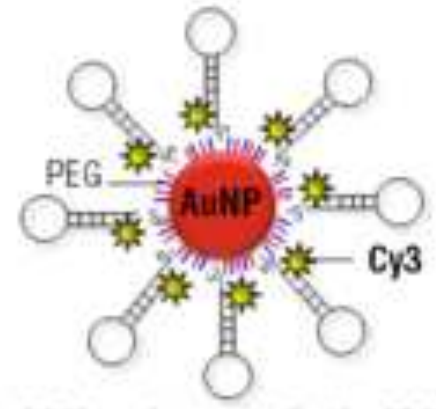

Gold Nanobeacon Anti-siRNA to block siRNA for EGFP

INTERFERENCE APPROACH
MRNA

\section{EGFP silencing via}

\section{NO LIGHT}

Gold Nanobeacon Antisense

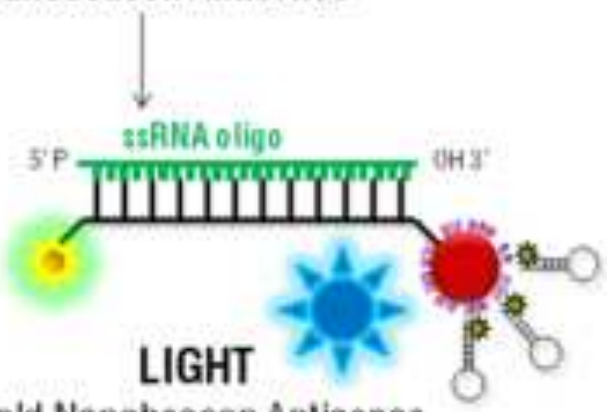

Gold Nanobeacon Antisense blockage via RNA oligo

(AAA)

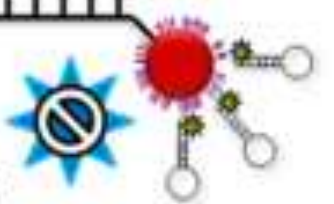
SIRNA

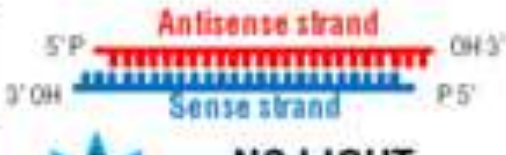

\section{NO LIGHT}

EGFP silencing via SIRNA

siRNA blockage via

Gold Nanobeacon Anti-siRNA
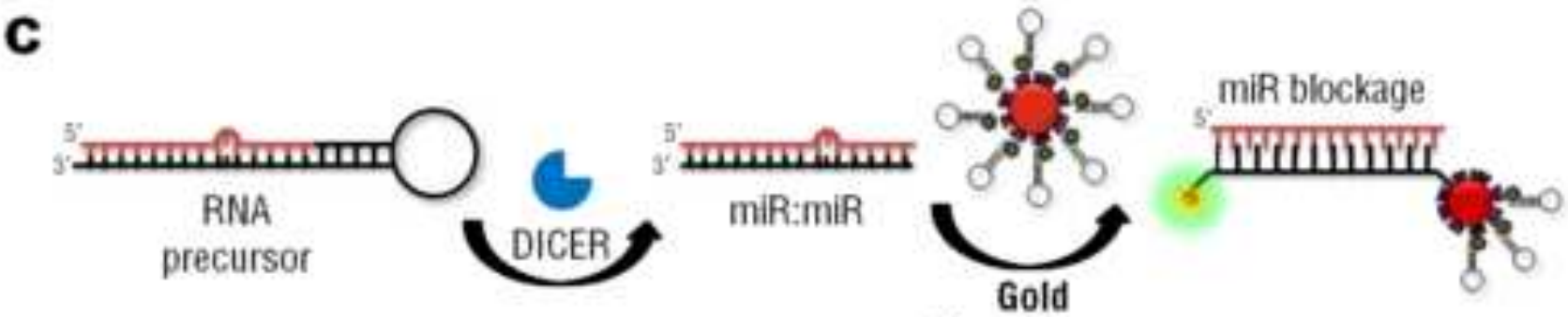

Nanobeacon

Anti-miR 
Click here to download high resolution image
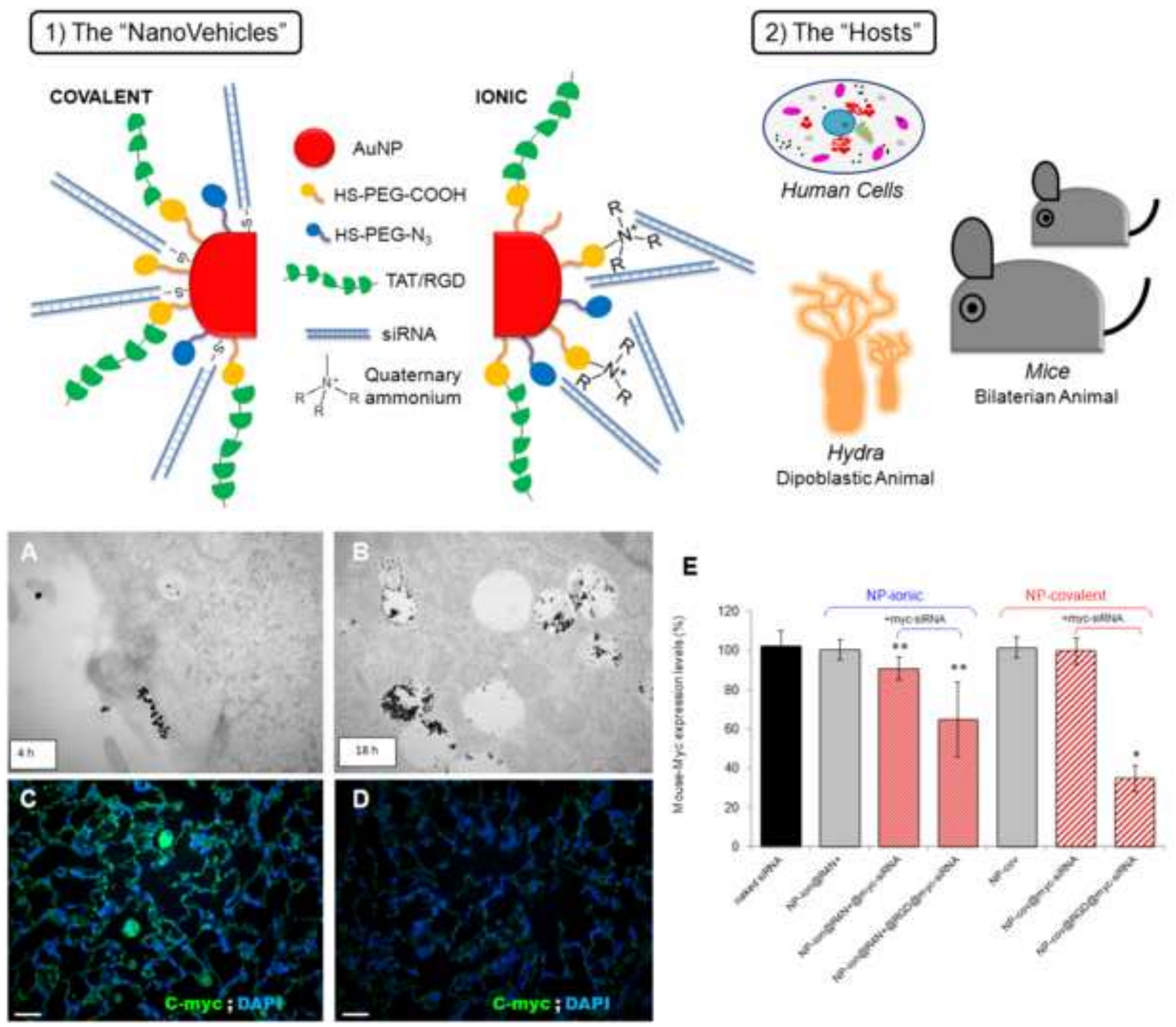
LipoMag (using oleic acid-coated magnetic nanocrystals)

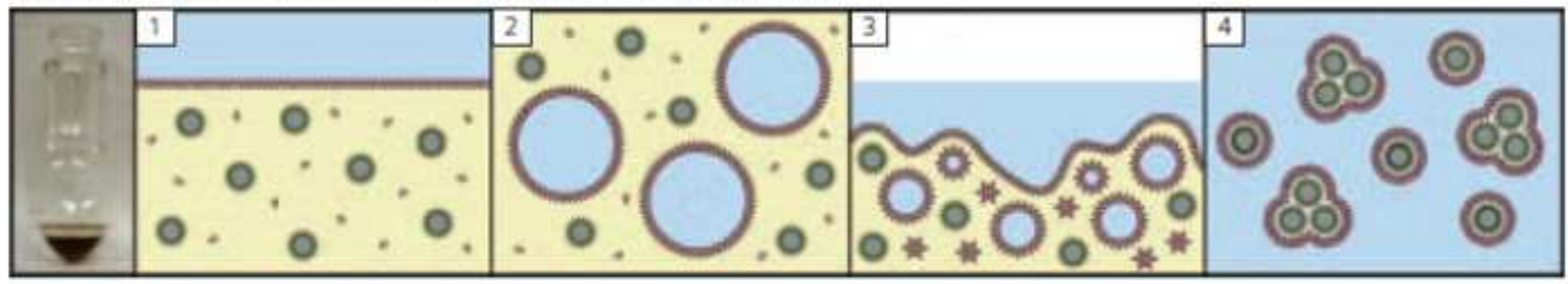

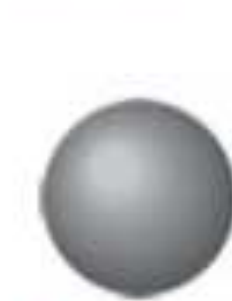

Magnetite nanocrystal

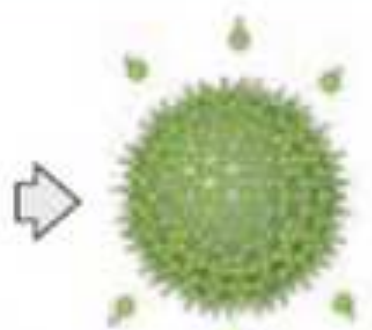

9

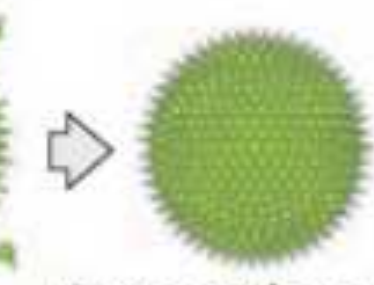

Oleic acid-coated magnetite nanocrystal

\section{9}

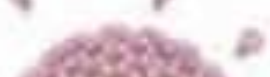

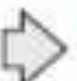

\section{0}

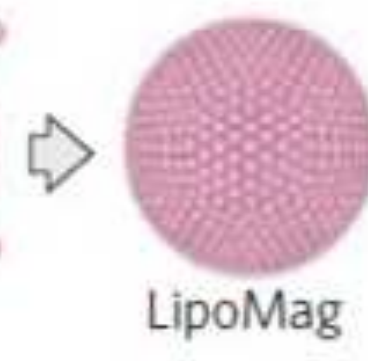

LipoMag

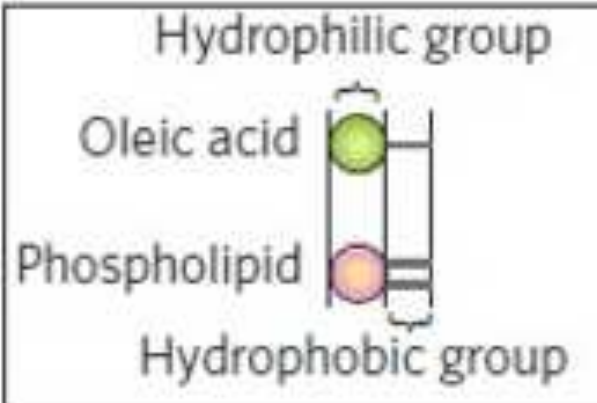

Evaporated magnetic liposomes (using non-coated magnetic nanocrystals)

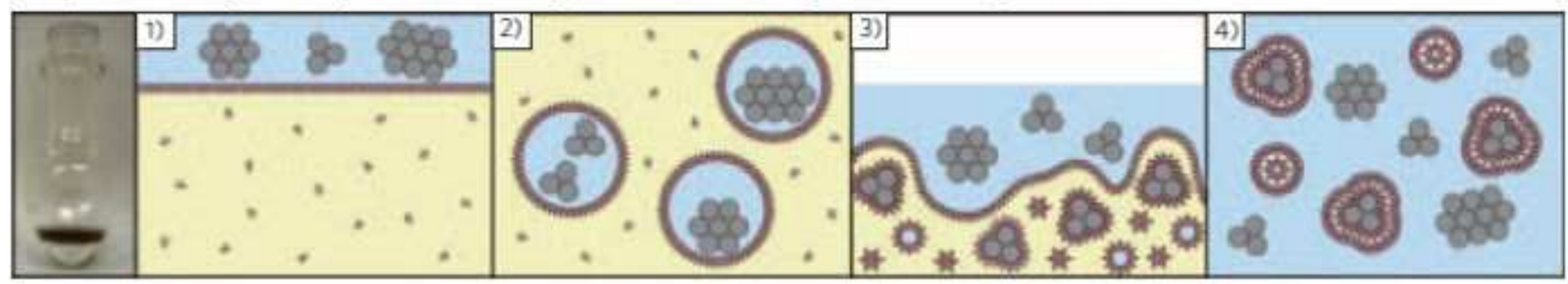


Click here to download high resolution image
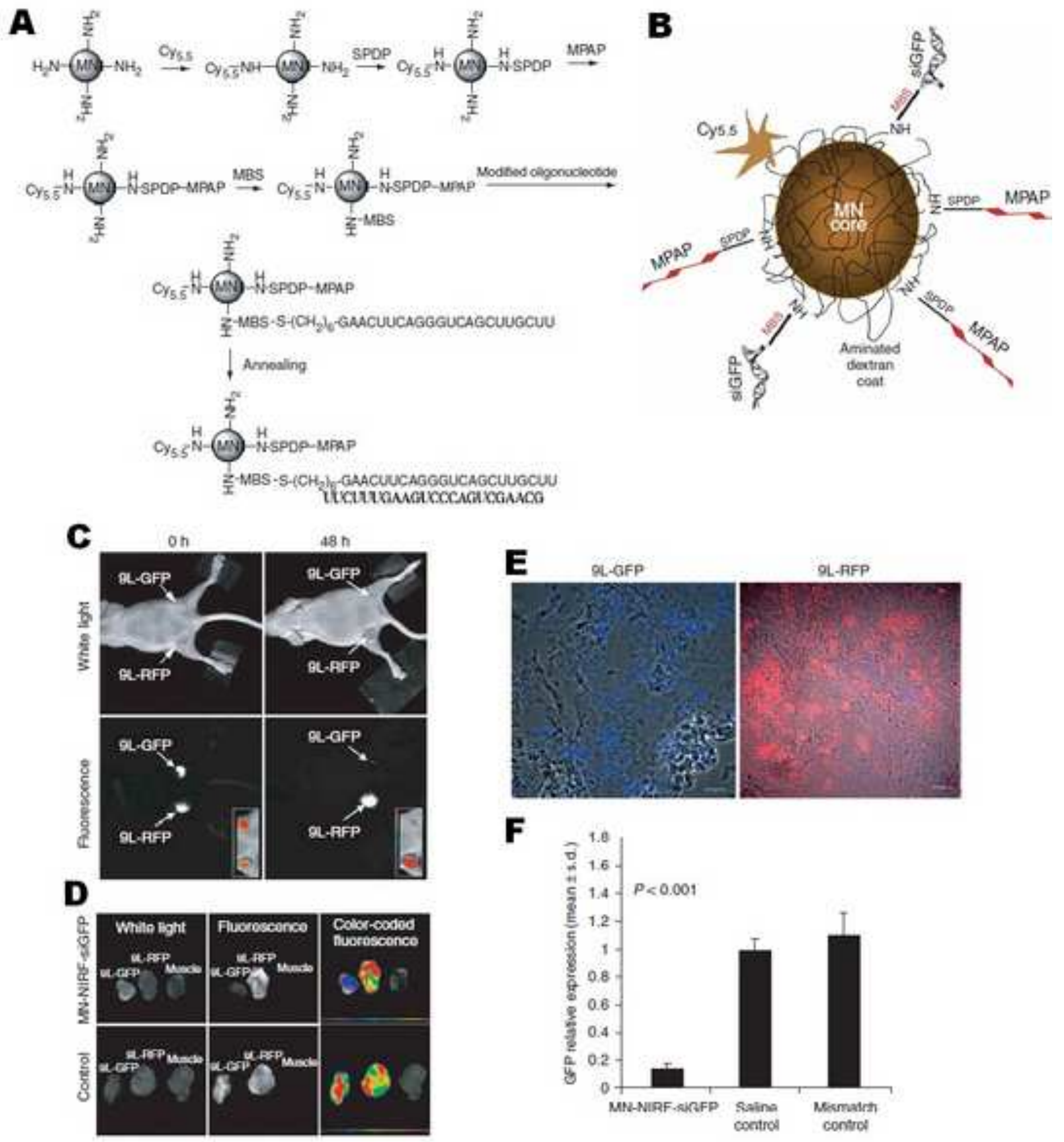

$\mathbf{F}$

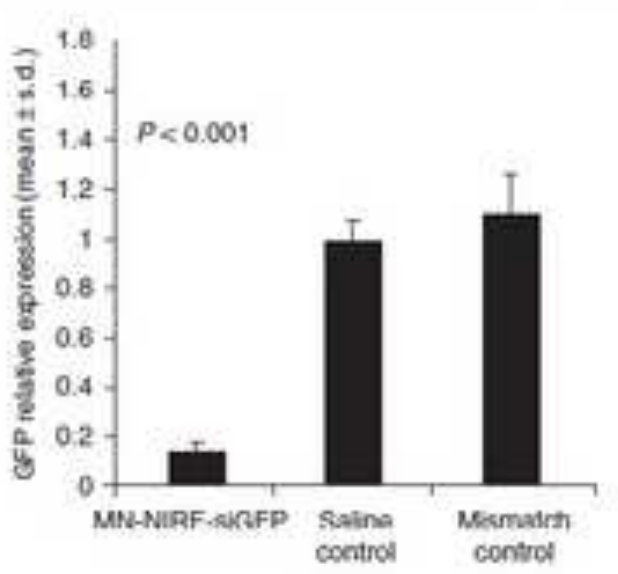




\section{Figure 7}

Click here to download high resolution image

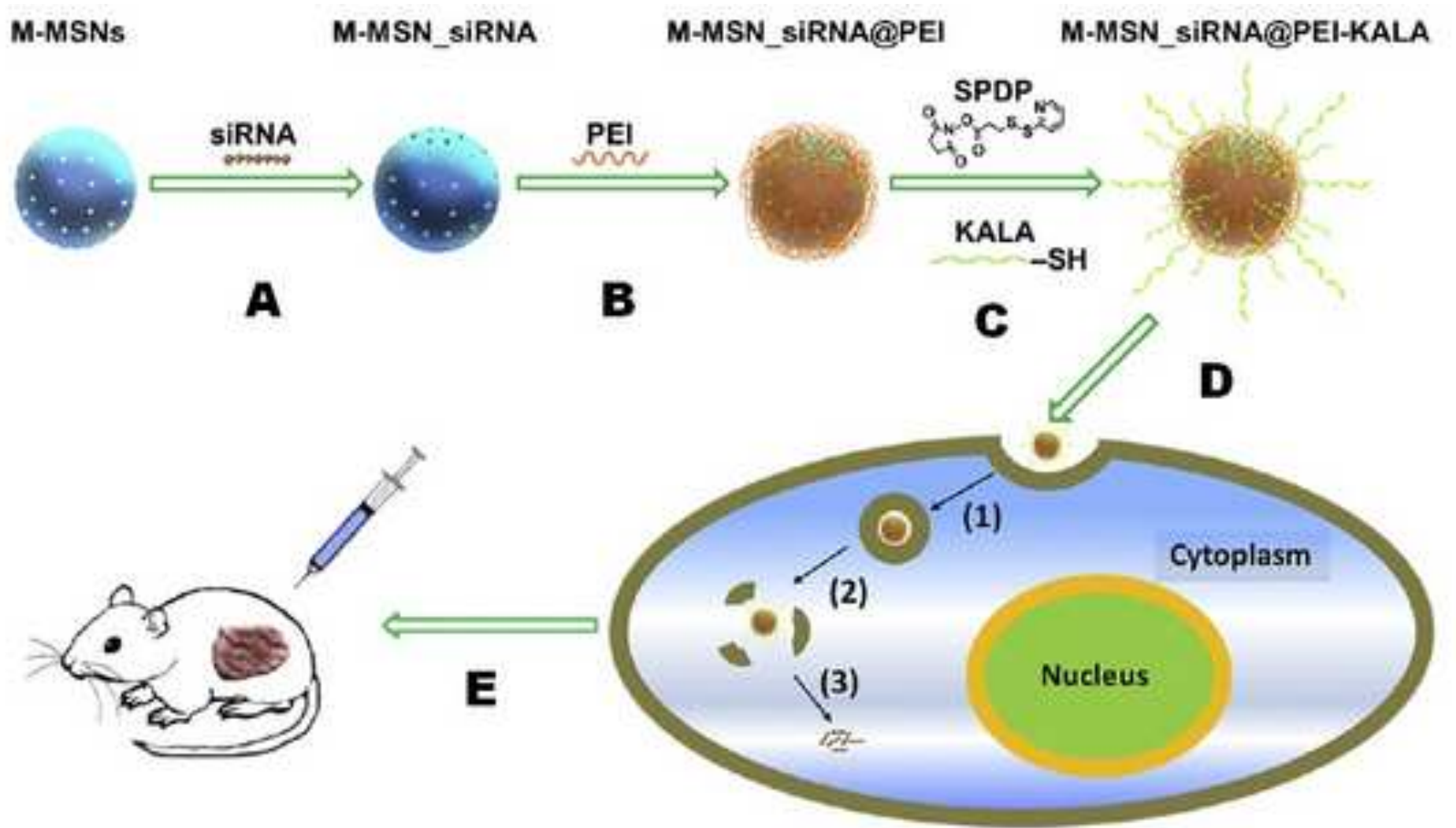

In vivo Cancer Treatment

In vitro RNAi Experiments

$\mathbf{F}$

10 Days
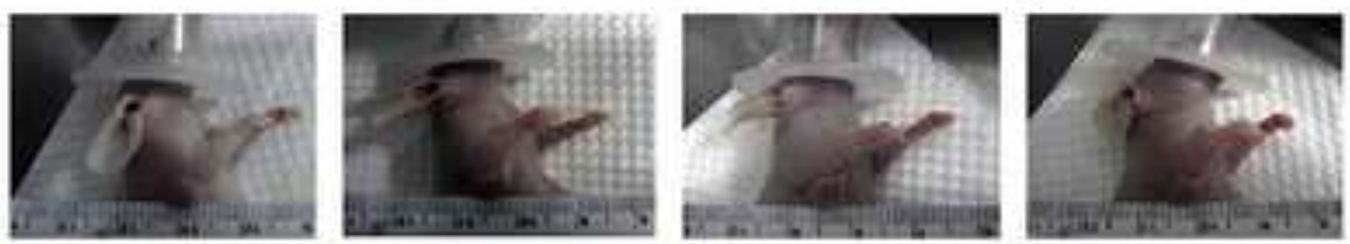

20 Days
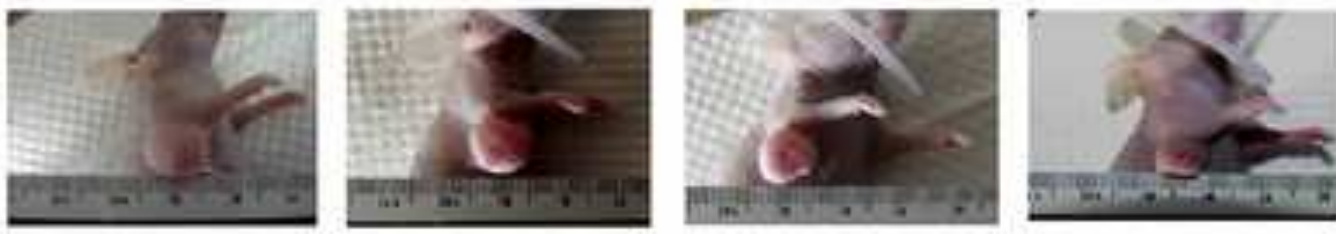

30 Days
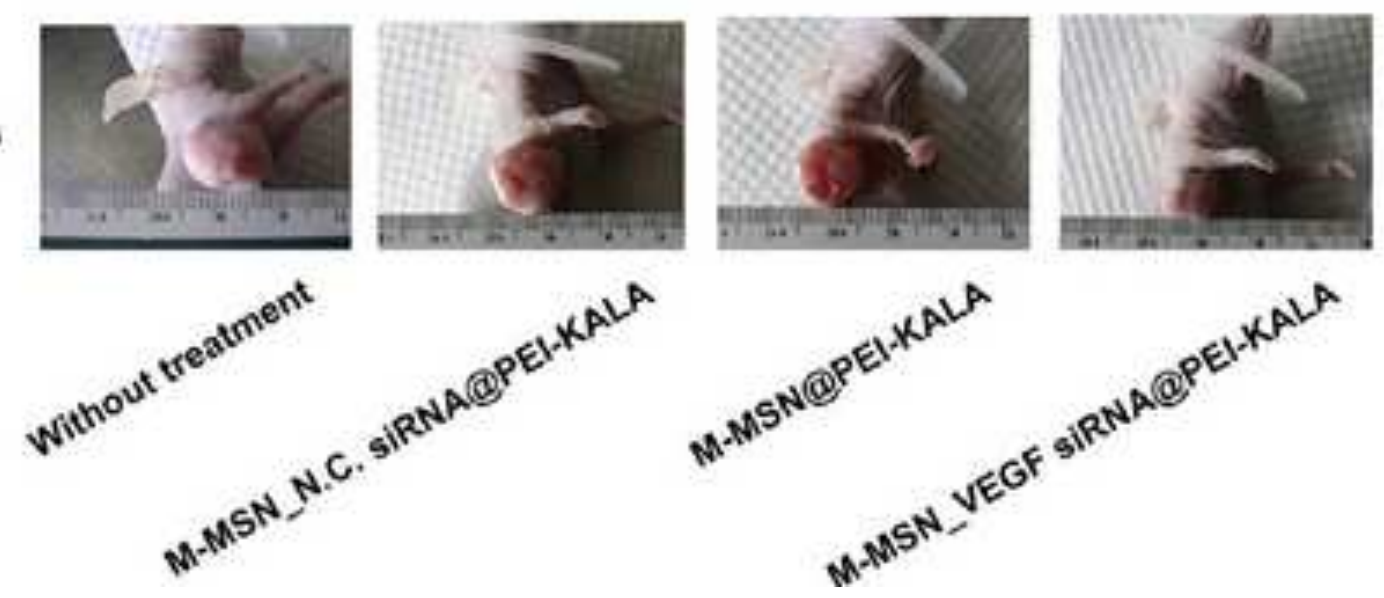
A
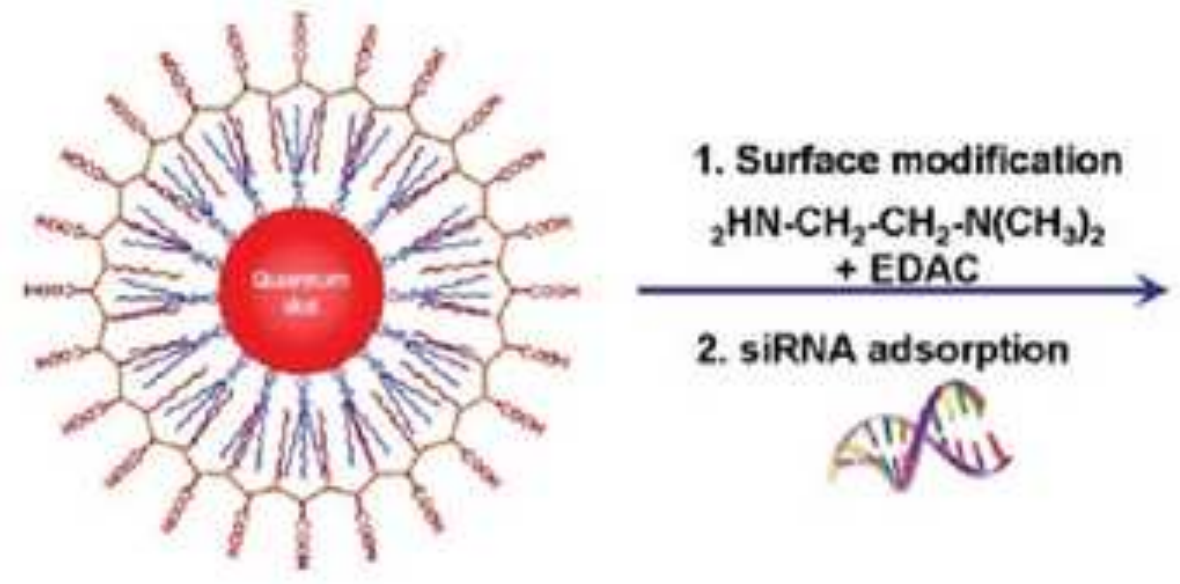

2. SIRNA adsorption
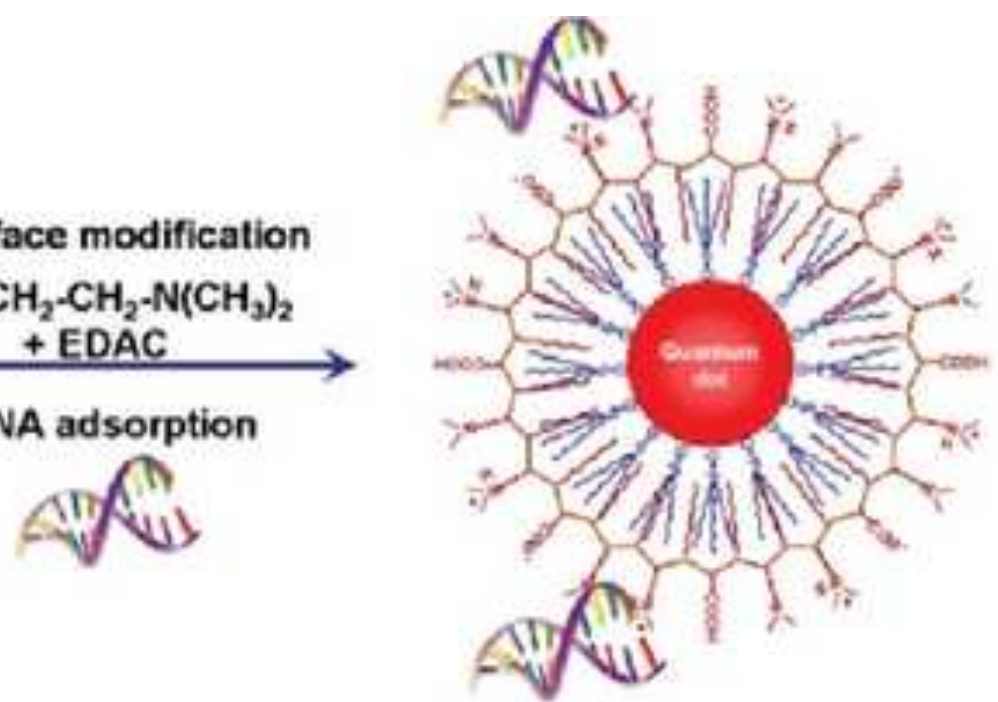

B

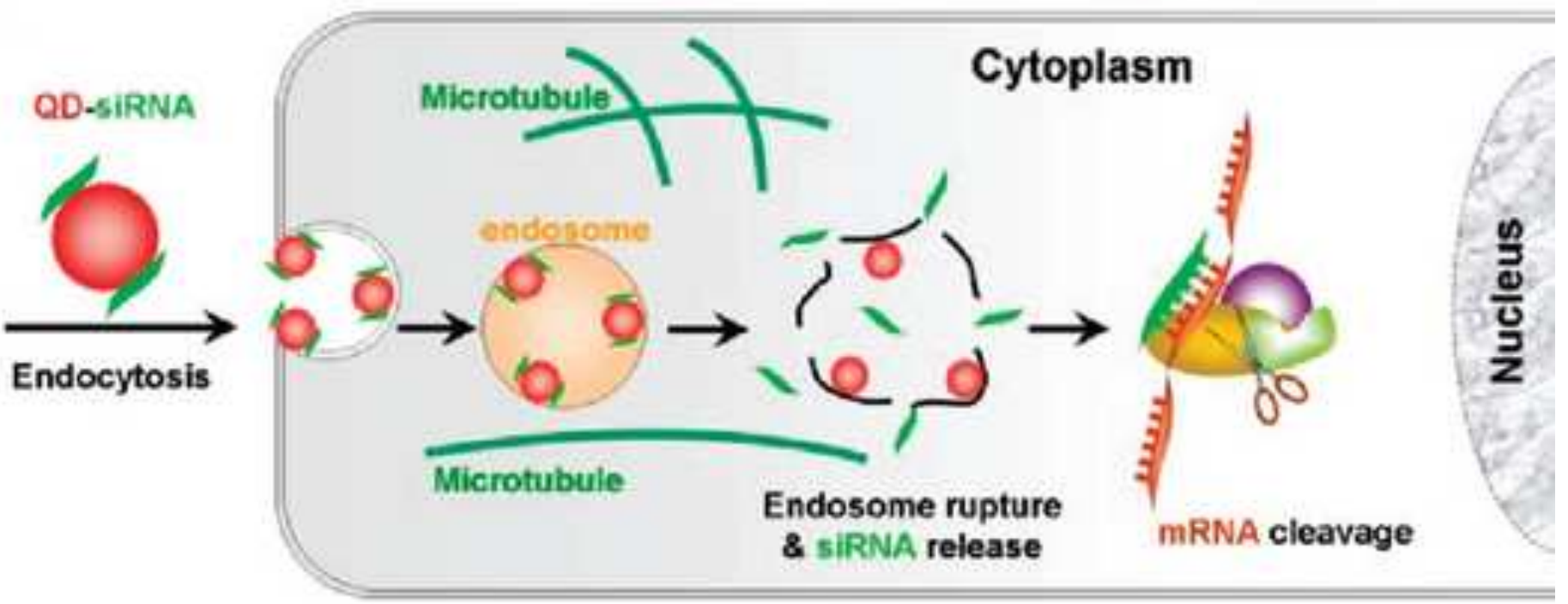

c

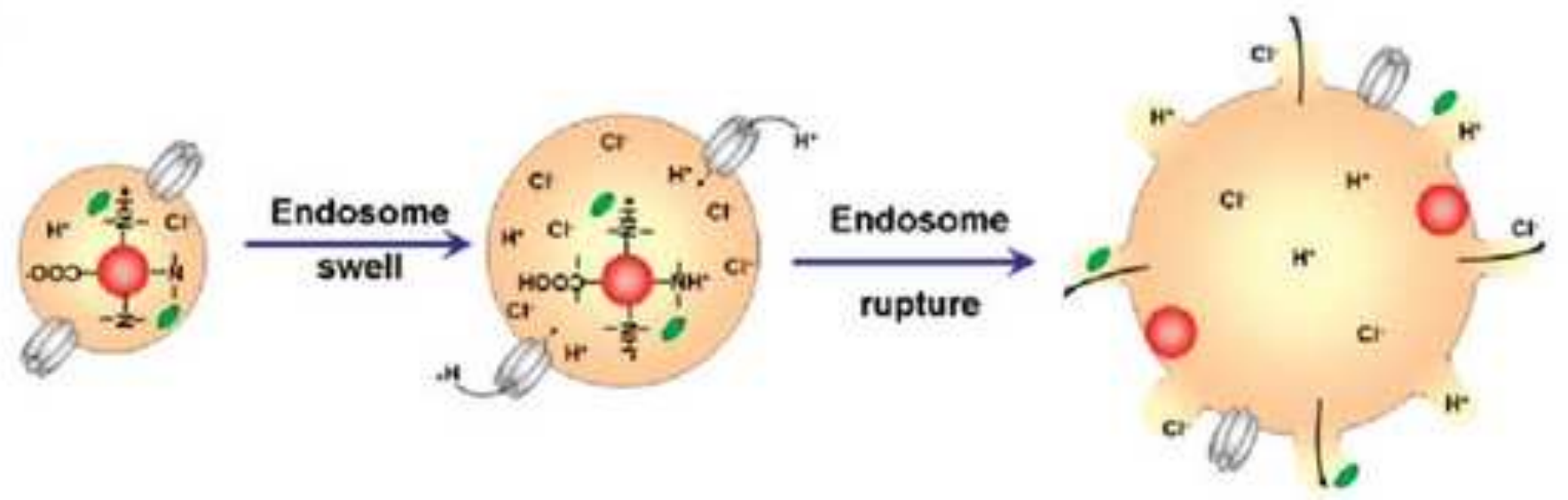


Click here to download high resolution image

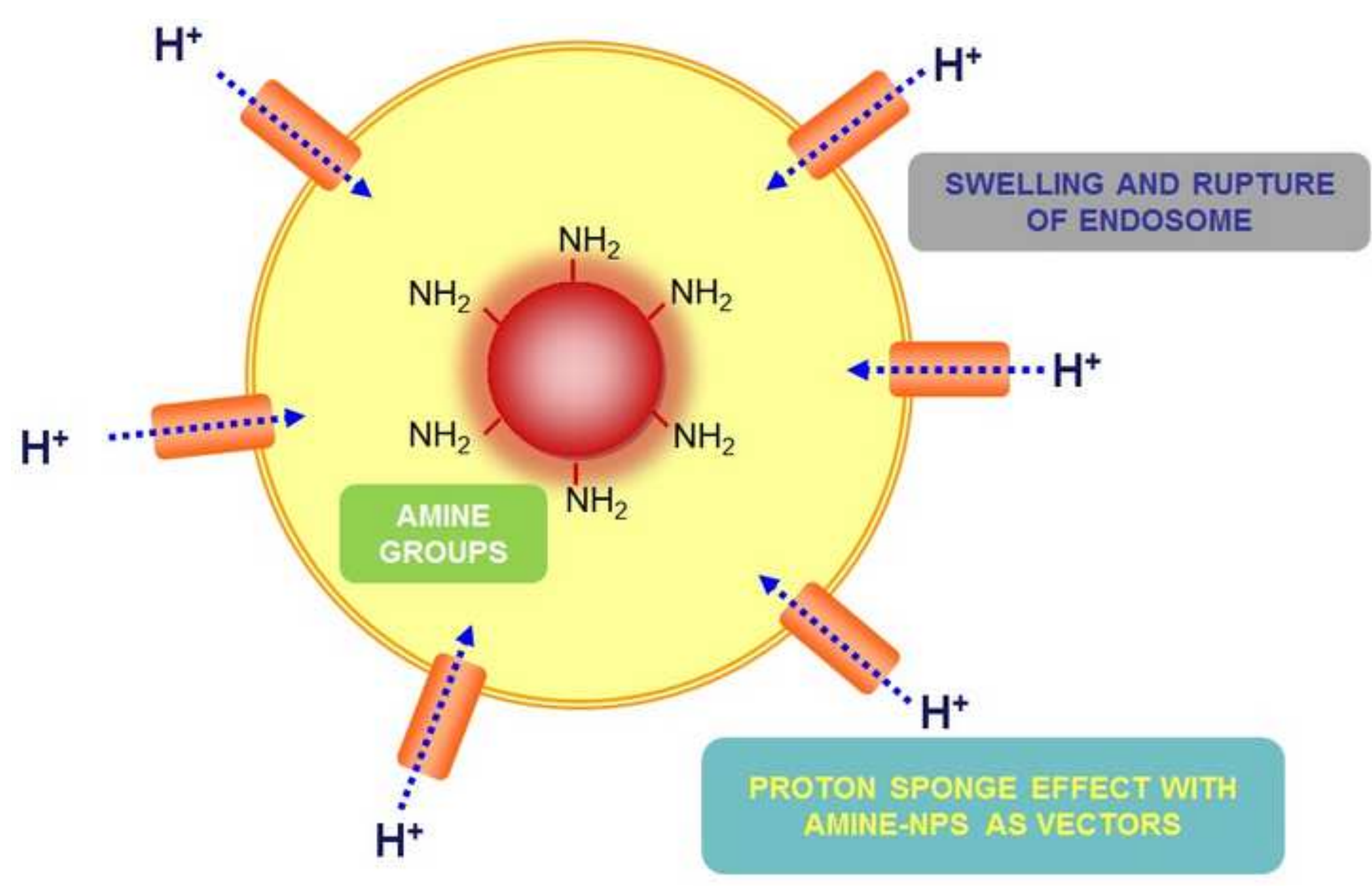




\section{Figure 10}

Click here to download high resolution image
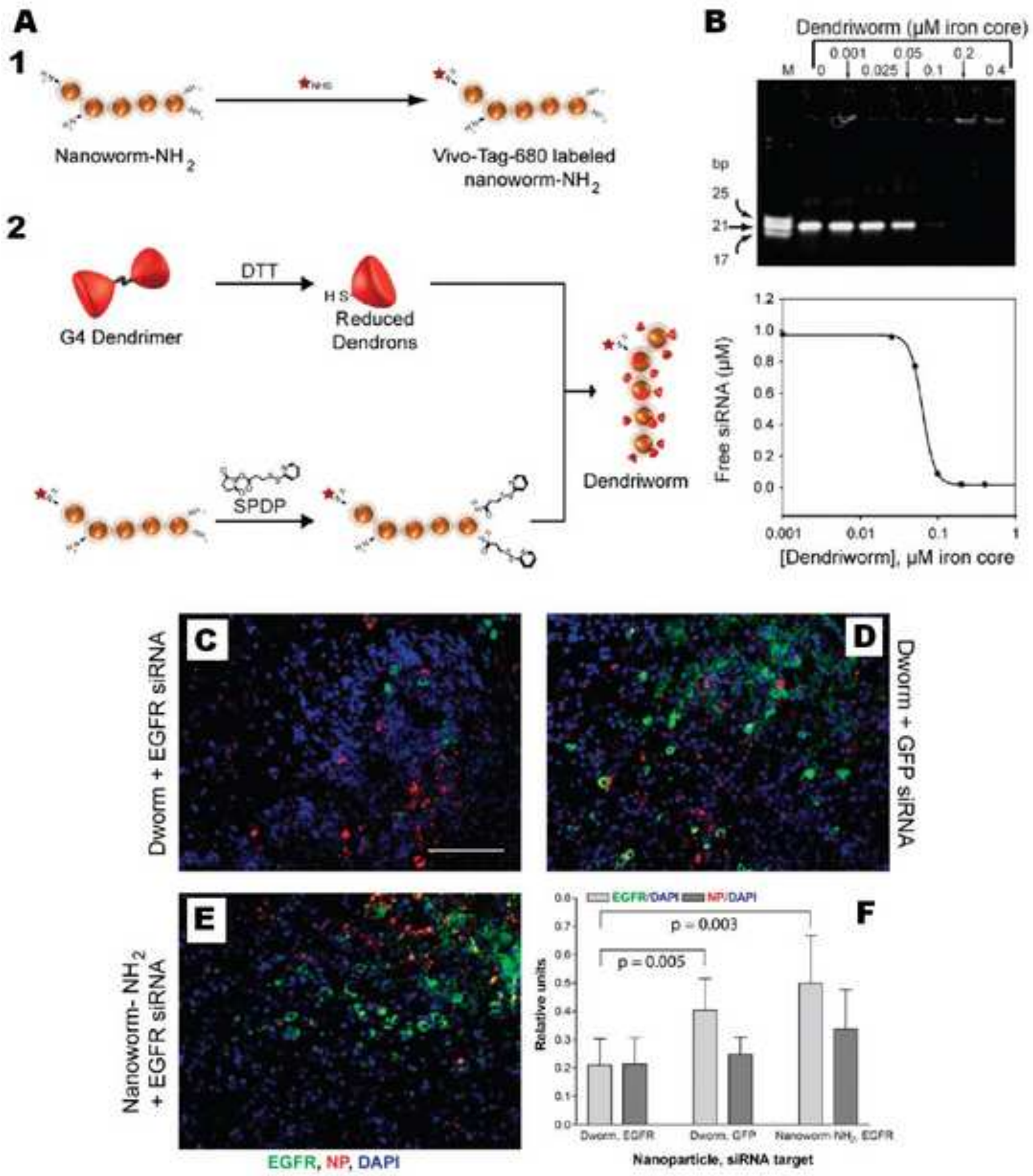

EGFR, NP, DAPI

Nanoparticle, siRNA target 


\section{A Probe Design}

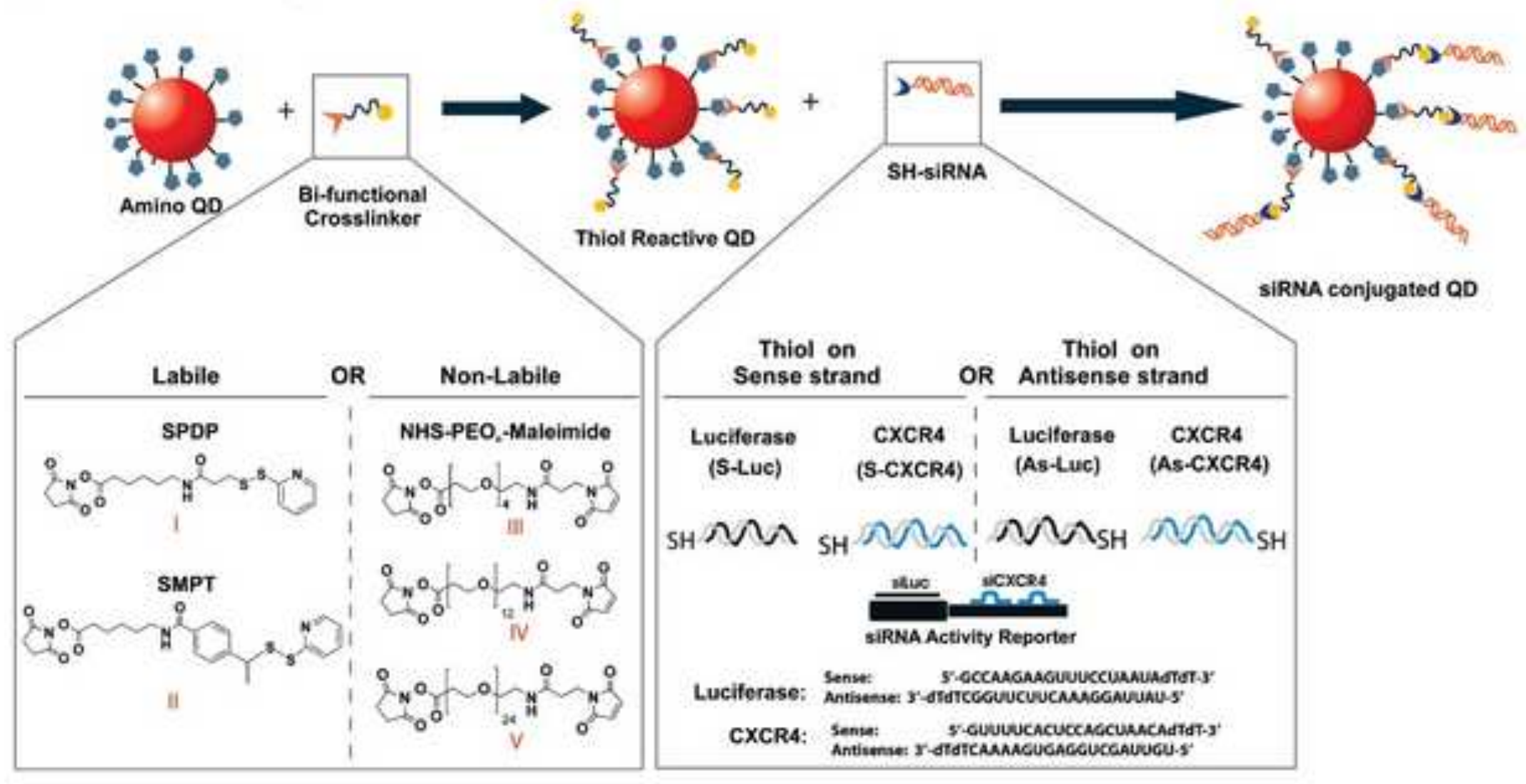

\section{B Probe Characterization}
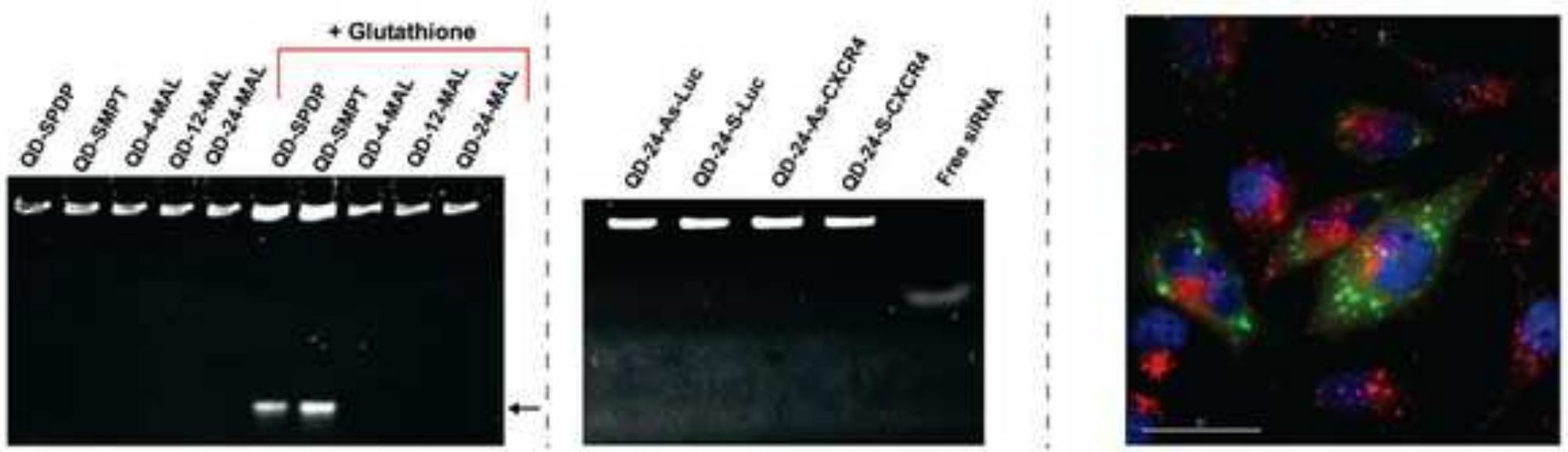
Click here to download high resolution image

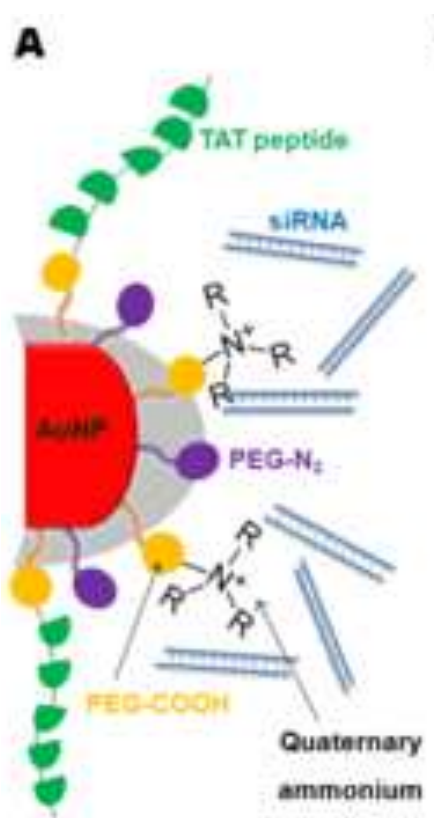

\section{IONIC APPROACH}

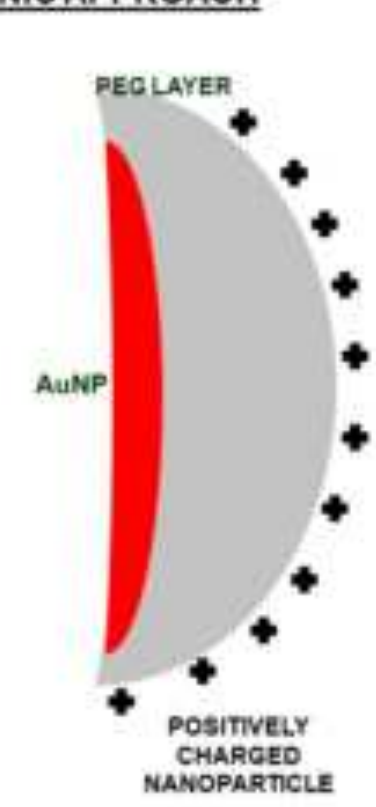

o

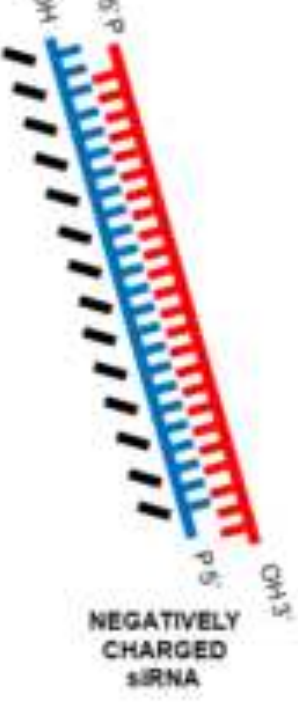

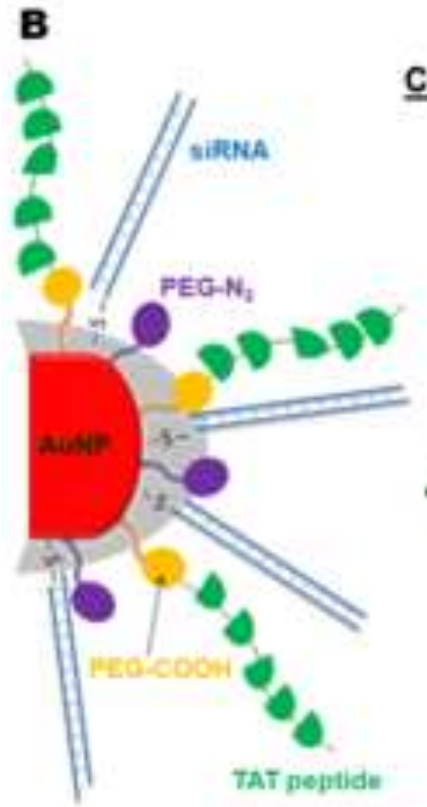

COVALENTAPPROACH

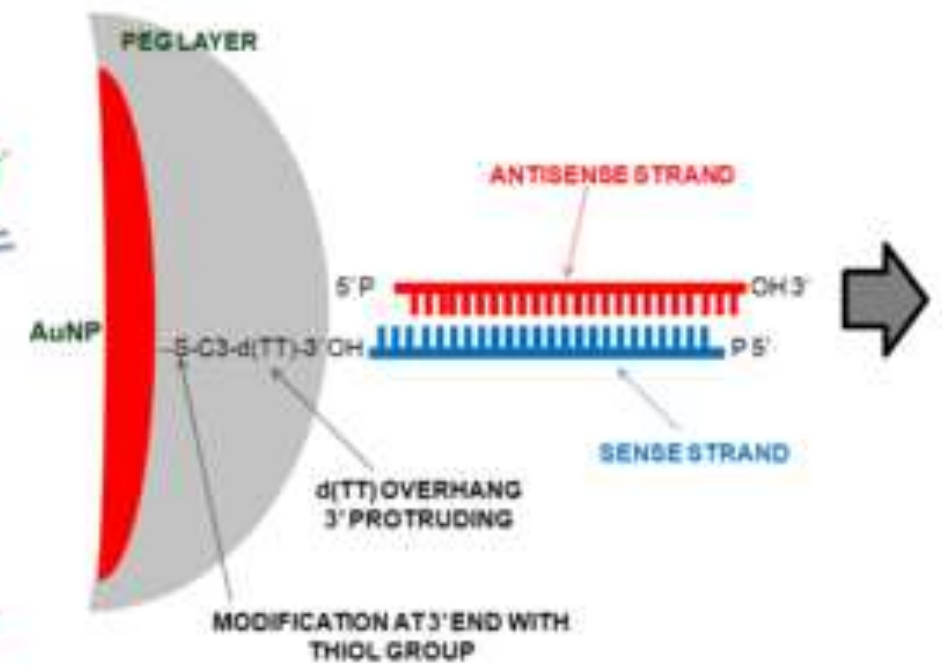

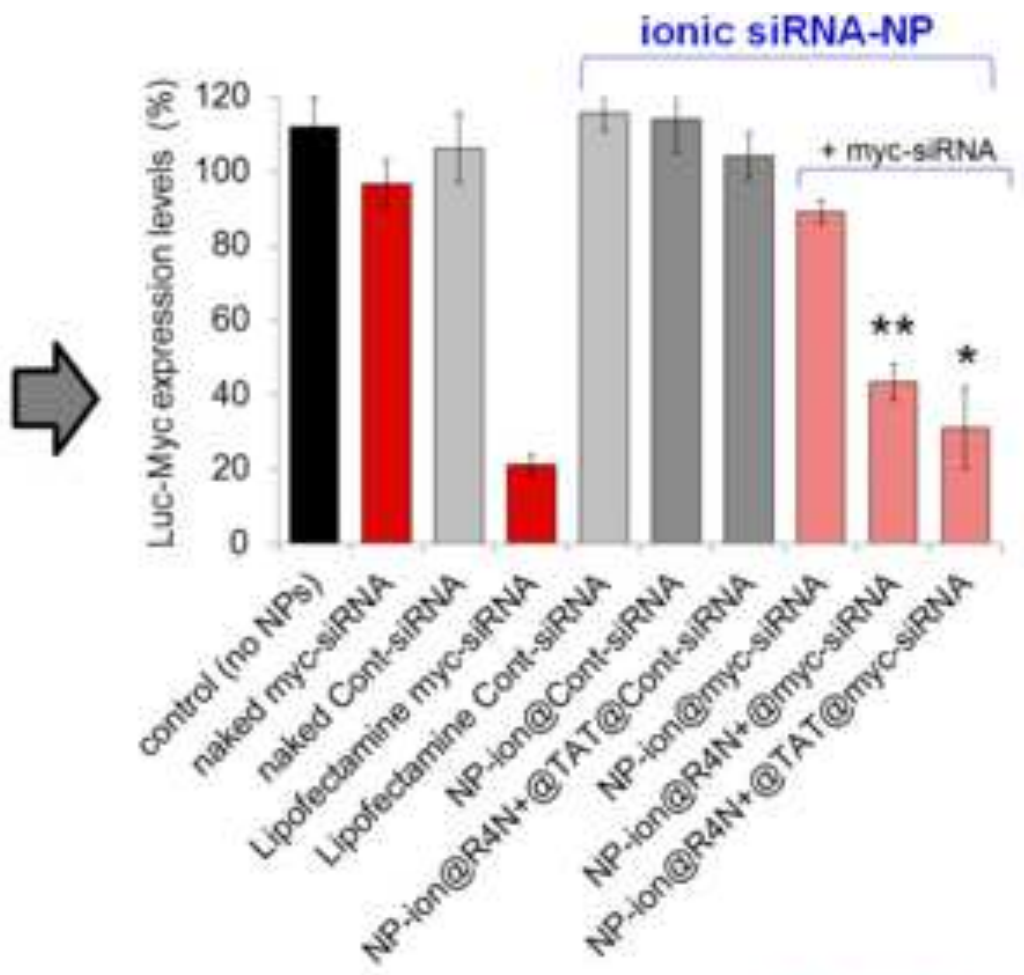

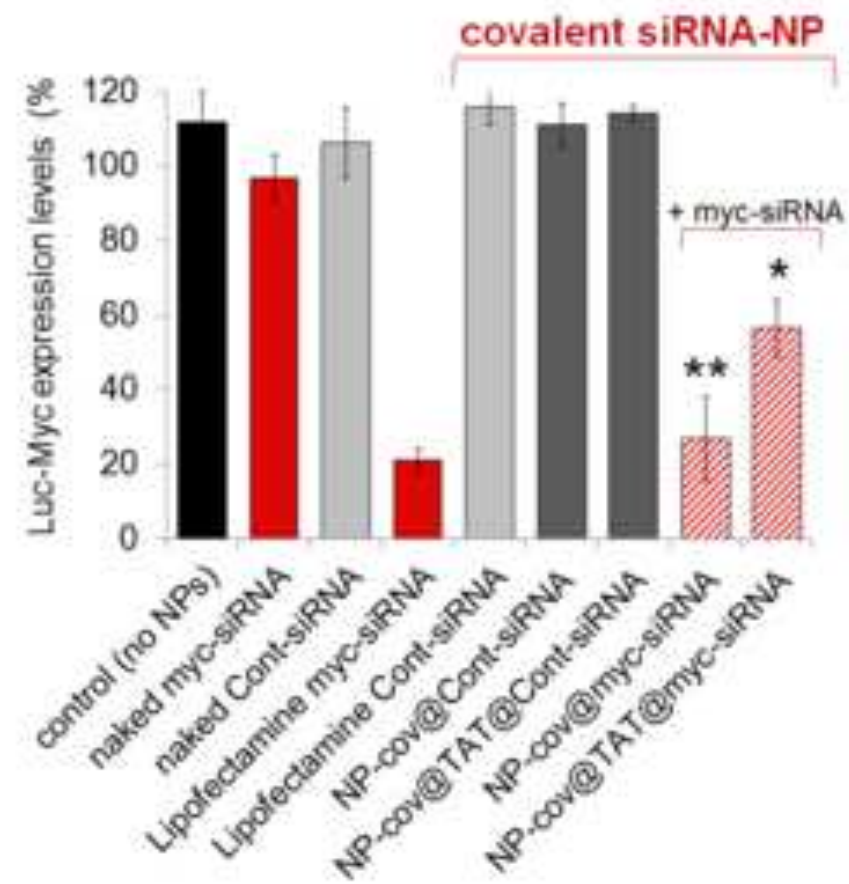



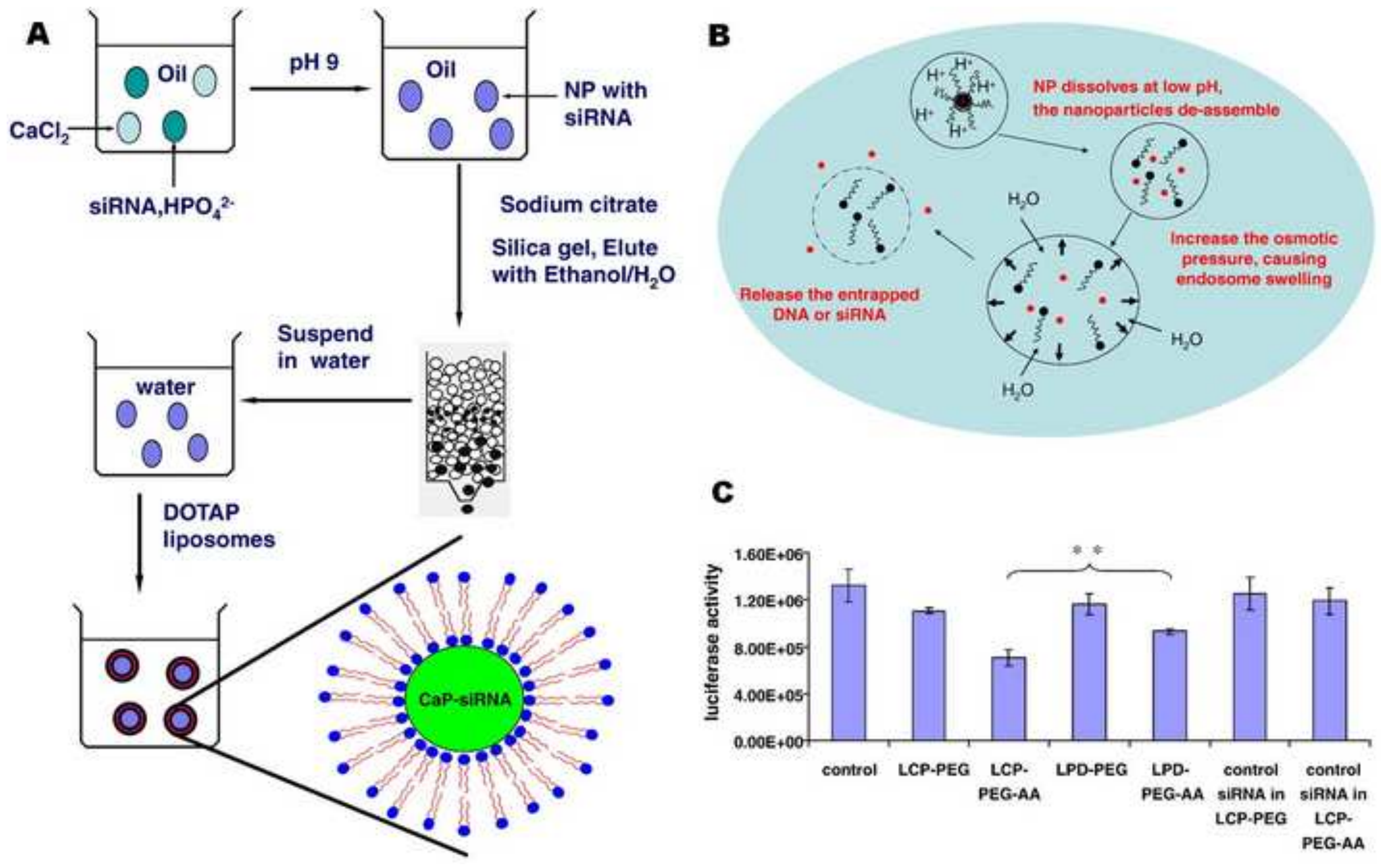

C

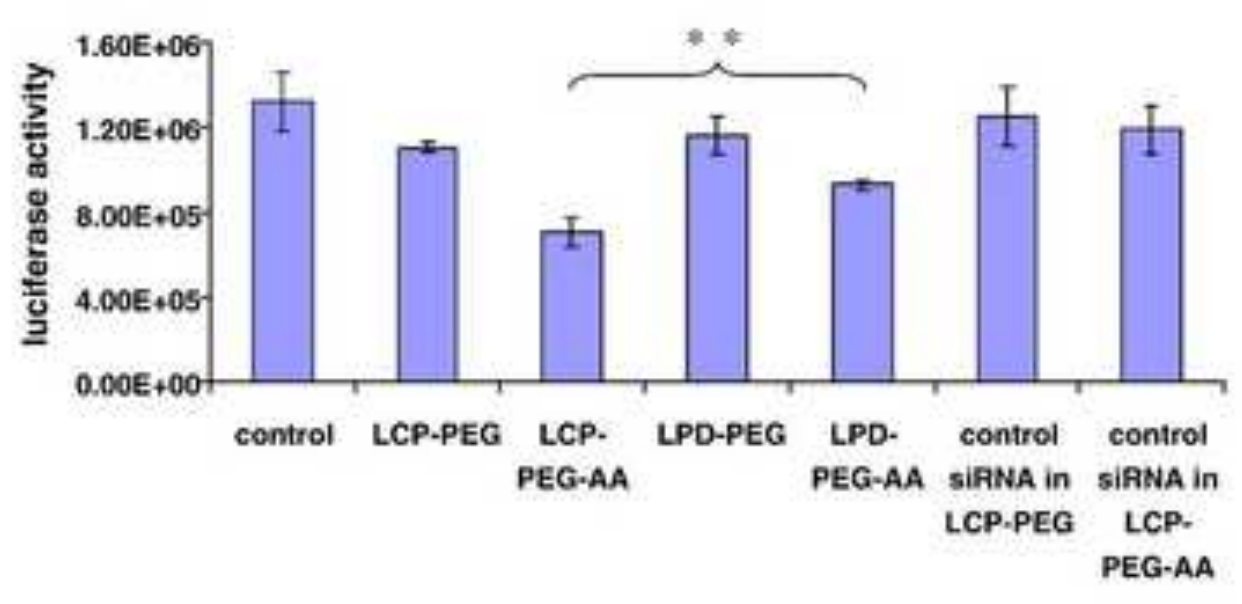


A

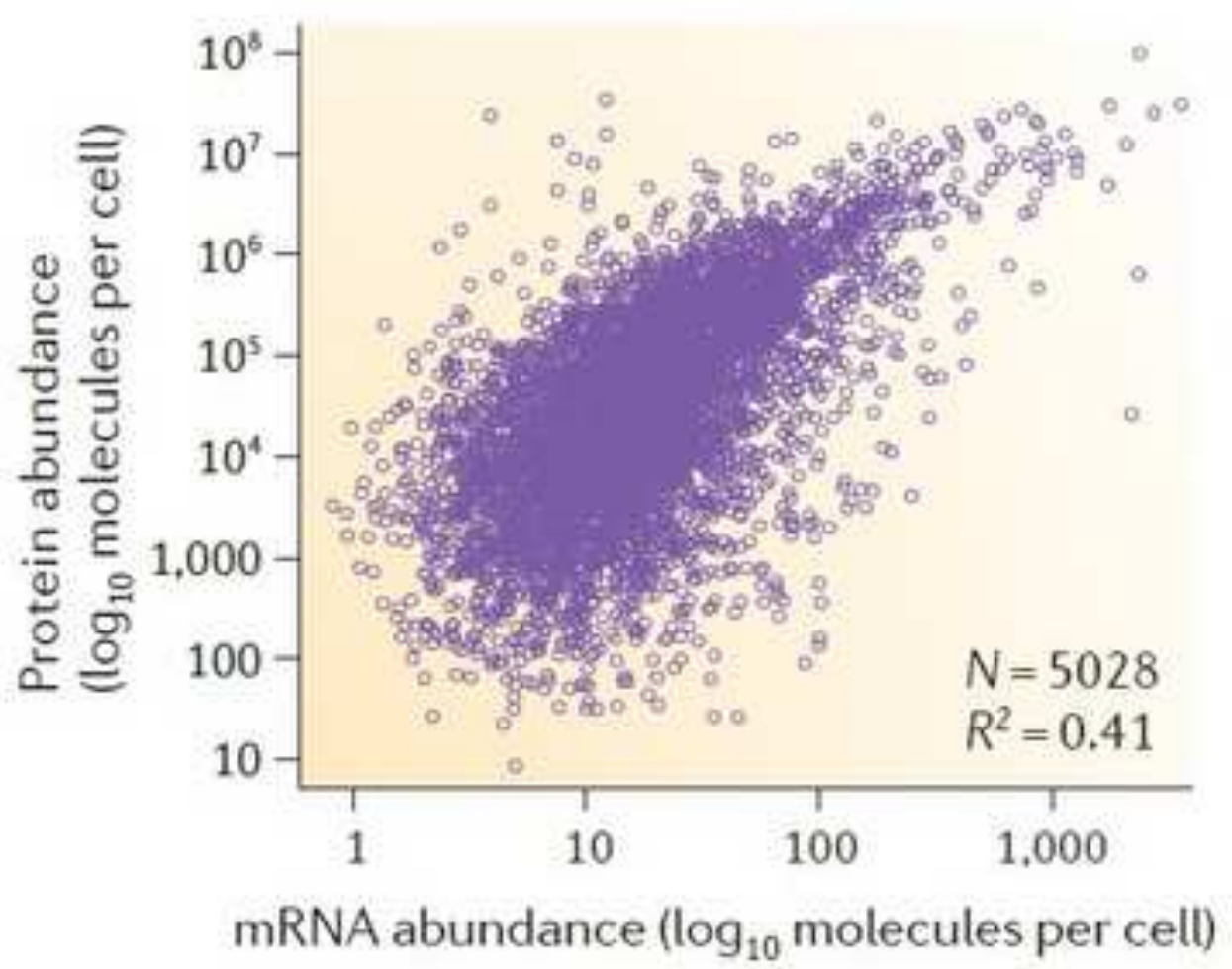

B

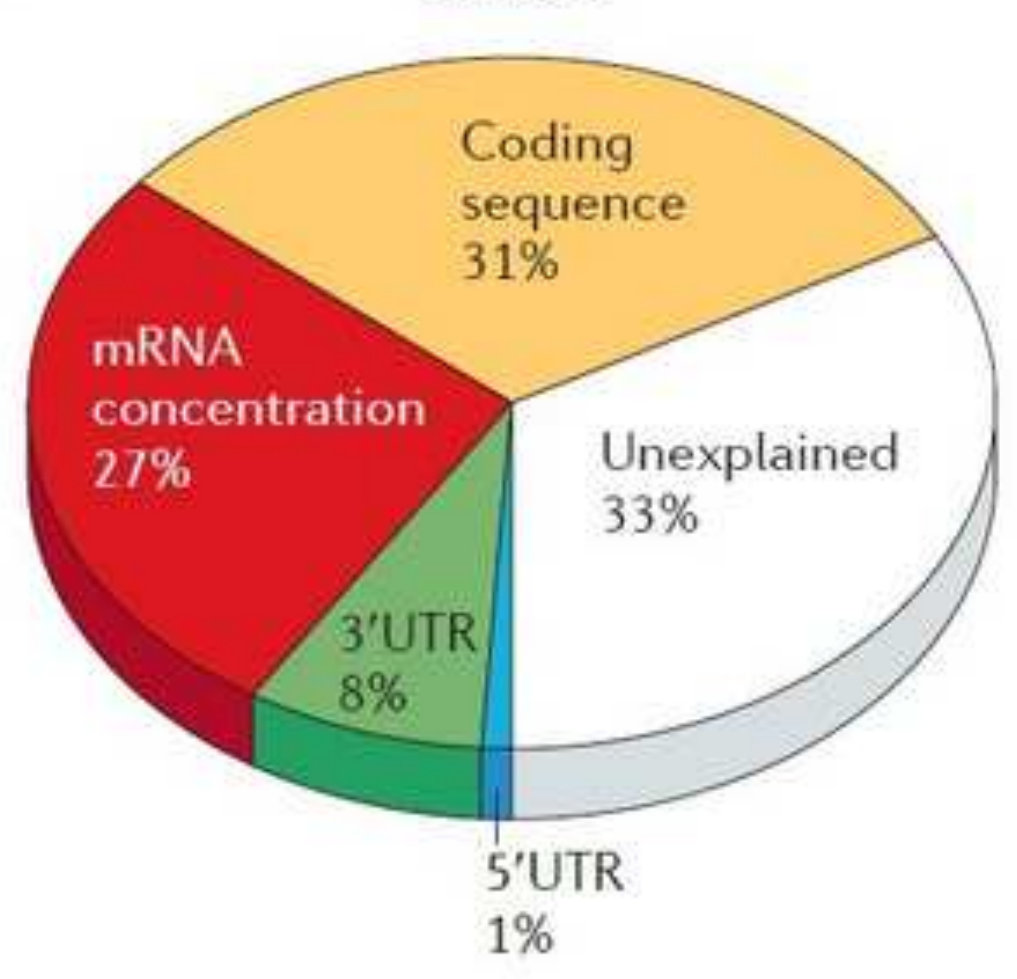

Human

Coding sequence

$1 \%$ 
A

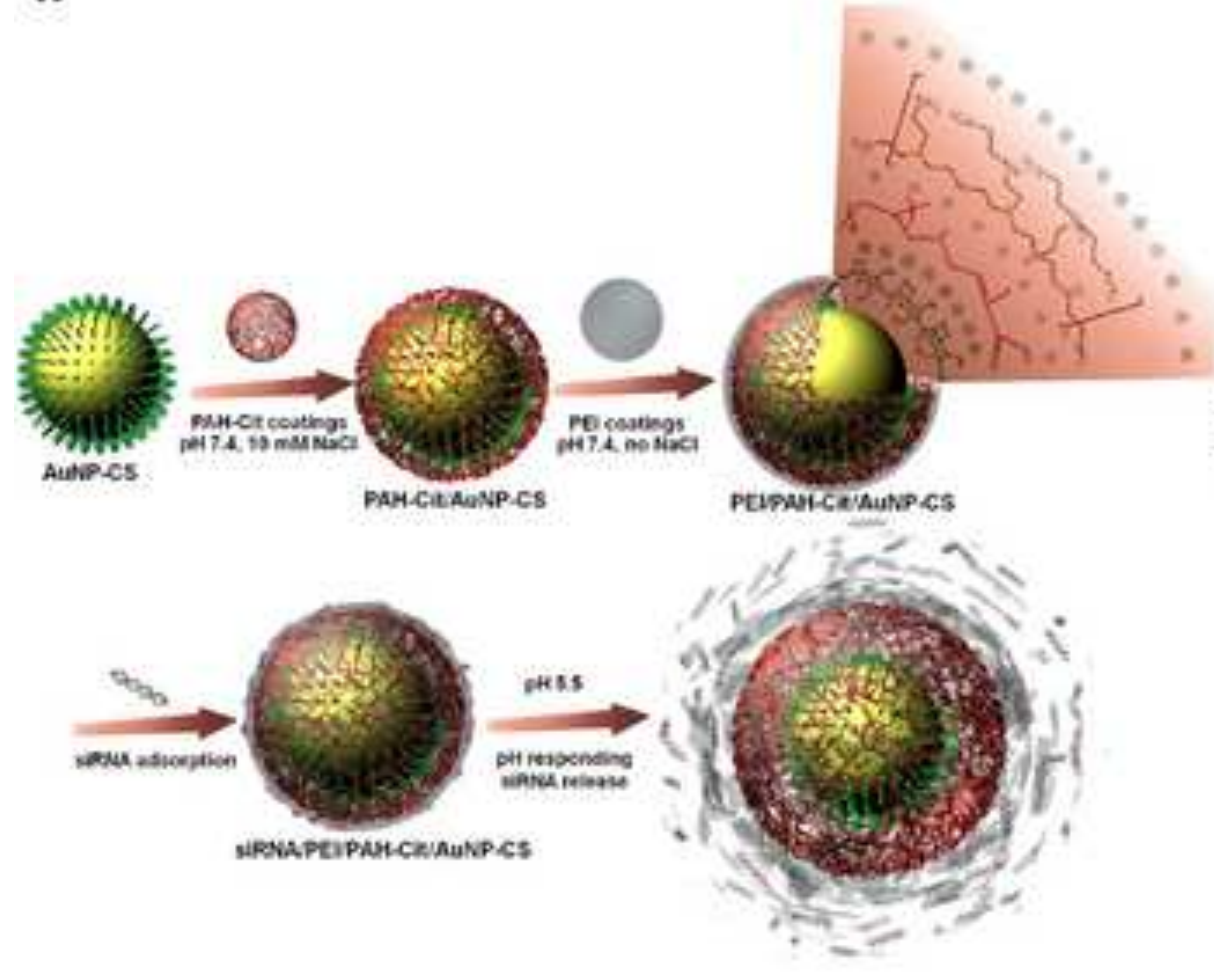

B

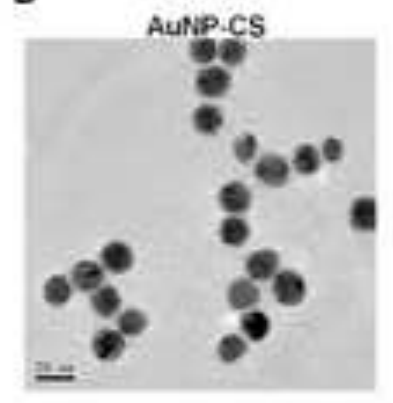

PAH-CTIANNPACS

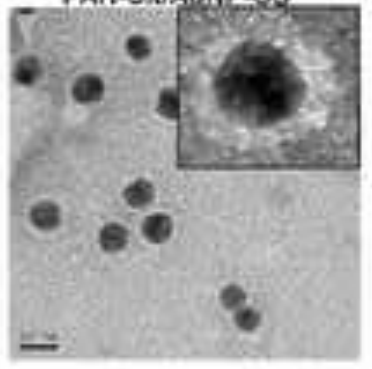

PEUPAH-CIULANP_CS E

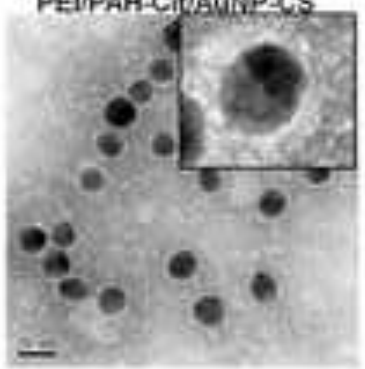

c

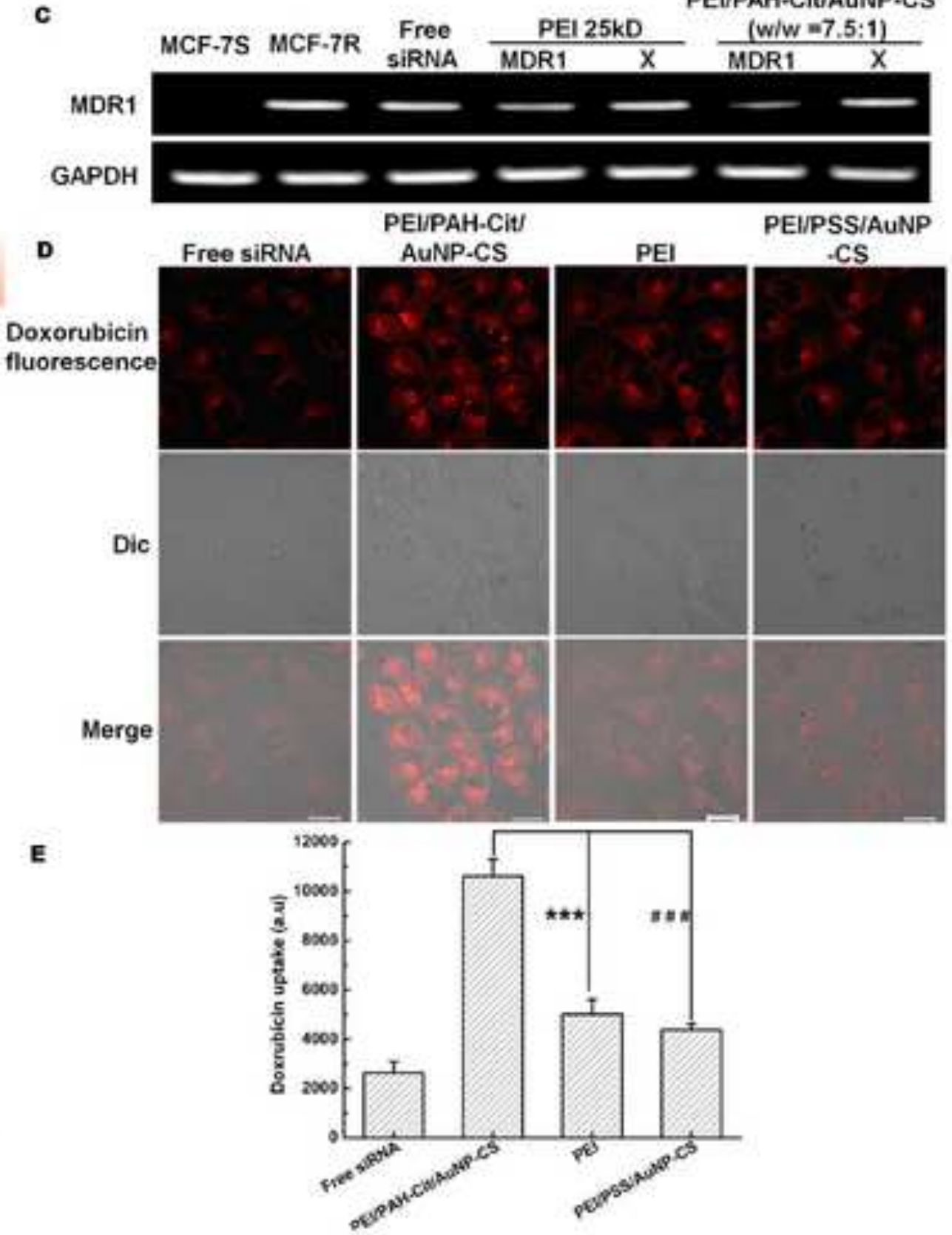

PEU/PAH-CIt/AuNP.CS 
Click here to download high resolution image

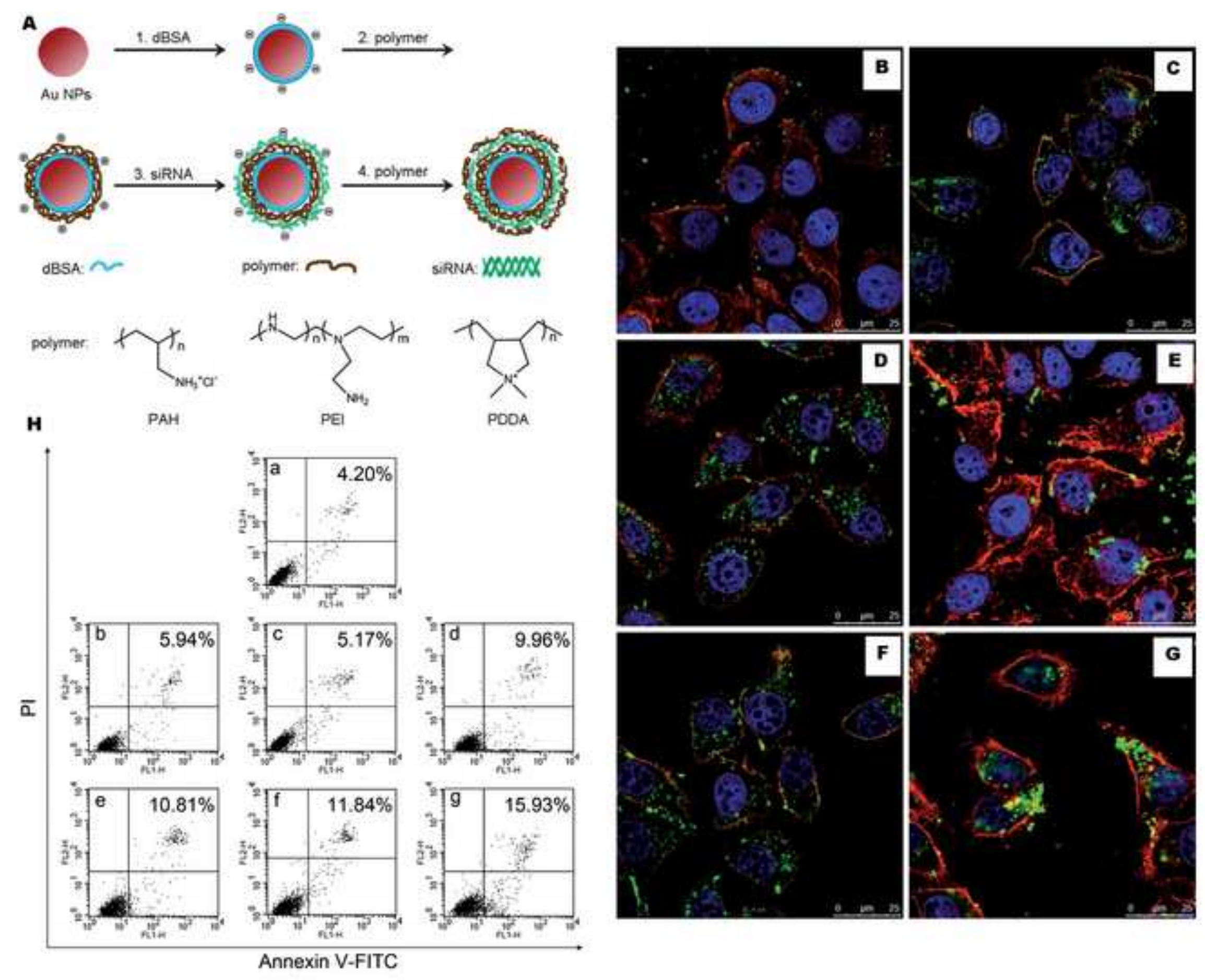




\section{Figure 17}

Click here to download high resolution image
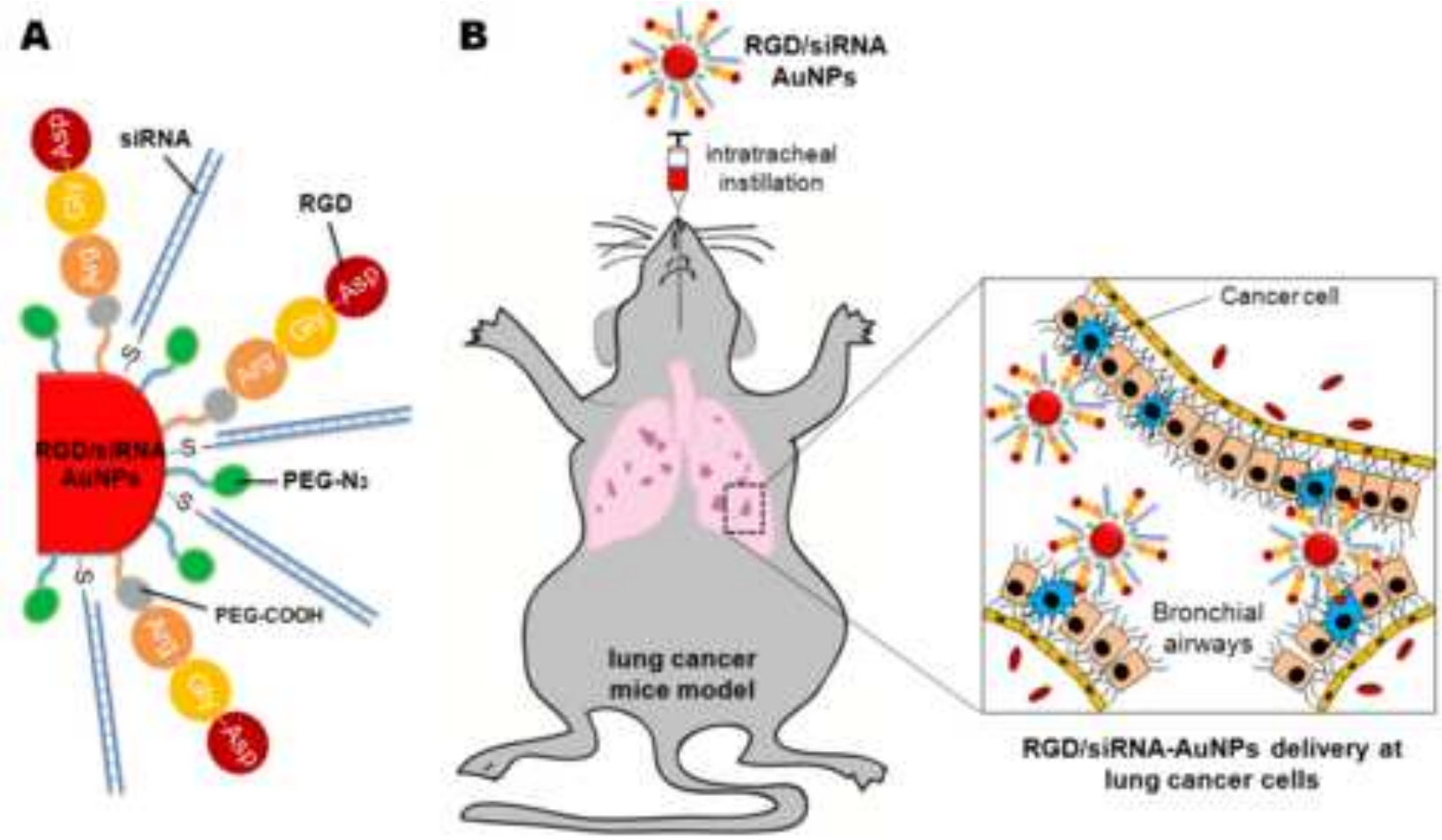

RGDisiRNA-AuNPs delivery at lung cancer cells
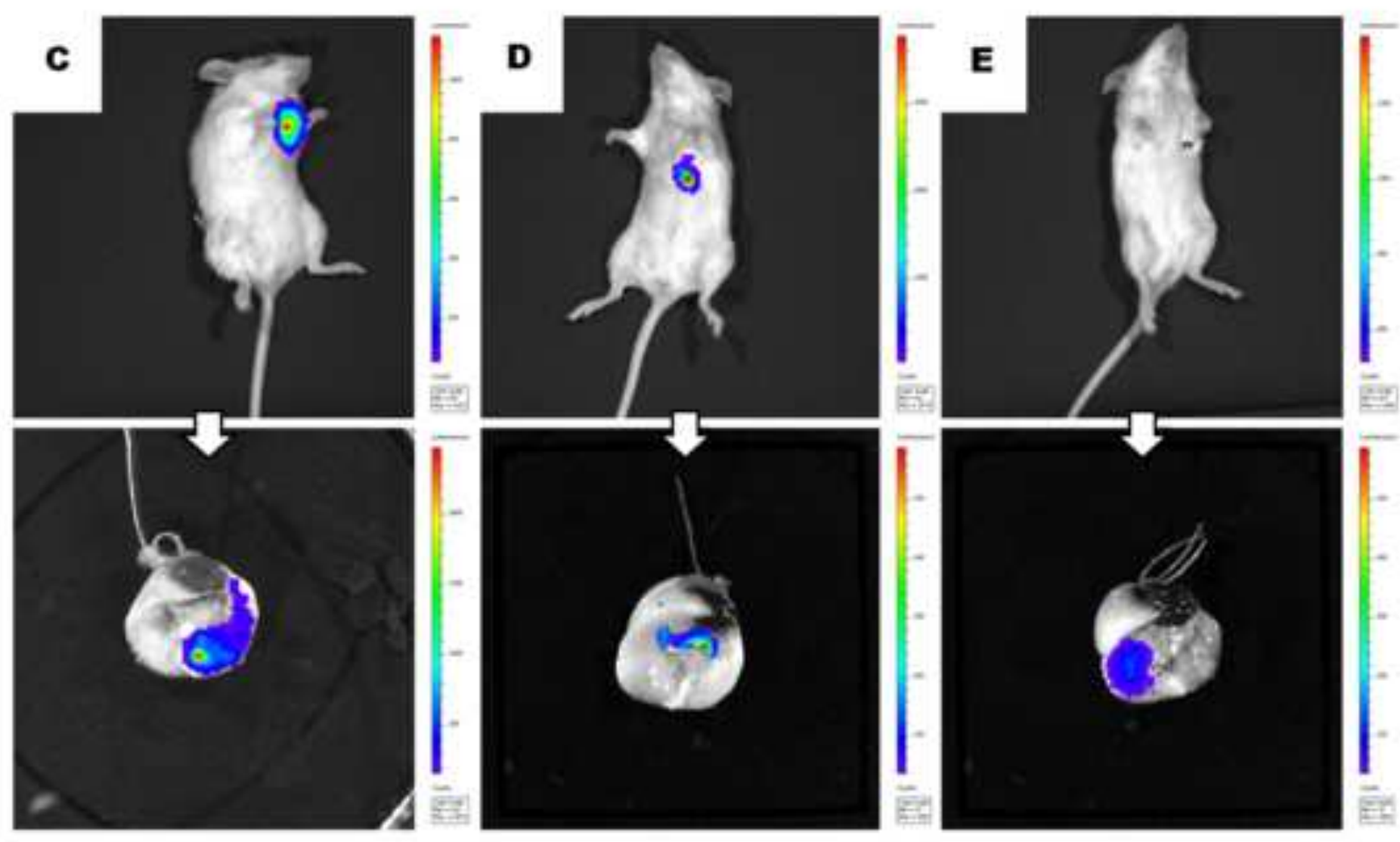
Click here to download high resolution image

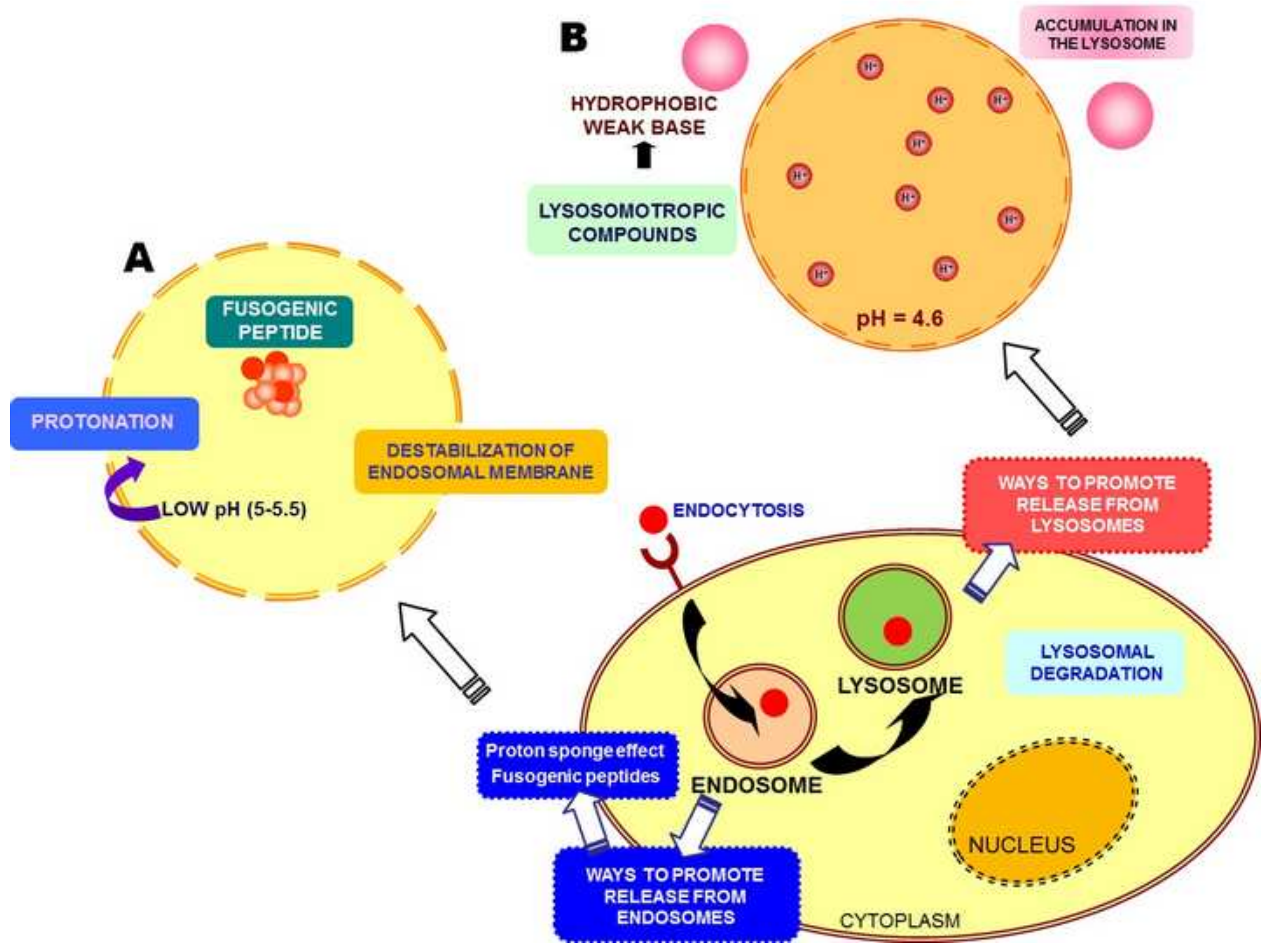




\section{Authors' Biographies}

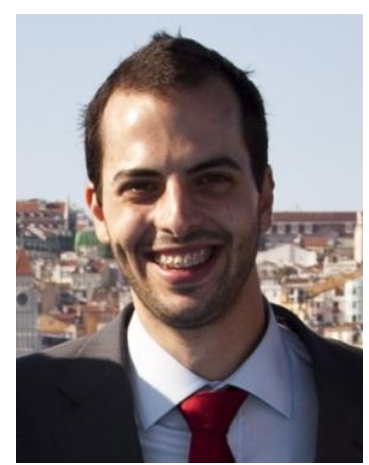

Dr. João Conde received his $\mathrm{PhD}$ in Biotechnology from the New University of Lisbon in 2013, under the European Consortium NanoScieE ${ }^{+}$NANOTRUCK for the development of multifunctional gold nanoparticles for gene silencing. Currently, he is a Marie Curie Associate at the Massachusetts Institute of Technology, Harvard-MIT Division for Health Sciences and Technology and in School of Engineering and Materials Science, Queen Mary University of London. His scientific interests are focused in biofunctionalization and in vitro and in vivo applications of multifunctional metal nanoparticles and hydrogels for cancer therapy, especially for tumor targeting, gene therapy and drug delivery. He has authored more than 30 papers with almost 600 citations and 1 international patent.

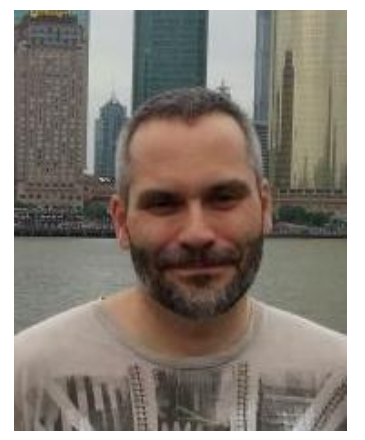

Dr. Jesus M. de la Fuente (Barakaldo, 1975) started his PhD work in 1999 on the evaluation of carbohydrate-carbohydrate interactions using gold nanoparticles (IIQ-CSIC, Seville, Spain). Once he obtained his $\mathrm{PhD}$, he was funded by the Spanish Science Ministry to work in the Centre for Cell Engineering at The University of Glasgow (UK) to develop a research project involving the biological application of nanoparticles. In June 2007, he gained a permanent position in the Institute of Nanoscience of Aragón (INA) belonging to the University of Zaragoza (Spain) as Senior Researcher supported by ARAID. He currently leads the research group specialized in the Biofunctionalization of Nanoparticles and Surfaces. His research interests are based on the development of general and simple strategies for the functionalization of nanoparticles and surfaces for biomedical and biotechnological applications. He has 100 published articles with more than 2800 citations and 5 international patents. From 2014 he is a visiting Professor at the Shanghai Jiao Tong University (P.R. China) under the "1000 People Plan Program". 